\title{
A test of the space-for-time substitution hypothesis: North American bird responses to forest loss over space do not predict their responses over time
}

\author{
Kayla Attinello
}

A thesis submitted to the Faculty of Graduate and Postdoctoral Affairs in partial fulfillment of the requirements of the degree of

Master of Science

in

Biology

Carleton University

Ottawa, Ontario

(C) 2021

Kayla Attinello 


\begin{abstract}
The practice of space-for-time substitution in landscape ecology has provided vital insights for conservation policy, but whether these insights are reliable remains inconclusive. Here, my objective was to test space-for-time substitution using data from the North American Breeding Bird Survey (BBS) and Global Forest Change (GFC) to compare the effects of landscape-level forest cover on bird community metrics over time and space across 31 space-time comparisons in the United States and Canada. Temporal and spatial effects of forest cover on mean bird species richness and mean bird abundance were weakly correlated across the 31 comparisons for both forest and open-habitat species. Bird-forest cover relationships measured over time were more variable and inconsistent than those observed in space. Overall, my study results do not support the use of space-for-time substitution when studying North American birds.
\end{abstract}




\section{Acknowledgements}

I would first like to thank my co-supervisors Lenore Fahrig and Scott Wilson for their mentorship and guidance. Thank you also to Greg Mitchell and Gabriel BlouinDemers for their helpful comments on developing versions of this project during the committee meetings. Additionally, I would like to extend my gratitude to Adam Smith for his help with learning how to build and run statistical models, the Bayesian way.

A big thank you goes out to all of the dedicated staff and volunteers of the North American Breeding Bird Survey (BBS). Likewise, thank you to the researchers at University of Maryland for producing Global Forest Change dataset. Without their shared knowledge, projects like mine would not be possible.

Last but not least, I would like to thank my dear friends and family, who offered shoulders to lean on, listening ears, and unconditional love and support. 


\section{Table of Contents}

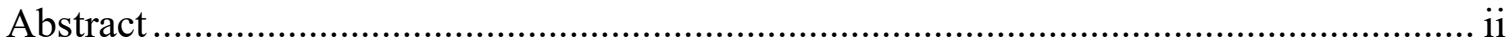

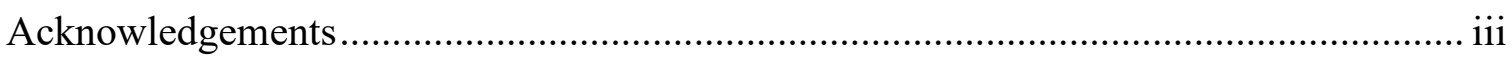

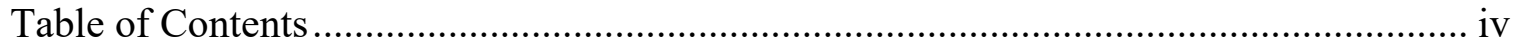

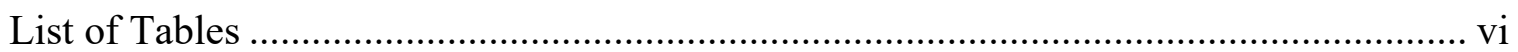

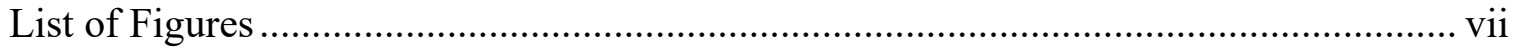

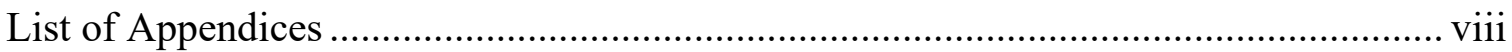

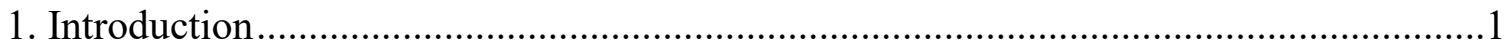

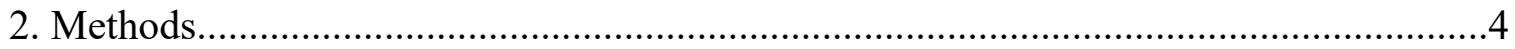

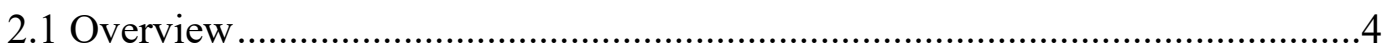

2.2 Bird Surveys.........................................................................................

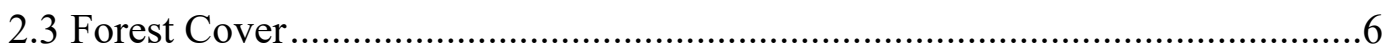

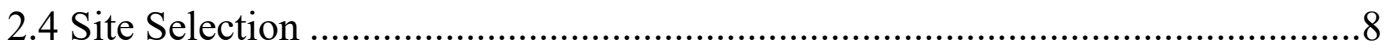

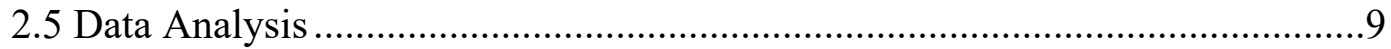

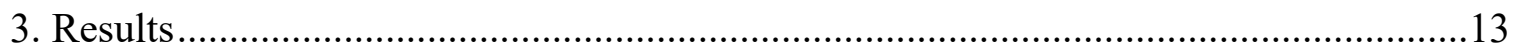

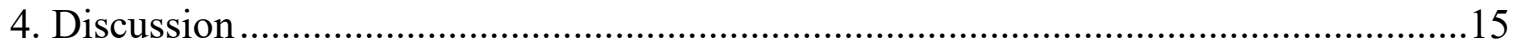

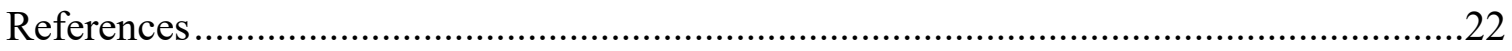

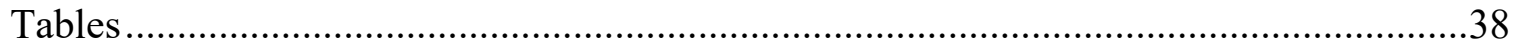

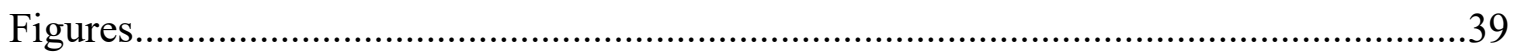

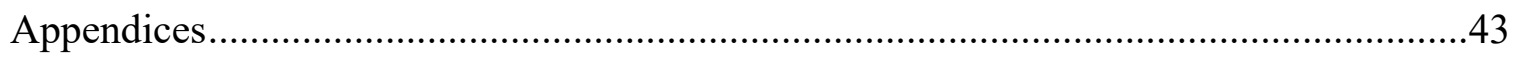




\section{List of Tables}

Table 1. Mean regression coefficients (with associated 95\% percentile intervals (PI)) and correlation coefficients (Pearson's r) measuring the congruency between a) estimated forest and open-habitat bird-forest cover slopes over time at a temporal site from 2000 to 2019 ("temporal slope") and b) estimated forest and open-habitat bird-forest cover slopes in space across a set of neighbouring spatial sites in 2019 ("spatial slope"). Spatial slopes were estimated twice: once where the number of spatial sites informing the spatial slope matched with the number of years informing the corresponding temporal slope (scenario I) and again where the maximum number of eligible spatial sites was used to inform the

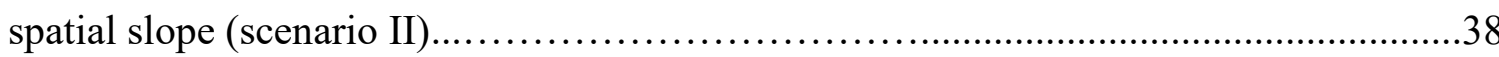




\section{List of Figures}

Figure 1. Visual description of the space-time comparison study design where A) a site consisted of the first 11 "stops" of a North American Breeding Bird Survey (BBS) route, along with the landscape within 1-km, within which forest cover was measured. Individual stops were characterized as forested ( $\geq 60 \%$ forest within $100 \mathrm{~m}$ ) or not forested ( $\leq 40 \%$ forest within $100 \mathrm{~m})$. B) Sites were organized into "space-time comparisons," consisting of a single "temporal site" with bird and forest information from 2000 to 2019, and multiple "spatial sites" covering the same 2019 forest gradient over space as the forest gradient over time at the associated temporal site. C) The relationship between bird species responses and percent forest cover was estimated as a slope over time at the temporal site and over space across the associated spatial sites.

Figure 2. Locations of 31 space-time comparisons within the continental United States (U.S.) and Canada, each consisting of a single temporal site (gradient of forest cover over time) and a series of matched spatial sites (gradient of forest cover across space) located within a 300-km radius buffer of the temporal site. Comparison regions fell in two Level I Ecoregions: Marine West Coastal Forest (left-most dark grey area) and the Eastern

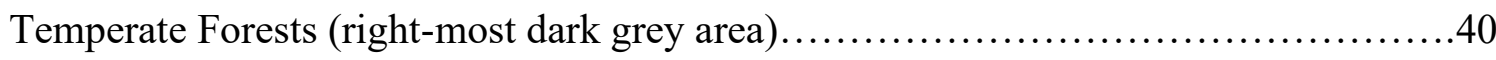

Figure 3. Relationships between estimated slopes measuring the effect of forest cover change on forest (A) and open-habitat (B) mean bird species richness over time at a temporal site from 2000 to 2019 ("temporal slope") and in space across a set of neighbouring spatial sites in 2019 ("spatial slope"). Each of the 31 space-time comparisons contains one temporal and one spatial slope measuring forest cover effects and corresponds to a single point in the figure. Spatial slopes were estimated twice: once 
where the number of spatial sites informing the spatial slope matched with the number of years informing the corresponding temporal slope (scenario I) and again where the maximum number of eligible spatial sites was used to inform the spatial slope (scenario II). Plotted regression lines represent the mean relationship obtained by summarizing over 12,000 linear regressions for each of 12,000 sets of Markov Chain Monte Carlo parameter iterations, with $95 \%$ percentile intervals shaded. The dotted line represents a $1: 1$ relationship $(\alpha=0, \beta=1)$.

Figure 4. Correlation between estimated slopes measuring the effect of forest cover change on forest (A) and open-habitat (B) mean bird abundance over time at a temporal site from 2000 to 2019 ("temporal slope") and in space across a set of neighbouring spatial sites in 2019 ("spatial slope"). Each of the 31 space-time comparisons contains one temporal and one spatial slope measuring forest cover effects and corresponds to a single point in the figure. Spatial slopes were estimated twice: once where the number of spatial sites informing the spatial slope matched with the number of years informing the corresponding temporal slope (scenario I) and again where the maximum number of eligible spatial sites was used to inform the spatial slope (scenario II). Plotted regression lines represent the mean relationship obtained by summarizing over 12,000 linear regressions for each of 12,000 sets of Markov Chain Monte Carlo parameter iterations, with 95\% percentile intervals shaded. The dotted line represents a 1:1 relationship $(\alpha=0$,

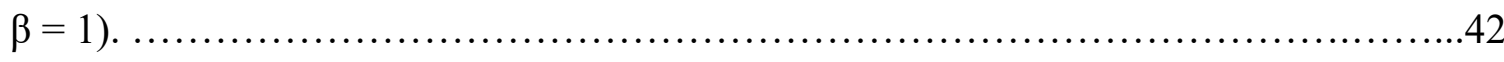




\section{List of Appendices}

Table A. Summary of 31 space-time comparisons selected for analysis. Space-time comparisons were centered on a modified BBS route that has experienced at least $20 \%$ forest cover change from 2000 to 2019 ("temporal site") and that has at least 15 years' worth of BBS data spanning the full 19-year time period. Each temporal site was matched to a series of neighbouring spatial sites in the same EPA Level I Ecoregion (Ecoregion 7 $=$ Marine West Coast Forests, Ecoregion $8=$ Eastern Temperate Forests; EPA 2021) that collectively covered a similar forest cover gradient in 2019 ("spatial sites"). All sites used in the analysis were composed of the first 11 stops (approximately $8 \mathrm{~km}$ ) of the original BBS route.

Table B. All species detected in the bird surveys used in this study. In our analyses we included only the 118 forest breeding species (F) and the 38 open-habitat breeding species $(\mathrm{O})$. Other symbols are $\mathrm{FE}=$ forest- or shrub-edge breeders, $\mathrm{W}=$ wetland or shoreline breeders, $\mathrm{N}=$ nocturnal species. Species designations were based on information in the Birds of North America (Rodewald 2018)....

Figure A. Posterior difference between temporal slopes and spatial slopes (= temporal slope - spatial slope) measuring the effect of forest cover on mean forest (A) and openhabitat (B) bird species richness over time at a temporal site from 2000 to 2019 and in space across neighbouring spatial sites in 2019, respectively. The 31 space-time comparisons are listed in order from top-to-bottom. Spatial slopes were estimated twice: once where the number of spatial sites informing the spatial slope matched with the number of years informing the corresponding temporal slope (scenario I) and again where the maximum number of eligible spatial sites was used to inform the spatial slope 
(scenario II). Space-time comparisons where the difference between temporal and spatial slopes do not overlap with zero are highlighted in colour, representing comparisons where the estimated forest cover effects in time and space are significantly unequal and thus, where space-for-time substitution fails most notably............................57

Figure B. Posterior difference between temporal slopes and spatial slopes (= temporal slope - spatial slope), each measuring the effect of forest cover on mean forest (A) and open-habitat (B) bird abundance over time at a temporal site from 2000 to 2019 and in space across neighbouring spatial sites in 2019 , respectively. The 31 spacetime comparisons are listed from 1 to 31 . Spatial slopes were estimated twice: once where the number of spatial sites informing the spatial slope matched with the number of years informing the corresponding temporal slope (scenario I) and again where the maximum number of eligible spatial sites was used to inform the spatial slope (scenario II). Space-time comparisons where the difference between temporal and spatial slopes do not overlap with zero are highlighted in colour, representing comparisons where the estimated forest cover effects in time and space are significantly unequal and thus, where space-for-time substitution fails most notably

Table C. Slope parameter coefficient estimates measuring the effect of forest cover on forest bird mean species richness over time at a temporal site from 2000 to 2019 ("temporal slope") and in space across a set of neighbouring spatial sites in 2019 ("spatial slope") for all 31 space-time comparisons in the U.S. and Canada. Here, each of the spatial slopes were informed by the full number of available spatial sites within each space-time comparison, which may exceed the number of years informing the

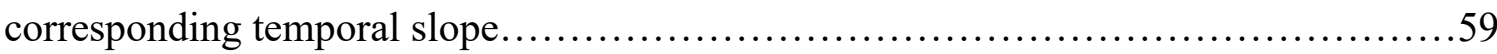


Figure C. Slope estimates (with 95\% percentile interval shaded) measuring the effect of forest cover on forest bird mean species richness over time at a temporal site from 2000 to 2019 (in blue) and in space across a set of neighbouring spatial sites in 2019 (in red) for all 31 space-time comparisons in the U.S. and Canada. Here, each of the spatial slopes were informed by the full number of available spatial sites within each space-time comparison, which may exceed the number of years informing the corresponding temporal slope.... .64

Table D. Slope parameter coefficient estimates measuring the effect of forest cover on forest bird mean species richness over time at a temporal site from 2000 to 2019 ("temporal slope") and in space across a set of neighbouring spatial sites in 2019 ("spatial slope") for all 31 space-time comparisons in the U.S. and Canada. Here, each of the spatial slopes were informed by a subset number of eligible spatial sites equal to the number of years informing the corresponding temporal slope......................65

Figure D. Slope estimates (with 95\% percentile interval shaded) measuring the effect of forest cover on forest bird mean species richness over time at a temporal site from 2000 to 2019 (in blue) and in space across a set of neighbouring spatial sites in 2019 (in red) for all 31 space-time comparisons in the U.S. and Canada. Here, each of the spatial slopes were informed by a subset number of eligible spatial sites equal to the number of years informing the corresponding temporal slope

Table E. Slope parameter coefficient estimates measuring the effect of forest cover on open-habitat bird mean species richness over time at a temporal site from 2000 to 2019 ("temporal slope") and in space across a set of neighbouring spatial sites in 2019 ("spatial slope") for all 31 space-time comparisons in the U.S. and Canada. Here, each of the 
spatial slopes were informed by the full number of available spatial sites within each space-time comparison, which may exceed the number of years informing the

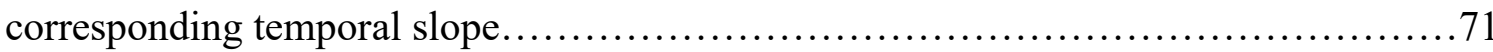

Figure E. Slope estimates (with 95\% percentile interval shaded) measuring the effect of forest cover on open-habitat bird mean species richness over time at a temporal site from 2000 to 2019 (in blue) and in space across a set of neighbouring spatial sites in 2019 (in red) for all 31 space-time comparisons in the U.S. and Canada. Here, each of the spatial slopes were informed by the full number of available spatial sites within each space-time comparison, which may exceed the number of years informing the corresponding

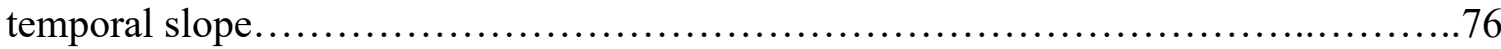

Table F. Slope parameter coefficient estimates measuring the effect of forest cover on open-habitat bird mean species richness over time at a temporal site from 2000 to 2019 ("temporal slope") and in space across a set of neighbouring spatial sites in 2019 ("spatial slope") for all 31 space-time comparisons in the U.S. and Canada. Here, each of the spatial slopes were informed by a subset number of eligible spatial sites equal to the number of years informing the corresponding temporal slope

Figure F. Slope estimates (with 95\% percentile interval shaded) measuring the effect of forest cover on open-habitat bird mean species richness over time at a temporal site from 2000 to 2019 (in blue) and in space across a set of neighbouring spatial sites in 2019 (in red) for all 31 space-time comparisons in the U.S. and Canada. Here, each of the spatial slopes were informed by a subset number of eligible spatial sites equal to the number of years informing the corresponding temporal slope 
Table G. Slope parameter coefficient estimates measuring the effect of forest cover on forest bird mean abundance over time at a temporal site from 2000 to 2019 ("temporal slope") and in space across a set of neighbouring spatial sites in 2019 ("spatial slope") for all 31 space-time comparisons in the U.S. and Canada. Here, each of the spatial slopes were informed by the full number of available spatial sites within each space-time comparison, which may exceed the number of years informing the corresponding

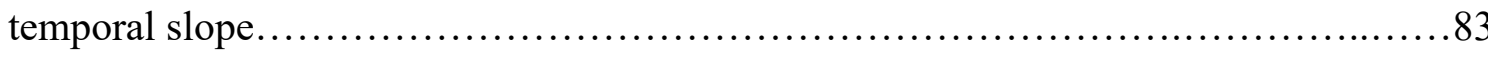

Figure G. Slope estimates (with 95\% percentile interval shaded) measuring the effect of forest cover on forest bird mean abundance over time at a temporal site from 2000 to 2019 (in blue) and in space across a set of neighbouring spatial sites in 2019 (in red) for all 31 space-time comparisons in the U.S. and Canada. Here, each of the spatial slopes were informed by the full number of available spatial sites within each space-time comparison, which may exceed the number of years informing the corresponding temporal slope. .88

Table H. Slope parameter coefficient estimates measuring the effect of forest cover on forest bird mean abundance over time at a temporal site from 2000 to 2019 ("temporal slope") and in space across a set of neighbouring spatial sites in 2019 ("spatial slope") for all 31 space-time comparisons in the U.S. and Canada. Here, each of the spatial slopes were informed by a subset number of eligible spatial sites equal to the number of years informing the corresponding temporal slope

Figure H. Slope estimates (with 95\% percentile interval shaded) measuring the effect of forest cover on forest bird mean abundance over time at a temporal site from 2000 to 2019 (in blue) and in space across a set of neighbouring spatial sites in 2019 (in red) for 
all 31 space-time comparisons in the U.S. and Canada. Here, each of the spatial slopes were informed by a subset number of eligible spatial sites equal to the number of years informing the corresponding temporal slope.................................. 94

Table I. Slope parameter coefficient estimates measuring the effect of forest cover on open-habitat bird mean abundance over time at a temporal site from 2000 to 2019 ("temporal slope") and in space across a set of neighbouring spatial sites in 2019 ("spatial slope") for all 31 space-time comparisons in the U.S. and Canada. Here, each of the spatial slopes were informed by the full number of available spatial sites within each space-time comparison, which may exceed the number of years informing the corresponding temporal slope...........................................95

Figure I. Slope estimates (with 95\% percentile interval shaded) measuring the effect of forest cover on open-habitat bird mean abundance over time at a temporal site from 2000 to 2019 (in blue) and in space across a set of neighbouring spatial sites in 2019 (in red) for all 31 space-time comparisons in the U.S. and Canada. Here, each of the spatial slopes were informed by the full number of available spatial sites within each space-time comparison, which may exceed the number of years informing the corresponding temporal slope............................................................... 98

Table J. Slope parameter coefficient estimates measuring the effect of forest cover on open-habitat bird mean abundance over time at a temporal site from 2000 to 2019 ("temporal slope") and in space across a set of neighbouring spatial sites in 2019 ("spatial slope") for all 31 space-time comparisons in the U.S. and Canada. Here, each of the spatial slopes were informed by a subset number of eligible spatial sites equal to the number of years informing the corresponding temporal slope......................101 
Figure J. Slope estimates (with 95\% percentile interval shaded) measuring the effect of forest cover on open-habitat bird mean abundance at a temporal site from 2000 to 2019 (in blue) and in space across a set of neighbouring spatial sites in 2019 (in red) for all 31 space-time comparisons in the U.S. and Canada. Here, each of the spatial slopes were informed by a subset number of eligible spatial sites equal to the number of years informing the corresponding temporal slope................................. 106 


\section{Introduction}

Using long time series to study the causes of wildlife population change is frequently encouraged as a "gold standard" (Kratz et al. 2003) but is often not possible because time series data are lacking for most taxa (Strayer et al. 1988; McGarigal \& Cushman 2002). This is because they are effort- and time-intensive to collect, costly, and complicated by land ownership, especially at the broad spatial scales most relevant for assessing population change (McGarigal \& Cushman 2002). As a result, ecologists have used a so-called "space-for-time substitution" approach by studying wildlife responses along spatial gradients to predict how they would change along similar temporal gradients (Pickett 1989; De Palma et al. 2018). Space-for-time substitution remains a popular strategy despite a persisting lack of evidence that it produces reliable predictions.

In its early days, space-for-time substitution was used in chronosequence studies of vegetation succession and soil development (Cowles 1899; Pickett 1989) and is still commonly used today in those contexts (Walker et al. 2010; Miao et al. 2018). In recent decades, space-for-time substitution has been used to provide improved guidance for conservation decisions and land management. As one application, studies along altitudinal, $\mathrm{CO}_{2}$, precipitation, and temperature gradients have been important for predicting how climate change affects biodiversity (Schlesinger 1990; Moore et al. 1999; Lester et al. 2014; Rustad 2008; Lemoine et al. 2007; Cushman \& McGarigal 2003; De Palma et al. 2018). Other studies using space-for-time substitutions predict species responses to land cover change using comparisons across spatial gradients between disturbed and undisturbed sites (De Palma et al. 2018). Space-for-time substitution has also been used to predict the response of native communities to invasion by non-native 
species by comparing sites where invasive species are present vs. absent (Sax et al. 2005; Hejda et al. 2009).

Landscape ecology frequently assumes space-for-time substitution for questions relevant to conservation decisions (Fahrig 2003, Wardle et al. 1997; Marchand \& Litvaitis 2004; Pardini et al. 2005; Sodhi et al. 2010; Frey-Ehrenbold et al. 2013). For example, Frey-Ehrenbold et al. (2013) suggest that measures to increase landscape connectivity could promote bat diversity, based on their comparisons across landscapes in Switzerland. Fahrig et al. (2015) and Martin et al. (2020) suggest that policies aimed at reducing crop field sizes would increase biodiversity, based on comparisons across agricultural landscapes in Canada. Galán-Acedo et al. (2019) state that forest restoration is needed to ensure persistence of primates, from their review of studies comparing primate abundance and occurrence across landscapes with different forest amounts. Such recommendations assume that patterns across space provide valid information for predicting what would happen over time under a given policy change.

Despite its application to inform conservation and land management policies, assuming that spatial patterns can predict temporal trends may be problematic. An inherent assumption when using space-for-time substitution is that the landscapes studied across space share identical histories and represent different stages of the temporal process being investigated (Pickett 1989; Johnson \& Miyanishi 2008). However, different ecological mechanisms acting over time can produce similar patterns in space (Damgaard 2019). For instance, because each landscape arrives at its observed state in a given year from potentially different ecological processes other than the one being studied, a resulting spatial relationship might not be a reliable measure of the dynamics observed at 
a landscape that changes over time along a single trajectory. Critically, in spatial analysis scenarios, we often lack the historical data at our chosen landscapes to verify this assumption.

Birds are an excellent case study for testing the space-for-time substitution because, unlike most taxa, we have both extensive temporal and spatial data on birds. This wealth of data derives from citizen science databases such as the Christmas Bird Count (CBC) (National Audubon Society 2020), eBird (Sullivan et al. 2014), and the British Breeding Bird Survey (Harris et al. 2021). The North American Breeding Bird Survey (BBS), conducted since the 1970s, is probably the longest-running continent-scale citizen science database. The BBS, combined with advances in our ability to remotelysense land cover change over time, provides an opportunity to the test space-for-time substitution over a broad spatial extent with a sufficiently-long time series.

Spatial analyses demonstrate that conversion of forest to farmland is a threat to forest birds and a benefit to open-habitat birds (Fischer et al. 2011; Mahood et al. 2012; Wilson et al. 2017; Endenburg et al. 2019). Variation in forest cover across space is a strong, positive predictor of forest bird abundance and richness (Trzcinski et al. 1999; Villard et al. 1999; Bélisle et al. 2001; Fahrig 2003; Betts et al. 2007). This relationship suggests that a similar change in forest cover over time would cause similar change in forest bird abundance and richness over time. We also expect that such a change in forest cover would cause the opposite change in open-habitat birds, which depend on landscapes dominated by crops, grasses, and pastures (Wright et al. 2012). While this type of space-for-time prediction is common in ecology, we lack evidence that wildlife 
community responses to forest change over time can be reliably predicted from community responses to similar differences in forest amount over space.

My objective was to test the space-for-time substitution assumption using the responses of North American forest-breeding and open-habitat-breeding birds to forest cover. If responses over time can be predicted by responses over space, then bird richness and abundance should respond to variation in forest cover similarly over time and space. Specifically, the slopes of the bird-forest cover relationships over time and space in the same region should be equal to each other.

\section{Methods}

\subsection{Overview}

I compared temporal and spatial bird responses to forest cover for 31 space-time comparisons. Each comparison contained one "temporal" site and multiple nearby (within $300 \mathrm{~km}$ ) "spatial" sites. At the temporal site, I obtained data on birds and forest cover from 2000 to 2019 . The spatial sites associated with that temporal site were sites that collectively represented a gradient in forest cover in the year 2019 that matched the gradient in forest cover that occurred at the temporal site before this. In other words, I asked whether a relationship across spatial sites between bird richness and abundance and forest cover in 2019 accurately predicted the actual change over time in bird richness and abundance over the same gradient in forest cover during the previous 19 years. In this way, my study mimicked 31 hypothetical field studies, each of which would have measured effects on bird richness and abundance of forest cover across space, and used the resulting relationship to infer changes in bird richness and abundance in response to an equivalent change in forest cover over time. 


\subsection{Bird Surveys}

The BBS is a long-running bird monitoring program (1966 - present) consisting of over 4,000 annual volunteer-driven, roadside, count-based surveys (Environment Canada 2021). These standardized surveys are conducted in Canada, the US, and northern Mexico during peak breeding season between late May and early July (Sauer et al. 2013). Each $39.5-\mathrm{km}$-long route contains 50 stops spaced approximately $800 \mathrm{~m}$ apart along the road. At each stop, volunteers spend 3 minutes counting all individuals, identified to species, that are heard or seen within $400 \mathrm{~m}$ of the stop (Sauer et al. 2013). The BBS is cooperatively-run by the U.S. Geographic Survey's (USGS) Patuxent Wildlife Research Center (PWRC), Environment Canada's Canadian Wildlife Service (CWS), and Mexico's National Commission for the Knowledge and Use of Biodiversity (CONABIO). For my analysis, I only considered routes from Canada and continental U.S. because the survey has not been running long enough in Mexico to analyze long-term effects of changing forest cover (USGS \& CONABIO 2021).

I obtained an up-to-date Canadian BBS route geodatabase with stop-level location information from the CWS's BBS administration team (personal communication 202002-03). A similar geodatabase was not available from the USGS and was instead obtained from a publicly-available online source (Patuxent Wildlife Research Center 1999). This US dataset contained geospatial data for whole routes but lacked individual stop locations. I estimated stop locations for the US routes by placing points $800 \mathrm{~m}$ apart along the length of the route using R 4.0.3 (R Core Team 2020) and ArcMap 10.8. I removed any routes where estimating stop locations would be difficult due to irregularly- 
branching roads, incomplete roads, or digitized routes with inaccurate BBS start point coordinates.

My sites consisted of bird occurrence data from the first 11 stops of each BBS route. I then created oblong landscapes surrounding each of the road segments. These extended 1 $\mathrm{km}$ from the road on either side, making each landscape approximately $8-\mathrm{km}$ long to encompass the 11 stops, and covering an area of approximately $18-\mathrm{km}^{2}$. The $1-\mathrm{km}$ distance was selected as the distance likely to encompass landscape features (here, forest cover) that might influence the individuals detected locally at each stop in the site (Wilson et al. 2017; Dornak et al. 2020). I used only the first 11 stops of the BBS routes based on Endenburg et al. (2019), and because using landscapes with smaller total area would increase the likelihood of finding sites that experienced enough percent forest cover change over time to evaluate a relationship over, which was required for the temporal site selection.

\subsection{Forest Cover}

I obtained forest cover information for 2000 to 2019 from the University of Maryland's Global Forest Change (GFC) dataset (v1.7; Hansen et al. 2013). This dataset consisted of three $30-\mathrm{m}$ resolution raster layers. The first raster layer summarized global tree cover extent in 2000, where a given pixel's value reflected the percent canopy closure of the tree stands falling within the encompassed $900-\mathrm{m}^{2}$ area. The second raster layer contained annual tree cover loss information, where pixel classifications from 1 to 19 corresponded to the year (from 2001 to 2019) in which a given pixel experienced complete tree stand removal (Hansen et al. 2013). Lastly, the tree cover gain raster layer summarized pixels in which tree cover reached at least a 50\% crown cover density in 
2012 where previously there was none in 2000 (Hansen et al. 2013). Thus, tree cover gain information is only available for a single year, 2012, as a summary of all pixels that experienced tree cover gain some time within the 2000 to 2012 period. Using the $\mathrm{R}$ package gfcanalysis (v1.6.0; Cooper \& Zvoleff 2020), I processed all three raster layers such that pixels containing tree stands with $\geq 50 \%$ canopy closure in 2000 were considered forest and any pixels $<50 \%$ canopy closure were considered open-habitat matrix. The transition from open habitat to forest is frequently defined by, or around, a threshold of 50\% canopy closure (Rushing et al. 2016, Ocampo-Peñuela et al. 2016, Taylor \& Stutchbury 2016; Hanberry \& Thompson 2019).

I calculated forest cover from 2001 to 2019 at each site by extracting the number of forested pixels that were lost in each year and iteratively subtracting them from the number of forested pixels in the year before, starting with the layer of forest cover in 2000. In 2012, I added the number of pixels gained within the 2000 to 2012 period before subtracting lost pixels for that year. I calculated percent forest cover as the proportion of forested pixels in the landscape of each site-year combination. In addition, I calculated percent forest cover within $100 \mathrm{~m}$ of each stop of a given site-year to account for the effect of the adjacent habitat on forest or open-habitat bird detection. Using a buffer of $100 \mathrm{~m}$ ensured I was focusing on the immediate local surroundings of each stop, obtaining a more accurate representation of whether it was a survey point count that was truly located within either forested or open habitat. Within a site, I designated stops as being forested $(\geq 60 \%$ forest cover within $100 \mathrm{~m})$ or open $(\leq 40 \%$ forest cover within 100 m). A stop's categorization as forested or open then determined whether the survey data collected at that stop contributed to the calculation of overall site-level response metrics 
of either forest or open-habitat birds, respectively (see Methods section 2.5). This was done so that both forest and open-habitat bird responses to forest cover change were being analyzed using data collected at survey points located adjacent to or within their preferred habitat.

\subsection{Site Selection}

To create multiple space-time comparisons, I carried out site selection in two distinct parts. First, I found sites that had sufficient forest cover and bird occurrence data spanning 2000 to 2019; these were potential temporal sites. I needed one temporal site for each evaluation of the space-for-time substitution. Second, for each temporal site, I selected a set of nearby spatial sites with forest and bird data available in the year 2019 . The spatial sites associated with a given temporal site had to cover the same range in forest cover over space as the range in forest cover over time at the temporal site.

I selected potential temporal sites as those experiencing $\geq 20 \%$ change in forest cover from 2000 to 2019 and having at least 15 years of bird occurrence data over that time period. Applying a threshold of $\geq 20 \%$ forest cover change was important because analyzing how birds respond to forest cover change requires that forest cover actually changes. While the $20 \%$ change threshold is somewhat arbitrary, I chose this value as a trade-off between ensuring the forest cover gradients were large enough to detect species responses and maximizing the number of space-time comparisons I could make.

I matched spatial sites to each temporal site based on three criteria: a) the spatial sites had to fall within the same North American Level I Ecoregion (U.S. Environmental Protection Agency 2020) as the matching temporal site; b) the spatial sites had to be within $300 \mathrm{~km}$ of the matching temporal site; and c) the range of forest cover surrounding 
the spatial sites (in 2019) had to match the range of forest cover in the years 2000 to 2019 at the matching temporal site $( \pm 5 \%)$. Using Level I Ecoregions and a distance criterion of $300 \mathrm{~km}$ ensured similar species pools among the spatial sites for a given space-time comparison. In particular, $300 \mathrm{~km}$ was chosen to ensure at least 15 spatial sites could be found to inform each comparison's spatial relationship, while also acting as the maximum distance before communities across landscapes would become too dissimilar to compare (Endenburg et al. 2019). In most comparisons, the number of spatial sites exceeded the number of years in the temporal site. To explore the role this might have played in the results of the space-time comparisons, I conducted each space-time comparison twice: once including all available spatial sites, and again including the number of spatial sites reduced to match the number of years in the corresponding temporal site. For the latter, I selected the spatial sites whose forest cover values most closely matched the forest cover values across years at the matching temporal site.

The final set of space-time comparisons fell within two Level I Ecoregions: 30 in the Eastern Temperate Forests of the eastern and southeastern US, and 1 in the Marine West Coastal Forests on Vancouver Island, Canada. The proximity between most eligible temporal sites meant that the spatial sites selected for each space-time comparison often overlapped (Figure 2). This means that the same spatial site could be included in more than one space-time comparison (Figure 2). However, no two comparisons had an identical set of spatial sites.

\subsection{Data Analysis}

My analysis focused on two bird guilds: species that breed in forests and species that breed in open grasslands (so-called "forest" or "open-habitat" birds; see Appendix 
Table 1 for habitat designations). I summarized communities of forest and open-habitat birds at a given site using two metrics: mean species richness and mean abundance. Species richness at a stop was calculated as the total number of unique forest (or openhabitat) species present. Mean species richness was then the average number of forest (or open-habitat) species per forested (or open) stop. In other words, mean forest species richness was calculated only over the forested stops within the site and mean open-habitat species richness was calculated only over the open-habitat stops within the site. Bird abundance at a stop was the total number of forest (or open-habitat) individuals recorded, and mean abundance for a site was the average forest (or open-habitat) individuals per forested (or open) stop.

In all of the models, forest cover refers to the percent of forest in the landscape surrounding all 11 stops at a site (see above). The modelling was conducted in two stages. In the first stage, for each of the 31 space-time comparisons I estimated slopes relating bird responses to forest cover at (i) the temporal site over time ("temporal slopes"), and (ii) across the spatial sites ("spatial slopes"). There were four temporal slopes estimated per temporal site, one for each of mean species richness and mean abundance of forest species, and one for each of mean species richness and mean abundance of open-habitat species. The same four spatial slopes were estimated across the spatial sites associated with each temporal site. In addition, the set of four spatial slopes were estimated twice more, once using all of the spatial sites associated with a temporal site, and once using a subset of spatial sites that were selected to match the number of years of bird sampling at the associated temporal site (see Methods section 2.4 above). This resulted in eight dataset scenarios. Note that for each scenario, both 
temporal and spatial slopes were actually fit using a single model (see below). In the second stage, for each of these eight scenarios I then modelled the temporal slopes as a function of the spatial slopes across the 31 space-time comparisons. If the spatial relationships between birds and forest cover can predict the effect on birds of the same change in forest cover over time, then the slopes of these regressions should be 1 .

I fit each of the eight models for estimating the temporal and spatial slopes using a Bayesian general linear model. Models were compiled and run with Stan's Hamiltonian Monte Carlo samplers using the $\mathrm{R}$ wrapper packages $\mathrm{cmdstan} R$ and $r$ stan (Stan Development Team 2020). The models consisted of an intercept and slope parameter that varied by slope type (spatial or temporal) and by space-time comparison. Importantly, the model did not share or pool information across space-time comparisons for any parameter estimates. Intercepts and slopes were independently estimated within their grouping levels (space or time for each individual space-time comparison) and were not shrunk toward any grouping-level mean.

A known source of variation when analysing BBS data is the influence of different volunteers, or observer effects, on bird counts (Sauer et al. 1994). In the BBS, a single observer often surveys the same route for multiple years but most observers do not survey multiple routes. This means there are likely to be more different observers across spatial sites than over time for a temporal site (Sauer et al. 1994). It is also known that first-time observers tend to underestimate bird occurrences compared to their second or later surveys (Kendall et al. 1996). Thus, I controlled for observer effects and first-time observer effects by including both as covariates. As a final covariate, I also included the 
number of forested (or open-habitat) stops over which mean richness and abundance were calculated.

The final models for the slopes were structured as follows, where intercept $(\alpha)$ and slope $(\beta)$ parameters were grouped by space-time comparison number (from 1 to 31 ) and slope type (temporal $=1$, spatial $=2)$ :

$$
\begin{aligned}
\text { bird response } & \sim \alpha_{\text {comparison \#, slope type }}+\beta_{\text {comparison \#, slope type }} * \text { percent forest } \\
& + \text { observer }_{\text {observer } \#}+\text { first observer } \text { observation rank }+ \text { stops }_{\text {no. stops }}
\end{aligned}
$$

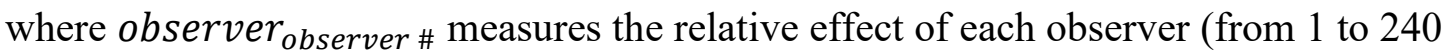
observers) on bird richness or abundance, first observer observation rank $_{\text {measures the }}$ relative effect of observations being in an observer's first survey or not, and stops $_{\text {no. stops }}$ measures the relative effect of how many forested (or open) survey points the bird response was measured over (from 1 to 11 stops) for a given site-year observation.

I assessed the models for reasonable priors and posterior convergence using key diagnostic methods. I used weakly informative priors (i.e., $~ \operatorname{Normal}(0,1)$ and $\sim$ Student$\mathrm{t}(4,0,1))$ that I established using prior predictive checks (Gabry et al. 2019). I ran each model for 2,000 iterations and 4 chains (for a total of 8,000 iterations). I assessed model convergence and fit using traceplots, the Gelman-Reuben statistic (R-hat; Gelman \& Reuben 1992), the number of effective samples $\left(N_{\text {eff }}\right)$, and posterior predictive checks.

I then evaluated the space-for-time substitution in two ways for each of the eight scenarios. First, I modelled temporal slopes as a function of spatial slopes across the 31 space-time comparisons using a series of simple linear regressions. To preserve the model's uncertainty around the temporal and spatial slope estimates, I repeated the 
regression 8,000 times for each of 8,000 sets of parameter iterations and calculated the mean predicted relationship with a $95 \%$ confidence interval. Second, I calculated the difference between temporal slopes and spatial slopes across all iterations for each spacetime comparison to quantify how unequal the temporal and spatial slopes could be within the same space-time comparison.

\section{Results}

Overall, the 31 space-time comparisons included 118 forest species and 38 openhabitat species. For a given site, mean forest bird species richness ranged from 0 species per forested stop to 15 species per stop, with an average of 4.48. Mean open-habitat bird species richness ranged from 0 to 3.17 species per open-habitat stop, with an average of 0.59. Mean forest bird abundance for a site varied between 0 and 22 individuals per forested stop, with an average of 5.85. Mean open-habitat abundances spanned a larger range, from 0 to 27.14 individuals per open-habitat stop, but with a much lower average of 1.28.

All 31 temporal sites experienced net forest loss over the 19 years, from $20 \%$ (the minimum based on my site selection criteria), to largest forest loss of $49.2 \%$ loss (from $82.7 \%$ forest in 2000 to $33.5 \%$ forest in 2019). In some cases, temporal sites lost forest in small bursts every few years, while others experienced relatively continuous annual declines over the 19-year period. Only two sites experienced most of the forest loss in the span of only one or two years within the time period.

In general, results suggest that observed bird responses to forest cover over time do not align with the observed responses to forest cover over space. Notably, not only were temporal and spatial slopes typically uncorrelated and/or unequal (Table 1; 
Appendix Figures A and B), but they could predict opposite directions of forest cover effects on birds in the same space-time comparison (i.e., a negative effect of forest cover over time and a positive effect of forest cover in space)). Out of the 8 data scenarios analyzed, 6 showed low - or even negative - correlations between the 31 matched temporal and spatial slopes measuring forest cover responses for forest and open-habitat birds (Figures 3, 4, and Table 1). The exception was for the scenarios of open-habitat bird richness and abundance when all spatial sites were included (time-versus-space slope $=$ $0.610,95 \%$ P.I. [-0.246, 1.912] and $1.251,95 \%$ P.I. [0.121, 2.744], respectively; see Figures 3, 4, and Table 1). These showed the strongest congruence in forest cover effects between time and space although correlations were low (Pearson's $r=0.286$ and 0.390 , respectively; see Table 1). Interestingly, for both forest and open-habitat birds, when more spatial sites were considered in a comparison's spatial gradient relative to the number of years considered in the temporal gradient, the relationship between time and space effects became stronger (Table 1).

Across the 31 comparisons and 7 out of 8 scenarios, spatial slopes were consistently positive for forest birds and consistently negative for open-habitat birds, as expected (see $x$-axis of Figures 2 and 3). In contrast, the relationships between forest cover over time and forest bird richness or abundance over time were not as consistently positive (see y-axis of Figures 2 and 3; Appendix Figures and Tables C, D, G, H). Likewise, the relationships between forest cover over time and open-habitat bird richness or abundance over time were not consistently negative (see Appendix Figures and Tables E, F, I, J). Interestingly, even temporal sites with very similar forest cover gradients 
sometimes experienced opposite temporal trends in bird richness or abundance (e.g., compare Regions 28 and 31 in Appendix Figure C).

\section{Discussion}

I did not find support for the space-for-time substitution for North American birds. Specifically, I found that slopes measuring the effects of forest cover on bird richness and abundance over time were not consistently equal nor even positively correlated to spatial slopes across multiple comparisons. This mismatch between trends in time and space suggests that studies of bird responses differences across landscapes in forest cover are not a solid basis for making predictions about how birds would respond to a loss or gain in forest cover over time.

My results are consistent with the findings of other studies that attempt to directly compare time and space effects in birds. An early study by Flather \& Sauer (1999) used data from the BBS to compare time and space effects of landscape structure on Neotropical migratory birds. They found that, over time, migrant birds were often negatively associated with increased vegetation cover, in contradiction to the consistently positive associations observed in space (Flather \& Sauer 1999). At the time, the authors were limited to a cross-sectional dataset of land cover snapshots in 1966 and 1993 only and lacked the ability to annually track land cover change (Flather \& Sauer 1999). More recently, La Sorte and colleagues used BBS data to compare temporal trends in North American bird responses to climate change with a space-for-time substitution, finding that the predicted responses of bird body mass and occupancy to changing temperature measured in space were not able to sufficiently explain actual observed trends in body mass and occupancy over time (La Sorte et al. 2009). This incongruence between time 
and space was also shown by Bonthoux et al. (2013). They sampled an agricultural landscape in southwest France in 1982 and 2007. They found that species richness and two community specialisation indices were associated with landscape composition less consistently over time than in space (Bonthoux et al. 2013). Finally, a recent study by Gaüzère \& Devictor (2021) in France revealed that the effect of local human activities on bird distributions in space was not a strong predictor of how bird distributions changed in response to human activities over time. They even found that bird abundance patterns in time and space became more different from each other with greater anthropogenic disturbance.

In this study, the mismatch between temporal slopes and spatial slopes appears to be tied to greater inconsistency in bird responses to forest cover over time than over space, mirroring the results of Bonthoux et al. 2013. My results showed that, across the 31 space-time comparisons, spatial slopes aligned more consistently than temporal slopes to the expected relationships between bird richness or abundance and forest cover change. Specifically, bird responses across space aligned well with the expectation that forest birds increase and open-habitat birds decrease, in both richness and abundance, as forest cover increases. In contrast, bird responses to forest change over time were often opposite to these expectations, with both negative and positive temporal slopes (Figures 2 and 3). In a conservation context, this indicates that how birds respond to changing forest cover amount across landscapes in space might produce overly optimistic predictions for how a certain increase in forest cover over time would be expected to result in an certain increase in forest birds and a certain decrease in open-habitat birds. Here, temporal relationships instead suggest that restoring forest cover in a landscape over time may not 
always have as strong of an effect on recovering species as was predicted by a spatial analysis.

I speculate that bird-forest cover relations over space are more consistent than they are over time because more variables influence birds over time than over space. The most obvious are weather variables. Within a given year (here 2019) the spatial sites in a particular space-time comparison likely experienced similar weather conditions. In contrast, at a given temporal site, weather will fluctuate over time. Changing weather patterns can both directly and indirectly impact bird populations on the breeding grounds, wintering grounds, and along the migratory routes (Sillett et al. 2000; Drake et al. 2014; Wilson et al. 2010; Wilson et al. 2018; Hill et al. 2019). These impacts may influence local abundance and diversity on the breeding grounds to a greater extent than forest cover alone. Acting directly, weather conditions along the migratory route - such as storms, high winds, or drought - can influence the number of individuals that settle on the breeding grounds in the spring (Drake et al. 2014; Wilson et al. 2018). Indirectly, climatic conditions can create variability in local availability of fruits, seeds, and insects, which can affect bird survival rates (Both et al. 2010; Sillett et al. 2000; Hill et al. 2019). In addition, seasonal disease outbreaks would add to inter-annual variation in bird abundance and diversity (Hochachka \& Dhondt 2000; Hernandez et al. 2012), further decoupling the relationship between birds and forest cover.

The fact that many of the species included in my analysis are seasonal and directional migrants could explain the greater inconsistency in the effects of breeding ground forest cover over time than in space. Here, 80 out of the 118 forest species and 17 out of the 36 open-habitat species were migratory. Migratory birds have complex annual 
cycles, such that their populations are limited by a host of factors operating simultaneously on the breeding grounds, migratory route, and on the non-breeding grounds, with evidence pointing toward migration (Sillett \& Holmes 2002; Klaassen 2014; Lok et al. 2015; Hewson et al. 2016) and non-breeding ground threats (Taylor \& Stutchbury 2016; La Sorte et al. 2017; Dokter et al. 2018) being the most relevant. Changes not only in climate, but in forest and matrix composition and configuration at critical stopover sites or overwintering grounds over time, may be considerable drivers of population change that cannot be accounted for by a spatial analysis focusing solely on breeding ground forest cover amounts in a single year.

Unmeasured lag effects might further decouple the relationship in time between birds and first cover. Observed annual bird richness and abundance may be more strongly related to past forest cover at a site than to the forest cover present in that year. Indeed, a site's past landscape has been shown to be a powerful predictor of present-day species assemblages in birds and other taxa, in some cases with a time lag of up to 25 years (Wiens \& Rotenberry 1985; Brooks et al. 1999; Foster et al. 2003; Ernoult et al. 2005; Saether et al. 2005). In my study, time-lagged bird responses are a plausible explanation for some of the negative effects of increasing forest cover on forest birds and positive effects of increasing forest cover on open-habitat birds that were observed at some temporal sites. This would be the case if, at these temporal sites, forest and open-habitat birds were responding to past forest cover sequences that had occurred prior to my study period. For instance, if forest cover increased in the years leading up to my study and then only began to markedly decrease after 2000 , as observed here, the trend that forest 
birds seem to be increasing with forest loss from 2000 to 2019 might be a lagged response of 10 years or more to forest gain that had occurred previously.

Features of the dataset itself could be relevant for explaining inconsistent results in time. Most notably, the Global Forest Change (GFC) dataset is limited in its ability to track and quantify forest cover gain over time. Specifically, it only considers a 30-m pixel to have experienced tree cover gain if it transitioned from being completely open habitat in 2000 to having tree cover with at least 50\% crown cover density in 2012 (Hansen et al. 2013). Thus, my estimates of annual forest cover at a temporal site may be underestimated, which could explain why bird-forest cover relationships over time did not align consistently with my expectations. However, because my annual estimates of forest cover were calculated iteratively from year to year, the forest cover estimates in 2019 for each spatial site are also likely underestimated. Despite this, I still observed the expected bird-forest cover relationships more consistently in space for both forest and open-habitat birds across the majority of space-time comparisons.

The fact that many of the spatial sites were used in multiple space-time comparisons does not explain the observed higher consistency with expected bird-forest relationships in space than in time. Because of this overlap we expect sets of similar spatial slopes. However, we would still expect the bird-forest cover relationships observed in space to be reflected in the temporal trajectories of nearby sites if the spacefor-time substitution is valid (De Palma et al. 2018). Additionally, the overlap cannot explain why independent temporal sites show opposite effects of forest cover on birds (e.g., compare Region 28 to 31 in Appendix Figure C), or why effects in space are more 
consistent with the expected direction of forest cover effects for forest and open-habitat species.

The 1:1 assumption of space-for-time substitution is not unfamiliar to criticism in broader contexts. Indeed, other studies have also adverted caution in using space-fortime substitution when studying landscape processes, building climate forecasting models, sampling for occupancy, or evaluating vegetation succession dynamics (Adler \& Levine 2007; Isaac et al. 2011; Jochner et al. 2013; Mimet et al. 2016; França et al. 2016; Oedekoven et al. 2017; De Lombaerde et al. 2018). However, some studies have found moderate support for space-for-time substitutions (Charbonnel et al. 2014; Guittar et al. 2016; Miao et al. 2018; Klesse et al. 2020), and some even find that it works well (Sparling et al. 2003; Walker et al. 2010; Banet \& Trexler 2013, Hammond \& Kolasa 2014; Blois et al. 2013; Rolo et al. 2016; Wogan \& Wang 2018; Srivathsa et al. 2018). This inconsistency in support for space-for-time substitution over the past two decades suggests that the question is not simply "whether" space-for-time substitution is valid, but "where", "when", and in "what" systems it may be most reliable.

My study results, in combination with others, can provide insights into where space-for-time substitution might work best. Recent work suggests that space-for-time substitution may favour animals with high mobility and fast generation times (Banet \& Trexler 2013), because they can respond quickly to environmental change (Damgaard 2019). In particular, being highly mobile could allow animals to track local habitat changes as they occur throughout the year. However, animals that are migratory and return to the same location to breed every year, as in Neotropical birds, may have fewer opportunities to respond to unfavourable habitat changes that occurred during their 
absence promptly enough to still breed on time, especially if they decide on nesting sites based on past reproductive successes and/or proximity to their birth site (Hoover 2003; Harrison et al. 2010). From this, I speculate that the space-for-time substitution would likely also fail for other migratory animals, such as butterflies. Temporal variation in migratory butterfly abundance could be equal to or greater than in birds because annual butterfly distribution and seasonal migration is closely linked to climate conditions, which can be considerably variable over time (Isaac et al. 2011; Chowdhury et al. 2021). Taxa- or even species-specific analyses exploring the role of migratory behaviour in space-for-time substitution's effectiveness could be an interesting avenue for further exploration.

In conclusion, space-for-time substitution does not work consistently for predicting bird responses to changing forest cover in North America. As such, using patterns we observe in space to inform conservation policies requires caution and a need to better understand when space-for-time substitution is reliable. Space-for-time substitution, as applied through spatial analyses, remain a useful tool for investigating the impact of environmental variables on wildlife while controlling for temporal variation. However, my results highlight how spatial analyses may oversimplify the complex temporal processes responsible for long-term population change. Further, spatial analyses could be overly optimistic in predicting how changing breeding habitat actually affects birds relative to other important environmental variables operating over time. My results therefore underscore the importance of remaining critical of the assumptions associated with predicting wildlife changes over time based on observed spatial patterns. 


\section{References}

Adler, P.B. \& Levine, J.M. (2007). Contrasting relationships between precipitation and species richness in space and time. Oikos, 116(2): 221-232.

Banet, A. \& Trexler, J. (2013). Space-for-time substitution works in Everglades ecological forecasting models. PLoS ONE, 8(11): e81025.

Baselga, A., Bonthoux, S., \& Balent, G. (2015). Temporal beta diversity of bird assemblages in agricultural landscapes: Land cover change vs. stochastic processes. PLoS ONE, 109(5).

Bélisle, M., Desrochers, A., \& Fortin, M-J. (2001). Influence of forest cover on the movements of forest birds: A homing experiment. Ecology, 82(7): 1893-1904.

Betts, M.G., Forbes, G.J., \& Diamond, A.W. (2007). Thresholds in songbird occurrence in relation to landscape structure. Conservation Biology, 21(4): 1046-1058.

Blois, J.L., Williams, J.W., Fitzpatrick, M.C., Jackson, S.T., \& Ferrier, S. (2013). Space can substitute for time in predicting climate-change effects on biodiversity. Proceedings of the National Academy of Sciences, 110(23): 9374-9379.

Bonthoux, S., Barnagaud, J-Y., Goulard, M., \& Balent, G. (2013). Contrasting spatial and temporal responses of bird communities to landscape changes. Oecologia, 172(2): 563574.

Both, C., Van Turnhout, C.A.M., Bijlsma, R.G., Siepel, H., Van Striene, A.J., \& Foppen, R.P.B. (2009). Avian population consequences of climate change are most severe for long-distance migrants in seasonal habitats. Proceeding of the Royal Society B: Biological Sciences. 277(1685): 1259-1266. 
Brooks, T.M., Pimm, S.L., \& Oyugi, J.O. (1999). Time lag between deforestation and bird extinction in tropical forest fragments. Conservation Biology, 13(5): 1140-1150.

Charbonnel, A., D'Amico, F., Besnard, A., Blanc, F., Buisson, K., Nemoz, M., \& Laffaille, P. (2014). Spatial replicates as an alternative to temporal replicates for occupancy modelling when surveys are based on linear features of the landscape. Journal of Applied Ecology, 51(5): 1425-1433.

Chowdhury, S., Zalucki, M.P., Amano, T., Woodworth, B.K., Venegas-Li, R., \& Fuller, R.A. (2021). Seasonal spatial dynamics of butterfly migration. Ecology Letters, Early View.

Congdon, J.D., Dunham, A.E., \& Sels, R.C. (1993). Delayed sexual maturity and demographics of Blanding's turtles (Emydoidea blandingii): Implications for conservation and management of long-lived organisms. Conservation Biology, 7(4); 826833.

Cooper, M., \& Zvoleff, A. (2020). Gfcanalysis: Tools for Working with Hansen et al. Global Forest Change Dataset. R package version 1.6.0. Available at https://CRAN.Rproject.org/package $=$ gfcanalysis .

Cowles, H.C. (1899). The ecological relations of the vegetation on the sand dunes of Lake Michigan. Botanical Gazette, 27(2): 95-117.

Cushman, S.A. \& McGarigal, K. (2003). Landscape-level patterns of avian diversity in the Oregon Coast Range. Ecological Monographs, 73(2): 259-281. 
Damgaard, C. (2019). A critique of the space-for-time substitution practice in community ecology. Trends in Ecology \& Evolution, 34(5): 416-421.

De Lombaerde, E., Verheyen, K., Perring, M.P., Bernhardt-Romermann, M., Van Calster, H., Brunet, J., Chudomelová, M., Decocq, G., Diekmann, M., Durak, T., Hédl, R., Heinken, T., Hommel, P., Jaroszewicz, B., Kopecký, M., Lenoir, J., Macek, M., Máliš, F., Mitchell, F.J.G., Naaf, T., Newman, M., Petř́ik, P., Reczyńska, K., Schmidt, W., Świerkosz, K., Vild, O., Wulf, M., \& Batean, L. (2018). Responses of competitive understorey species to spatial environmental gradients inaccurately explain temporal changes. Basic and Applied Ecology, 30: 52-64.

De Palma, A., Sanchez-Ortiz, K., Martin, P.A., Chadwick, A., Gilbert, G., Bates, A.E., Börger, L., Contu, S., Hill, S.L.L., Purvis, A., Bohan, D.A., Dumbrell, A.J., Woodward, G., \& Jackson, M. (2018). Challenges with inferring how land-use affects terrestrial biodiversity: Study design, time, space and synthesis. Advances in Ecological Research, $1(58)$.

Desrochers, R.E., Kerr, J.T., \& Currie, D.J. (2011). How, and how much, natural cover loss increases species richness. Global Ecology and Biogeography, 20(6): 857-867.

Drake, A., Rock, C.A., Quinlan, S.P., Martin, M., \& Green, D.J. (2014). Wind speed during migration influences the survival, timing of breeding, and productivity of a Neotropical migrant, Setophaga petechia. PLoS ONE, 9(5): e97152.

Dokter, A.M., Farnsworth, A., Fink, D., Ruiz-Gutierrez, V., Hochachka, W.M., La Sorte, F.A., Robinson, O.J., Rosenberg, K.V., \& Kelling, S. (2018). Seasonal abundance and 
survival of North America's migratory avifauna determined by weather radar. Nature Ecology \& Evolution, 2: 1603-1609.

Dornak, L.L., Aycrigg, J.L., Sauer, J., \& Conway, C.J. (2020). Assessing the efficacy of protected and multiple-use lands for bird conservation in the U.S. PLOS ONE, 15(9): e0239184.

Ernoult, A., Tremauville, Y., Cellier, D., Margerie, P., Langlois, E., \& Alard, D. (2006). Potential landscape drivers of biodiversity components in a flood plain: Past or present patterns? Biological Conservation, 127(1): 1-17.

Endenburg, S., Mitchell, G.W., Kirby, P., Fahrig, L., Pasher, J., \& Wilson, S. (2019). The homogenizing influence of agriculture on forest bird communities at landscape scales. Landscape Ecology, 34: 2385-2399.

Environment Canada. (2021). Breeding Bird Survey Overview [Online]. Environment Canada, Gatineau.

Fahrig, L. (2003). Effects of habitat fragmentation on biodiversity. Annual Review of Ecology, Evolution, and Systematics, 34: 487-515.

Fahrig, L. (2015). Just a hypothesis: a reply to Hanski. Journal of Biogeography 42: 993 994.

Flather, C.H. \& Sauer, J.R. (1996). Using landscape ecology to test hypotheses about large-scale abundance patterns in migratory birds. Ecology, 77(1): 28-35.

França, F., Louzada, J., Korasaki, V., Griffiths, H., Silveira, J.M., \& Barlow, J. (2016).

Do space-for-time assessments underestimate the impacts of logging on tropical 
biodiversity? An Amazonian case study using dung beetles. Journal of Applied Ecology, 53(4): 1098-1105.

Fischer, J. \& Lindenmayer, D.B. (2002). Small patches can be valuable for biodiversity conservation: two case studies in southeastern Australia. Biological Conservation, 106(1): 129-136.

Fishcer, C., Flohre, A., Clement, L.W., Batary, P., Weisser, W.W., Tscharntke, T., \& Thies, C. (2011). Mixed effects of landscape structure and farming practice on bird diversity. Agriculture, Ecosystems \& Environment, 141(1): 119-125.

Frey-Ehrenbold, A., Bontadina, F., Artlettaz, R., \& Obrist, M.K. (2013). Landscape connectivity, habitat structure and activity of bat guilds in farmland-dominated matrices. Journal of Applied Ecology, 50(1): 252-261.

Fukami, T. \& Wardle, D.A. (2005). Long-term ecological dynamics: reciprocal insights from natural and anthropogenic gradients. Proceedings of the Royal Society B: Biological Sciences, 272(1577): 2105-2115.

Gabry, J., Simpson, D., Vehtari, A., Betancourt, M., \& Gelman, A. (2019). Visualization in Bayesian workflow. Journal of the Royal Statistical Society: Series A (Statistics in Society), 182(2): 389-402.

Galán-Acedo, C., Arroyo-Rodriguez, V., Cudney-Valenzuela, S., \& Fahrig, L. (2019). A global assessment of primate responses to landscape structure. Biological Reviews, 94: $1605-1618$. 
Gaüzère, P. \& Devictor, V. (2021). Mismatches between birds' spatial and temporal dynamics reflect their delayed response to global changes. Oikos, Early View.

Gelman, A., \& Rubin, D.B. (1992). Inference from iterative simulation using multiple sequences. Statistical Science, 7(4): 457-472.

Gilliam, F.S., Goodale, C.L., Pardo, L.H., Geiser, L.H., \& Lilleskov, E.A. (2011). Eastern temperate forests, Chapter 10. In: Pardo, L.H., Robin-Abott, M.J., Driscoll, C.T., eds. Assessment of nitrogen deposition effects and empirical critical loads of nitrogen for ecoregions of the United States. Gen. Tech. Rep. NRS-80. Newtown Square, PA: U.S. Department of Agricultural, Forest Service, Northern Research Station: 99-116.

Guittar, J., Goldberg, D., Klanderud, K., Telford, R.J., \& Vandvik, V. (2016). Can trait patterns along gradients predict plant community responses to climate change? Ecology, 97(10): 2791-2801.

Hammond, M.P. \& Kolasa, J. (2014). Spatial variation as a tool for inferring temporal variation and diagnosing types of mechanisms in ecosystems. PLoS ONE, 9(2): e89245.

Hanberry, B.B. \& Thompson, F.R. (2019). Open forest management for early successional birds. Wildlife Society Bulletin, 43(1): 141-151.

Hansen, M.C., Potapov, P.V., Moore, R., Hancher, M., Turubanova, S.A., Tyukavina, A., Thau, D., Stehman, S.V., Goetz, S.J., Loveland, T.R., Kommareddy, A., Egorov, A., Chini, L., Justice, C.O., \& Townshend, J.R.G. (2013). High-resolution global maps of $21^{\text {st }}$-century forest cover change. Science, $342(6160): 850-853$. Available at http://earthenginepartners.appspot.com/science-2013-global-forest. 
Harris, S.J., Massimino, D., Balmer, D.E., Eaton, M.A., Noble, D.G., Pearce-Higgins, J.W., Woodcock, P., \& Gillings, S. (2021). The Breeding Bird Survey 2020. BTO Research Report 736. British Trust for Ornithology, Thetford.

Hejda, M., Pyšek, P., \& Jarošík, V. (2009). Impact of invasive plants on the species richness, diversity and composition of invaded communities. Journal of Ecology, 97(3): 393-403.

Hernandez, S.M., Keel, K., Sanchez, S., Trees, E., Gerner-Smidt, P., Adams, J.K., Cheng, Y., Ray, A., Martin, G., Presotto, A., Ruder, M.G., Brown, J., Blehert, D.S., Cottrell, W., \& Maurer, J.J. (2012). Epidemiology of a Salmonella enterica subsp. Enterica Serovar Tphymiurium strain associated with a songbird outbreak. Applied and Environmental Microbiology, 78(20): 7290-7298.

Hewson, C.M., Thorup, K., Pearce-Higgins, J.W., \& Atkinson, P.W. (2016). Population decline is linked to migration route in the Common Cuckoo. Nature Communications, 7: 12296.

Hill, J., Lloyd, J., McFarland, K., \& Rimmer, C. (2019). Apparent survival of a rangerestricted montane forest bird species is influenced by weather throughout the annual cycle. Avian Conservation and Ecology, 14(2).

Hochachka, W.M. \& Dhondt, A.A. (2000). Density-dependent decline of host abundance resulting from a new infectious disease. Proceedings of the National Academy of Sciences, 97(10): 5303-5306.

Hoover, J.P. (2003). Decision rules for site fidelity in a migratory bird, the Prothonotary Warbler. Ecology, 84(2): 416-430. 
Jochner, S., Caffarra, A., \& Menzel, A. (2013). Can spatial data substitute temporal data in phenological modelling? A survey using birch flowering. Tree Physiology, 33(12): 1256-1268.

Johnson, E.A. \& Miyanishi, K. (2008). Testing the assumptions of chronosequences in succession. Ecology Letters, 11(5); 419-431.

Kendall, W.L., Peterjohn, B.G., \& Sauer, J.R. (1996). First-time observer effects in the North American Breeding Bird Survey. The Auk, 113(4): 823-829.

Klaassen, R.H.G., Hake, M., Koks, B.J., Trierwiler, C., Exo, K-M., Bairlein, F., \& Alerstam, T. (2014). When and where does mortality occur in migratory birds? Direct evidence from long-term satellite tracking of raptors. Journal of Animal Ecology, 83(1); 176-184.

Klesse, S., DeRose, R.J., Babst, F., Black, B.A., Anderegg, L.D.L., Axelson, J., Ettinger, A., Griesbauer, H., Guiterman, C.H., Harley, G., Harvey, J.E., Lo, Y-H., Lynch, A.M., O'Connor, C., Restaino, C., Sauchyn, D., Shaw, J.D., Smith, D.J., Wood, L., VillaneuvaDíaz, J., \& Evans, M.E.K. (2020). Continental-scale tree-ring-based projection of Douglas-fir growth: Testing the limits of space-for-time substitution. Global Change Biology, 26(9): 5146-5163.

Kratz, T.K., Deegan, L.A., Harmon, M.E., \& Lauenroth, W.K. (2003). Ecological variability in space and time: Insights gained from the US LTER program. BioScience, 53(1): 57-67. 
Kupfer, J.A., Malanson, G.P., \& Franklin, S.B. (2006). Not seeing the ocean for the islands: the mediating influence of matrix-based processes on forest fragmentation effects. Global Ecology and Biogeography, 15(1): 8-20.

La Sorte, F.A., Lee, T.M., Wilman, H., \& Jetz, W. (2009). Disparities between observed and predicted impacts of climate change on winter bird assemblages. Proceedings of the Royal Society B: Biological Sciences, 276(1670): 3167-3174.

La Sorte, F.A., Fink, D., Blancher, B.J., Rodewald, A.D., Ruiz-Gutierrez, V., Rosenberg, K.V., Hochachka, W.M., Verburg, P.H., \& Kelling, S. (2017). Global change and the distributional dynamics of migratory bird populations wintering in Central America. Global Change Biology, 23(12): 5284-5296.

Lemoine, N., Schaefer, H-C., \& Böhning-Gaese, K. (2007). Species richness of migratory birds is influenced by global climate change. Global Ecology and Biogeography, 16(1): $55-64$.

Lester, R.E., Close, P.G., Barton, J.L., Pope, A.J., \& Brown, S.C. (2014). Predicting the likely response of data-poor ecosystems to climate change using space-for-time substitution across domains. Global Change Biology, 20(11): 3471-3481.

Lok, T., Overdijk, O., \& Piersma, T. (2014). The cost of migration: spoonbills suffer higher mortality during trans-Saharan spring migrations only. Biology Letters, 11: 20140944.

Mahood, S.P., Lees, A.C., \& Peres, C.A. (2012). Amazonian countryside habitats provide limited avian conservation value. Biodiversity and Conservation, 21(2): 383-405. 
Marchand, M.N. \& Litvaitis, J.A. (2004). Effects of habitat features and landscape composition on the population structure of a common aquatic turtle in a region undergoing rapid development. Conservation Biology, 18(3): 758-767.

Martin, A.E., Collins, S.J., Crowe, S., Girard, J., Naujokaitis-Lewis, I., Smith, A.C., Lindsay, K., Mitchell, S., \& Fahrig, L. (2020). Effects of farmland heterogeneity on biodiversity are similar to — or even larger than — the effects of farming practices. Agriculture, Ecosystems and Environment, 288: 106698.

McGarigal, K. \& Cushman, S.A. (2002). Comparative evaluation of experimental approaches to the study of habitat fragmentation effects. Ecological Applications, 12(2): 335-345.

Metzger, J.P., Martensen, A.C., Dixo, M., Bernacci, L.C., Ribeiro, M.C., Texeira, A.M.G., \& Pardini, R. (2009). Time-lag in biological responses to landscape changes in a highly dynamic Atlantic forest region. Biological Conservation, 142(6): 1166-1177.

Miao, R., Qiu, X., Guo, M., Musa, A., \& Jiang, D. (2018). Accuracy of space-for-time substitution for vegetation state prediction following shrub restoration. Journal of Plant Ecology, 11(2): 208-217.

Mimet, A., Pellissier, V., Houet, T., Julliard, R., \& Simon, L. (2016). A holistic landscape description reveals that landscape configuration changes more over time than composition: Implications for landscape ecology studies. PLoS ONE, 11(3); e0150111.

Moore, T.R., Trofymow, J.A., Taylor, B., Prescott, C., Camire, C., Dsuchene, L., Fyles, J., Kozak, L., Kranabetter, M., Morrison, I., Siltanen, M., Smith, S., Titus, B., Visser, S., 
Wein, R., \& Zoltai, S. (1999). Litter decomposition rates in Canadian forests. Global Change Biology, 5(1): 75-82.

National Audubon Society (2020). The Christmas Bird Count Historical Results [Online]. Available at http://www.christmasbirdcount.org.

Ocampo-Peñuela, N., Jenkins, C.N., Vijay, V., Li, B.V., \& Pimm, S.L. (2016). Incorporating explicit geospatial data shows more species at risk of extinction than the current Red List. Science Advances, 2(11): e1601367.

Oedekoven, C.S., Elston, D.A., Harrison, P.J., Brewer, M.J., Buckland, S.T., Johnston, A., Foster, S., \& Pearce-Higgins, J.W. (2017). Attributing changes in the distribution of species abundance to weather variables using the example of British breeding birds. Methods in Ecology and Evolution, 8(12): 1690-1702.

Patuxent Wildlife Research Center. (1999). Breeding Bird Survey Route Locations for Lower 48 States, 1966-1998. National Atlas of the United States. Available at http://purl.stanford.edu/vy474dv5024.

Pardieck, K.L., Ziolkowski, Jr., D.J., \& Hudson, M.-A.R. (2015). North American Breeding Bird Survey Dataset 1966-2019, version 2019.0. U.S. Geological Survey, Patuxent Wildlife Research Center, MD., USA. Available at https://www.pwrc.usgs.gov/BBS/RawData/.

Pardini, R., de Souza, S.M., Braga-Neto, R., \& Metzger, J.P. (2005). The role of forest structure, fragment size and corridors in maintaining small mammal abundance and diversity in an Atlantic forest landscape. Biological Conservation, 124(2): 253-266. 
Radford, J.Q. \& Bennett, A.F. (2007). The relative importance of landscape properties for woodland birds in agricultural environments. Journal of Applied Ecology, 44(4): 737747.

R Core Team. (2020). R: A language and environment for statistical computing. $\mathrm{R}$ Foundation for Statistical Computing, Vienna, Austria. https://www.R-project.org/ Rendell, W., Robertson, R.R., Tryjanowski, P., \& Visser, M.E. (2005). Generation time and temporal scaling of bird population dynamics. Nature, 436(7047): 99-102.

Rodewald, P. (2018). The Birds of North America [Online]. Cornell Laboratory of Ornithology, Ithaca, NY. Available at https://birdsoftheworld.org/bow/home.

Rolo, V., Olivier, P.I., Guldemond, R.A.R., \& Aarde, R.J. (2016). Validating space-fortime substitution in a new-growth coastal dune forest. Applied Vegetation Science, 19(2): $235-243$.

Rosenberg, K.V., Blancher, P.J., Stanton, J.C., \& Panjabi, A.O. (2017). Use of North American Breeding Bird Survey data in avian conservation assessments. The Condor, 119(3): 594-606.

Rushing, C.S., Ryder, T.B., \& Marra, P.P. (2016). Quantifying drivers of population dynamics for a migratory bird throughout the annual cycle. Proceedings of the Royal Society B, 283: 20152846.

Rustad, L.E. (2008). The response of terrestrial ecosystems to global climate change: Towards an integrated approach. Science of the Total Environment, 404(2): 222-235. 
Saether, B-E., Lande, R., Engen, S., Weimerskirch, H., Lillegård, M., Altwegg, R., Becker, P.H., Bregnballe, T., Brommer, J.E., McCleery, R.H., Merila, J., Nyholm, E., Sandel, B. (2019). Disequilibrium in trait-climate relationships of trees and birds. Frontiers in Ecology and Evolution, 7.

Sauer, J.R., Peterjohn, B.G., \& Link, W.A. (1994). Observer differences in the North American Breeding Bird Survey. The Auk, 111(1): 50-62.

Sax, D.F., Kinlan, B.P., \& Smith, K.F. (2005). A conceptual framework for comparing species assemblages in native and exotic habitats. Oikos, 108(3): 457-464.

Schlesinger, W.H. (1990). Evidence from chronosequences studies for a low carbonstorage potential of soils. Nature, 348(6298): 232-234.

Sillett, T.S., Holmes, R.T., \& Sherry, T.W. (2000). Impacts of a global climate cycle on population dynamics of a migratory songbird. Science, 2888(5473): 2040-2042.

Sillett, T.S. \& Holmes, R.T. (2002). Variation in survivorship of a migratory songbird throughout its annual cycle. Journal of Animal Ecology, 71(2): 296-308.

Sirami, C., Brotons, L., \& Martin, J-L. (2009). Do bird spatial distribution patterns reflect population trends in changing landscapes? Landscape Ecology, 24(7): 893-906.

Sodhi, N.S., Koh, L.P., Clements, R., Wanger, T.C., Hill, J.K., Hamer, K.C., Clough, Y., Tscharntke, T., Posa, M.R.C., \& Lee, T.M. (2010). Conserving southeast Asian forest biodiversity in human-modified landscapes. Biological Conservation, 143(10): 23752384. 
Srivathsa, A., Puri, M., Kumar, N.S., Jathanna, D., \& Karanth, K.U. (2018). Substituting space for time: Empirical evaluation of spatial replication as a surrogate for temporal replication in occupancy modelling. Journal of Applied Ecology, 55(2): 754-765.

Strayer, D., Glitzenstein, J., Jones, C., Kolasa, J., Likens, G.E., McDonell, M.J., Parker, G.G., \& Pickett, S.T.A. (1988). Long-term ecological studies: an illustrated account of their design, operation, and importance to ecology. Occasional Publication of the Institute of Ecosystem Studies: Number 2.

Stan Development Team. (2020). RStan: the R interface to Stan. R package version 2.21.2. Available at http://mc-stan.org/.

Sullivan, B.L., Aycrigg, J.L., Barry, J.H., Bonney, R.E., Bruns, N., Cooper, C.B., Damoulas, T., Dhondt, A.A., Dietterich, T., Farnsworth, A., Fink, D., Fitzpatrick, J.W., Fredericks, T., Gerbracht, J., Gomes, C., Hochachka, W.M., Iliff, M.J., Lagoze, C., La Sorte, F.A., Merrifield, M., Morris, W., Philips, T.B., Reynolds, M., Rodewald, A.D., Rosenberg, K.V., Tautrmann, N.M., Wiggins, A., Winkler, D.W., Wong, W-K., Wood, C.L., Yu, J., \& Kelling, S. (2014). The eBird enterprise: An integrated approach to development and application of citizen science. Biological Conservation, 169: 31-40. Taylor, C.M. \& Stutchbury, B.J.M. (2016). Effects of breeding versus winter habitat loss and fragmentation on the population dynamics of a migratory songbird. Ecological Applications, 26: 424-437.

Trzcinski, M.K., Fahrig, L., \& Merriam, G. (1999). Independent effects of forest cover and fragmentation on the distribution of forest breeding birds. Ecological Applications, 9(2): 586-593. 
United States Environmental Protection Agency (EPA). (2020). Level I Ecoregions of North America GIS shapefiles, metadata, and symbology. https://www.epa.gov/eco$\underline{\text { research/ecoregions-north-america }}$

U.S. Geological Survey (USGS) and Mexican National Commission for the Knowledge and Use of Biodiversity (CONABIO). (2021). The North American Breeding Bird Survey in Mexico, 2008 to 2018-A Status Report. U.S. Geological Survey Circular, 1479: $1-33$.

Villard, M-A., Trzcinski, M.K., \& Merriam, G. (1999). Fragmentation effects on forest birds: Relative influence of woodland cover and configuration on landscape occupancy. Conservation Biology, 13(4): 774-783.

Walker, L.R., Wardle, D.A., Bardgett, R.D., \& Clarkson, B.D. (2010). The use of chronosequences in studies of ecological succession and soil development. Journal of Ecology, 98(4): 725-736.

Wardle, D.A., Zackrisson, O., Hornberg, G., \& Gallet, C. (1997). The influence of island area on ecosystem properties. Science, 277(5330): 1296-1299.

Wiens, J.A. \& Rotenberry, J.T. (1985). Response of breeding passerine birds to rangeland alteration in a North American shrubsteppe locality. Journal of Applied Ecology, 22(3): $655-668$.

Wilson, S., Smith, A.C., \& Naujokaitis-Lewis, I. (2018). Opposing responses to drought shape spatial population dynamics of declining grassland birds. Diversity and Distributions, 24(11): 1687-1698. 
Wilson, S., LaDeau, S.L., Tottrup, A.P., \& Marra, P.P. (2010). Range-wide effects of breeding- and nonbreeding-season climate on the abundance of a Neotropical migrant songbird. Ecology, 92(9): 1789-1798.

Wilson, S., Mitchell, G.W., Pasher, J., McGovern, M., Hudson, M.R, \& Fahrig, L. (2017). Influence of crop type, heterogeneity and woody structure on avian biodiversity in agricultural landscapes. Ecological Indicators, 83: 218-226.

Wogan, G.O.U. \& Wang, I.J. (2018). The value of space-for-time substitution for studying fine-scale microevolutionary processes. Ecography, 41(9): 1456-1468.

Wright, H.L., Lake, I.R., \& Dolman, P.M. (2011). Agriculture - a key element for conservation in the developing world. Conservation Letters, 5(1): 11-19. 


\section{Tables}

Table 1. Mean regression coefficients (with associated $95 \%$ percentile intervals (PI)) and correlation coefficients (Pearson's r) measuring the congruency between a) estimated forest and open-habitat bird-forest cover slopes over time at a temporal site from 2000 to 2019 ("temporal slope") and b) estimated forest and open-habitat bird-forest cover slopes in space across a set of neighbouring spatial sites in 2019 ("spatial slope"). Spatial slopes were estimated twice: once where the number of spatial sites informing the spatial slope matched with the number of years informing the corresponding temporal slope (scenario I) and again where the maximum number of eligible spatial sites was used to inform the spatial slope (scenario II).

\begin{tabular}{|c|c|c|c|c|}
\hline $\begin{array}{l}\text { Response } \\
\text { Metric }\end{array}$ & Model & $\begin{array}{c}\text { Average Temporal vs. } \\
\text { Spatial Slope }\end{array}$ & 95\% PI & $\begin{array}{c}\text { Pearson's } \\
\mathbf{r}\end{array}$ \\
\hline \multirow{4}{*}{$\begin{array}{c}\text { Mean } \\
\text { species } \\
\text { richness }\end{array}$} & $\begin{array}{c}\text { Forest } \\
\text { (scenario I) }\end{array}$ & -0.259 & {$[-0.835,0.342]$} & -0.316 \\
\hline & $\begin{array}{l}\text { Open-habitat } \\
\text { (scenario I) }\end{array}$ & 0.192 & {$[-0.620,1.009]$} & 0.195 \\
\hline & $\begin{array}{c}\text { Forest } \\
\text { (scenario II) }\end{array}$ & 0.170 & {$[-0.520,0.866]$} & 0.105 \\
\hline & $\begin{array}{l}\text { Open-habitat } \\
\text { (scenario II) }\end{array}$ & 0.610 & {$[-0.246,1.912]$} & 0.286 \\
\hline \multirow{4}{*}{$\begin{array}{c}\text { Mean } \\
\text { abundance }\end{array}$} & $\begin{array}{c}\text { Forest } \\
\text { (scenario I) }\end{array}$ & -0.445 & {$[-0.981,0.089]$} & -0.402 \\
\hline & $\begin{array}{l}\text { Open-habitat } \\
\text { (scenario I) }\end{array}$ & 0.111 & {$[-0.988,1.169]$} & 0.096 \\
\hline & $\begin{array}{c}\text { Forest } \\
\text { (scenario II) }\end{array}$ & -0.557 & {$[-1.339,0.179]$} & -0.250 \\
\hline & $\begin{array}{l}\text { Open-habitat } \\
\text { (scenario II) }\end{array}$ & 1.251 & {$[0.121,2.744]$} & 0.390 \\
\hline
\end{tabular}


Figures

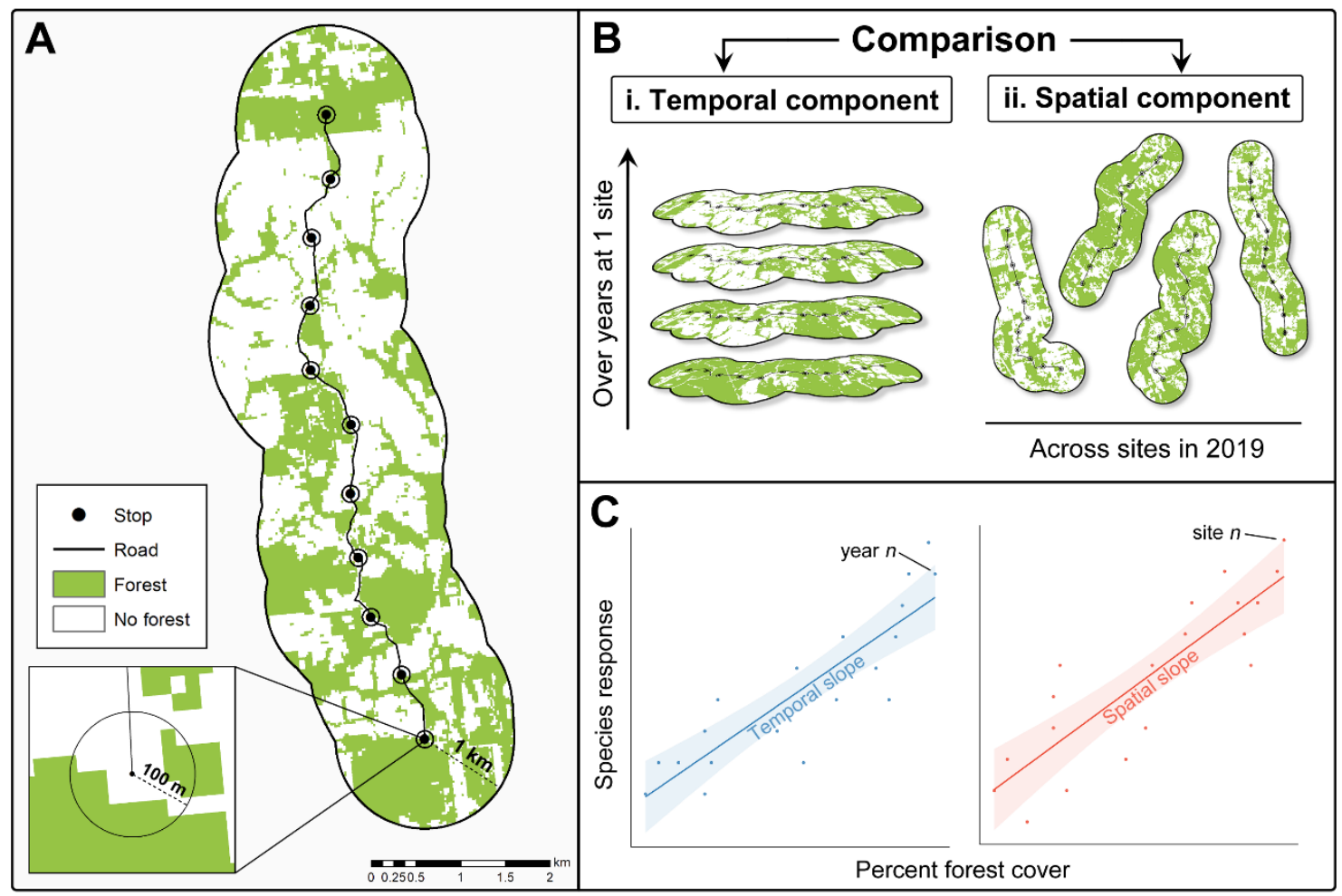

Figure 1. Visual description of the space-time comparison study design where A) a site consisted of the first 11 "stops" of a North American Breeding Bird Survey (BBS) route, along with the landscape within 1-km, within which forest cover was measured. Individual stops were characterized as forested $(\geq 60 \%$ forest within 100 m) or not forested ( $\leq 40 \%$ forest within $100 \mathrm{~m})$. B) Sites were organized into "spacetime comparisons," consisting of a single "temporal site" with bird and forest information from 2000 to 2019, and multiple "spatial sites" covering the same 2019 forest gradient over space as the forest gradient over time at the associated temporal site. C) The relationship between bird species responses and percent forest cover was estimated as a slope over time at the temporal site and over space across the associated spatial sites. 


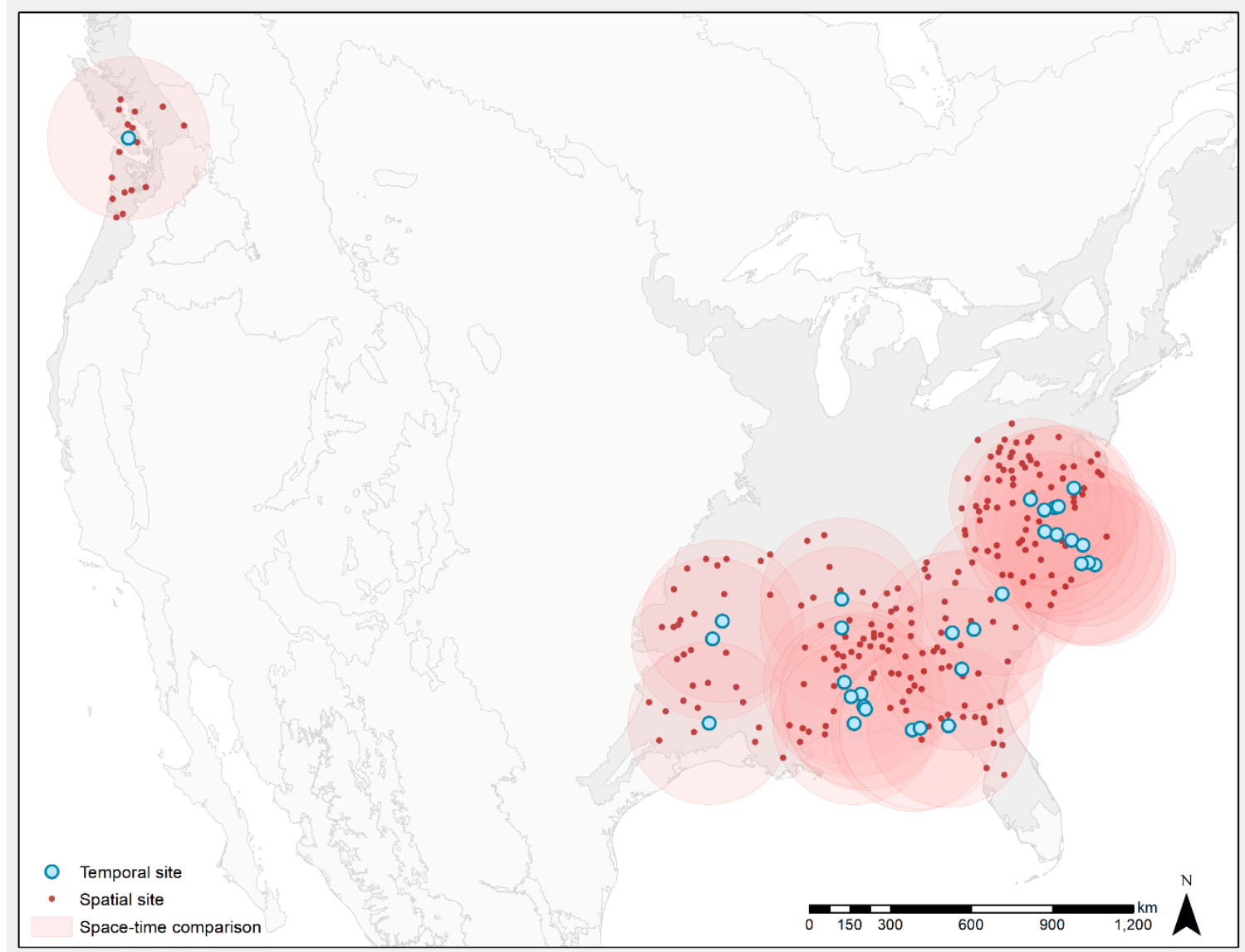

Figure 2. Locations of 31 space-time comparisons within the continental United States (U.S.) and Canada, each consisting of a single temporal site (gradient of forest cover over time) and a series of matched spatial sites (gradient of forest cover across space) located within a 300-km radius buffer of the temporal site. Comparison regions fell in two Level I Ecoregions: Marine West Coastal Forest (left-most dark grey area) and the Eastern Temperate Forests (right-most dark grey area). 


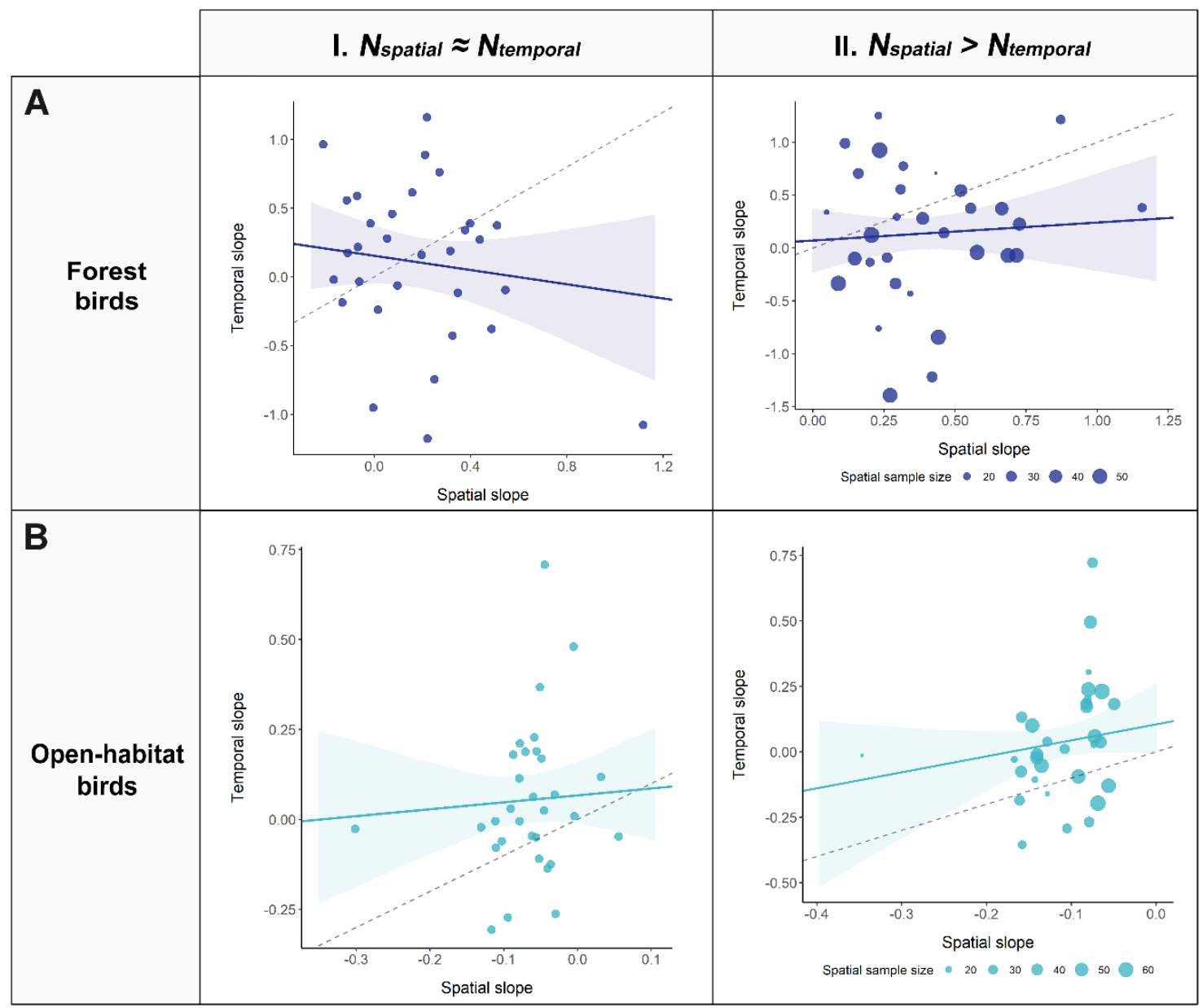

Figure 3. Relationships between estimated slopes measuring the effect of forest cover change on forest (A) and open-habitat (B) mean bird species richness over time at a temporal site from 2000 to 2019 ("temporal slope") and in space across a set of neighbouring spatial sites in 2019 ("spatial slope"). Each of the 31 space-time comparisons contains one temporal and one spatial slope measuring forest cover effects and corresponds to a single point in the figure. Spatial slopes were estimated twice: once where the number of spatial sites informing the spatial slope matched with the number of years informing the corresponding temporal slope (scenario I) and again where the maximum number of eligible spatial sites was used to inform the spatial slope (scenario II). Plotted regression lines represent the mean relationship obtained by summarizing over 12,000 linear regressions for each of 12,000 sets of Markov Chain Monte Carlo parameter iterations, with 95\% percentile intervals shaded. The dotted line represents a 1:1 relationship $(\alpha=0, \beta=$ 1). 


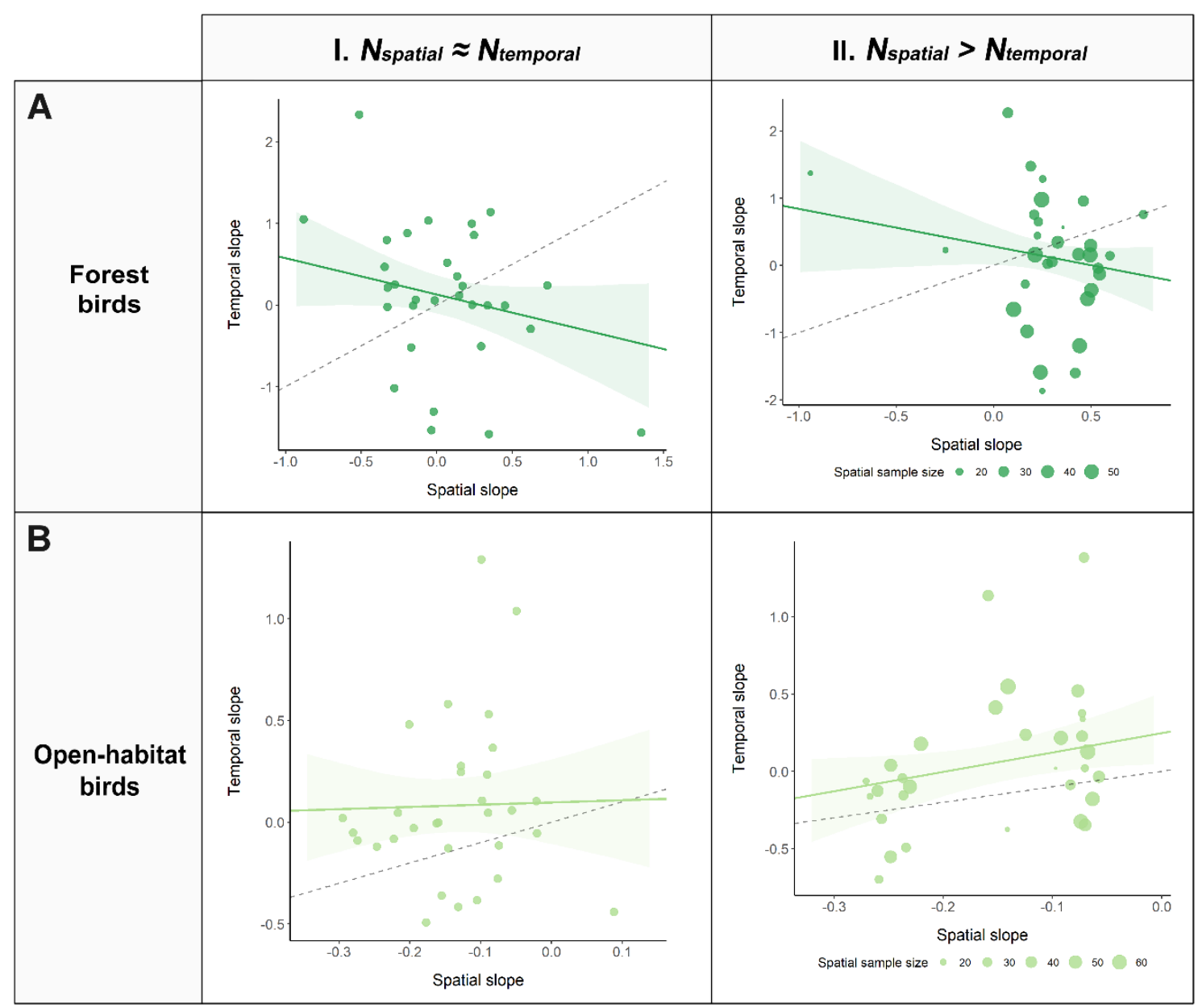

Figure 4. Correlation between estimated slopes measuring the effect of forest cover change on forest (A) and open-habitat (B) mean bird abundance over time at a temporal site from 2000 to 2019 ("temporal slope") and in space across a set of neighbouring spatial sites in 2019 ("spatial slope"). Each of the 31 space-time comparisons contains one temporal and one spatial slope measuring forest cover effects and corresponds to a single point in the figure. Spatial slopes were estimated twice: once where the number of spatial sites informing the spatial slope matched with the number of years informing the corresponding temporal slope (scenario I) and again where the maximum number of eligible spatial sites was used to inform the spatial slope (scenario II). Plotted regression lines represent the mean relationship obtained by summarizing over 12,000 linear regressions for each of 12,000 sets of Markov Chain Monte Carlo parameter iterations, with 95\% percentile intervals shaded. The dotted line represents a 1:1 relationship $(\alpha=0, \beta=$ 1). 


\section{Appendices}

Table A. Summary of 31 space-time comparisons selected for analysis. Space-time comparisons were centered on a modified BBS route that has experienced at least $20 \%$ forest cover change from 2000 to 2019 ("temporal site") and that has at least 15 years' worth of BBS data spanning the full 19-year time period. Each temporal site was matched to a series of neighbouring spatial sites in the same EPA Level I Ecoregion (Ecoregion $7=$ Marine West Coast Forests, Ecoregion $8=$ Eastern Temperate Forests; EPA 2021) that collectively covered a similar forest cover gradient in 2019 ("spatial sites"). All sites used in the analysis were composed of the first 11 stops (approximately $8 \mathrm{~km}$ ) of the original BBS route.

\begin{tabular}{|c|c|c|c|c|c|c|}
\hline $\begin{array}{l}\text { Space-time } \\
\text { Comparison }\end{array}$ & $\begin{array}{l}\text { BBS } \\
\text { Route }\end{array}$ & $\begin{array}{l}\text { Level I } \\
\text { Ecoregion }\end{array}$ & $\begin{array}{c}\text { Min \% } \\
\text { forest } \\
\text { cover }\end{array}$ & $\begin{array}{c}\text { Max \% } \\
\text { forest } \\
\text { cover }\end{array}$ & \# Years & $\begin{array}{c}\text { \# Spatial } \\
\text { sites }\end{array}$ \\
\hline 1 & 2021 & 8 & 0.417 & 0.774 & 19 & 39 \\
\hline 2 & 2036 & 8 & 0.586 & 0.810 & 16 & 25 \\
\hline 3 & 2038 & 8 & 0.389 & 0.726 & 19 & 42 \\
\hline 4 & 2045 & 8 & 0.449 & 0.720 & 20 & 52 \\
\hline 5 & 2066 & 8 & 0.371 & 0.668 & 19 & 40 \\
\hline 6 & 2214 & 8 & 0.599 & 0.904 & 19 & 20 \\
\hline 7 & 2218 & 8 & 0.455 & 0.757 & 19 & 31 \\
\hline 8 & 7013 & 8 & 0.497 & 0.733 & 18 & 15 \\
\hline 9 & 7111 & 8 & 0.391 & 0.882 & 20 & 31 \\
\hline 10 & 11402 & 7 & 0.482 & 0.714 & 20 & 16 \\
\hline 11 & 25005 & 8 & 0.395 & 0.688 & 16 & 25 \\
\hline 12 & 25010 & 8 & 0.514 & 0.864 & 20 & 28 \\
\hline 13 & 25108 & 8 & 0.393 & 0.594 & 15 & 24 \\
\hline 14 & 27031 & 8 & 0.371 & 0.636 & 20 & 49 \\
\hline 15 & 27032 & 8 & 0.439 & 0.668 & 15 & 39 \\
\hline 16 & 27050 & 8 & 0.285 & 0.689 & 20 & 50 \\
\hline 17 & 42122 & 8 & 0.449 & 0.814 & 18 & 17 \\
\hline 18 & 63002 & 8 & 0.458 & 0.716 & 20 & 17 \\
\hline 19 & 63010 & 8 & 0.345 & 0.564 & 20 & 30 \\
\hline 20 & 63024 & 8 & 0.521 & 0.747 & 20 & 30 \\
\hline 21 & 63108 & 8 & 0.474 & 0.804 & 20 & 20 \\
\hline 22 & 63109 & 8 & 0.285 & 0.768 & 18 & 34 \\
\hline
\end{tabular}




\begin{tabular}{ccccccc}
\hline $\begin{array}{c}\text { Space-time } \\
\text { Comparison }\end{array}$ & $\begin{array}{c}\text { BBS } \\
\text { Route }\end{array}$ & $\begin{array}{c}\text { Level I } \\
\text { Ecoregion }\end{array}$ & $\begin{array}{c}\text { Min \% } \\
\text { forest } \\
\text { cover }\end{array}$ & $\begin{array}{c}\text { Max \% } \\
\text { forest } \\
\text { cover }\end{array}$ & \# Years & $\begin{array}{c}\text { \# Spatial } \\
\text { sites }\end{array}$ \\
\hline 23 & 63232 & 8 & 0.522 & 0.763 & 18 & 44 \\
\hline 24 & 63311 & 8 & 0.335 & 0.827 & 20 & 29 \\
\hline 25 & 80112 & 8 & 0.546 & 0.807 & 16 & 24 \\
\hline 26 & 82015 & 8 & 0.449 & 0.708 & 17 & 51 \\
\hline 27 & 88023 & 8 & 0.577 & 0.814 & 20 & 53 \\
\hline 28 & 88025 & 8 & 0.501 & 0.768 & 17 & 55 \\
\hline 29 & 88028 & 8 & 0.416 & 0.734 & 20 & 56 \\
\hline 30 & 88049 & 8 & 0.486 & 0.707 & 16 & 50 \\
\hline 31 & 88914 & 8 & 0.613 & 0.835 & 20 & 30 \\
\hline
\end{tabular}


Table B. All species detected in the bird surveys used in this study. In our analyses we included only the 118 forest breeding species (F) and the 38 open-habitat breeding species $(\mathrm{O})$. Other symbols are $\mathrm{FE}=$ forest- or shrub-edge breeders, $\mathrm{W}=$ wetland or shoreline breeders, $N=$ nocturnal species. Species designations were based on information in the Birds of North America (Rodewald 2018).

\begin{tabular}{|c|c|c|}
\hline Common Name & Scientific Name & $\begin{array}{c}\text { Breeding } \\
\text { Habitat } \\
\end{array}$ \\
\hline Acadian Flycatcher & Empidonax virescens & $\mathrm{F}$ \\
\hline Acorn Woodpecker & Melanerpes formicivorus & $\mathrm{F}$ \\
\hline Alder Flycatcher & Empidonax alnorum & FE \\
\hline Allen's Hummingbird & Selasphorus sasin & $\mathrm{O}$ \\
\hline American Avocet & Recurvirostra americana & $\mathrm{W}$ \\
\hline American Bittern & Botaurus lentiginosus & $\mathrm{W}$ \\
\hline American Black Duck & Anas rubripes & $\mathrm{W}$ \\
\hline American Coot & Fulica americana & $\mathrm{W}$ \\
\hline American Crow & Corvus brachyrhynchos & FE \\
\hline American Dipper & Cinclus mexicanus & $\mathrm{F}$ \\
\hline American Goldfinch & Spinus tristis & FE \\
\hline American Kestrel & Falco sparverius & $\mathrm{O}$ \\
\hline American Pipit & Anthus rubescens & $\mathrm{O}$ \\
\hline American Redstart & Setophaga ruticilla & $\mathrm{F}$ \\
\hline American Robin & Turdus migratorius & FE \\
\hline American Three-toed Woodpecker & Picoides dorsalis & $\mathrm{F}$ \\
\hline American White Pelican & Pelecanus erythrorhynchos & $\mathrm{W}$ \\
\hline American Wigeon & Mareca americana & $\mathrm{W}$ \\
\hline American Woodcock & Scolopax minor & $\mathrm{F}$ \\
\hline Anhinga & Anhinga anhinga & $\mathrm{W}$ \\
\hline Anna's Hummingbird & Calypte anna & $\mathrm{FE}$ \\
\hline Arctic Tern & Sterna paradisaea & $\mathrm{W}$ \\
\hline Ash-throated Flycatcher & Myiarchus cinerascens & $\mathrm{FE}$ \\
\hline Bachman's Sparrow & Peucaea aestivalis & $\mathrm{F}$ \\
\hline Bald Eagle & Haliaeetus leucocephalus & $\mathrm{FE}$ \\
\hline Baltimore Oriole & Icterus galbula & $\mathrm{F}$ \\
\hline Band-tailed Pigeon & Patagioenas fasciata & $\mathrm{F}$ \\
\hline Bank Swallow & Riparia riparia & $\mathrm{O}$ \\
\hline Barn Owl & Tyto alba & $\mathrm{N}$ \\
\hline
\end{tabular}




\begin{tabular}{|c|c|c|}
\hline Common Name & Scientific Name & $\begin{array}{c}\text { Breeding } \\
\text { Habitat }\end{array}$ \\
\hline Barn Swallow & Hirundo rustica & $\mathrm{O}$ \\
\hline Barred Owl & Strix varia & $\mathrm{N}$ \\
\hline Barrow's Goldeneye & Bucephala islandica & $\mathrm{W}$ \\
\hline Bay-breasted Warbler & Setophaga castanea & $\mathrm{F}$ \\
\hline Bell's Sparrow & Artemisiospiza belli & $\mathrm{O}$ \\
\hline Belted Kingfisher & Megaceryle alcyon & $\mathrm{W}$ \\
\hline Bewick's Wren & Thryomanes bewickii & $\mathrm{F}$ \\
\hline Bicknell's Thrush & Catharus bicknelli & $\mathrm{F}$ \\
\hline Black Phoebe & Sayornis nigricans & $\mathrm{F}$ \\
\hline Black Swift & Cypseloides niger & $\mathrm{F}$ \\
\hline Black Tern & Chlidonias niger & $\mathrm{W}$ \\
\hline Black Vulture & Coragyps atratus & FE \\
\hline Black-and-white Warbler & Mniotilta varia & $\mathrm{F}$ \\
\hline Black-backed Woodpecker & Picoides arcticus & $\mathrm{F}$ \\
\hline Black-bellied Whistling-Duck & Dendrocygna autumnalis & $\mathrm{W}$ \\
\hline Black-billed Cuckoo & Coccyzus erythropthalmus & $\mathrm{F}$ \\
\hline Black-billed Magpie & Pica hudsonia & $\mathrm{O}$ \\
\hline Blackburnian Warbler & Setophaga fusca & $\mathrm{F}$ \\
\hline Black-capped Chickadee & Poecile atricapillus & $\mathrm{F}$ \\
\hline Black-chinned Hummingbird & Archilochus alexandri & $\mathrm{F}$ \\
\hline Black-chinned Sparrow & Spizella atrogularis & $\mathrm{O}$ \\
\hline Black-crowned Night-Heron & Nycticorax nycticorax & $\mathrm{W}$ \\
\hline Black-headed Grosbeak & Pheucticus melanocephalus & $\mathrm{F}$ \\
\hline Black-necked Stilt & Himantopus mexicanus & $\mathrm{W}$ \\
\hline Blackpoll Warbler & Setophaga striata & $\mathrm{F}$ \\
\hline Black-tailed Gnatcatcher & Polioptila melanura & $\mathrm{O}$ \\
\hline Black-throated Blue Warbler & Setophaga caerulescens & $\mathrm{F}$ \\
\hline Black-throated Gray Warbler & Setophaga nigrescens & $\mathrm{F}$ \\
\hline Black-throated Green Warbler & Setophaga virens & $\mathrm{F}$ \\
\hline Black-throated Sparrow & Amphispiza bilineata & $\mathrm{O}$ \\
\hline Blue Grosbeak & Passerina caerulea & FE \\
\hline Blue Jay & Cyanocitta cristata & $\mathrm{F}$ \\
\hline Blue-gray Gnatcatcher & Polioptila caerulea & $\mathrm{F}$ \\
\hline Blue-headed Vireo & Vireo solitarius & $\mathrm{F}$ \\
\hline Blue-winged Teal & Spatula discors & $\mathrm{W}$ \\
\hline
\end{tabular}




\begin{tabular}{|c|c|c|}
\hline Common Name & Scientific Name & $\begin{array}{c}\text { Breeding } \\
\text { Habitat }\end{array}$ \\
\hline Blue-winged Warbler & Vermivora cyanoptera & $\mathrm{O}$ \\
\hline Boat-tailed Grackle & Quiscalus major & $\mathrm{O}$ \\
\hline Bobolink & Dolichonyx oryzivorus & $\mathrm{O}$ \\
\hline Bohemian Waxwing & Bombycilla garrulus & $\mathrm{F}$ \\
\hline Bonaparte's Gull & Chroicocephalus philadelphia & $\mathrm{W}$ \\
\hline Boreal Chickadee & Poecile hudsonicus & $\mathrm{F}$ \\
\hline Brewer's Blackbird & Euphagus cyanocephalus & $\mathrm{O}$ \\
\hline Brewer's Sparrow & Spizella breweri & $\mathrm{O}$ \\
\hline Broad-tailed Hummingbird & Selasphorus platycercus & $\mathrm{F}$ \\
\hline Broad-winged Hawk & Buteo platypterus & $\mathrm{F}$ \\
\hline Brown Creeper & Certhia americana & $\mathrm{F}$ \\
\hline Brown Pelican & Pelecanus occidentalis & $\mathrm{W}$ \\
\hline Brown Thrasher & Toxostoma rufum & FE \\
\hline Brown-headed Cowbird & Molothrus ater & $\mathrm{O}$ \\
\hline Brown-headed Nuthatch & Sitta pusilla & $\mathrm{F}$ \\
\hline Bufflehead & Bucephala albeola & $\mathrm{W}$ \\
\hline Bullock's Oriole & Icterus bullockii & $\mathrm{F}$ \\
\hline Burrowing Owl & Athene cunicularia & $\mathrm{O}$ \\
\hline Bushtit & Psaltriparus minimus & $\mathrm{F}$ \\
\hline California Gull & Larus californicus & $\mathrm{W}$ \\
\hline California Quail & Callipepla californica & $\mathrm{O}$ \\
\hline California Scrub-Jay & Aphelocoma californica & $\mathrm{FE}$ \\
\hline California Thrasher & Toxostoma redivivum & $\mathrm{O}$ \\
\hline California Towhee & Melozone crissalis & $\mathrm{O}$ \\
\hline Calliope Hummingbird & Selasphorus calliope & $\mathrm{F}$ \\
\hline Canada Goose & Branta canadensis & $\mathrm{W}$ \\
\hline Canada Jay & Perisoreus canadensis & $\mathrm{F}$ \\
\hline Canada Warbler & Cardellina canadensis & $\mathrm{F}$ \\
\hline Canyon Wren & Catherpes mexicanus & $\mathrm{O}$ \\
\hline Cape May Warbler & Setophaga tigrina & $\mathrm{F}$ \\
\hline Carolina Chickadee & Poecile carolinensis & $\mathrm{F}$ \\
\hline Carolina Wren & Thryothorus ludovicianus & $\mathrm{F}$ \\
\hline Caspian Tern & Hydroprogne caspia & $\mathrm{W}$ \\
\hline Cassin's Finch & Haemorhous cassinii & $\mathrm{F}$ \\
\hline Cassin's Kingbird & Tyrannus vociferans & $\mathrm{F}$ \\
\hline
\end{tabular}




\begin{tabular}{|c|c|c|}
\hline Common Name & Scientific Name & $\begin{array}{c}\text { Breeding } \\
\text { Habitat } \\
\end{array}$ \\
\hline Cassin's Vireo & Vireo cassinii & $\mathrm{F}$ \\
\hline Cattle Egret & Bubulcus ibis & $\mathrm{W}$ \\
\hline Cave Swallow & Petrochelidon fulva & $\mathrm{O}$ \\
\hline Cedar Waxwing & Bombycilla cedrorum & $\mathrm{F}$ \\
\hline Cerulean Warbler & Setophaga cerulea & $\mathrm{F}$ \\
\hline Chestnut-backed Chickadee & Poecile rufescens & $\mathrm{F}$ \\
\hline Chestnut-sided Warbler & Setophaga pensylvanica & $\mathrm{F}$ \\
\hline Chimney Swift & Chaetura pelagica & $\mathrm{O}$ \\
\hline Chipping Sparrow & Spizella passerina & $\mathrm{F}$ \\
\hline Chuck-will's-widow & Antrostomus carolinensis & $\mathrm{N}$ \\
\hline Chukar & Alectoris chukar & $\mathrm{O}$ \\
\hline Cinnamon Teal & Spatula cyanoptera & $\mathrm{W}$ \\
\hline Clark's Nutcracker & Nucifraga columbiana & $\mathrm{F}$ \\
\hline Clay-colored Sparrow & Spizella pallida & $\mathrm{O}$ \\
\hline Cliff Swallow & Petrochelidon pyrrhonota & $\mathrm{O}$ \\
\hline Common Gallinule & Gallinula galeata & $\mathrm{W}$ \\
\hline Common Goldeneye & Bucephala clangula & $\mathrm{W}$ \\
\hline Common Grackle & Quiscalus quiscula & $\mathrm{F}$ \\
\hline Common Ground Dove & Columbina passerina & $\mathrm{O}$ \\
\hline Common Loon & Gavia immer & $\mathrm{W}$ \\
\hline Common Merganser & Mergus merganser & $\mathrm{W}$ \\
\hline Common Murre & Uria aalge & $\mathrm{W}$ \\
\hline Common Nighthawk & Chordeiles minor & $\mathrm{N}$ \\
\hline Common Poorwill & Phalaenoptilus nuttallii & $\mathrm{N}$ \\
\hline Common Raven & Corvus corax & $\mathrm{FE}$ \\
\hline Common Tern & Sterna hirundo & $\mathrm{W}$ \\
\hline Common Yellowthroat & Geothlypis trichas & $\mathrm{O}$ \\
\hline Connecticut Warbler & Oporornis agilis & $\mathrm{F}$ \\
\hline Cooper's Hawk & Accipiter cooperii & $\mathrm{F}$ \\
\hline Cordilleran Flycatcher & Empidonax occidentalis & $\mathrm{F}$ \\
\hline Costa's Hummingbird & Calypte costae & $\mathrm{O}$ \\
\hline Dark-eyed Junco & Junco hyemalis caniceps & $\mathrm{F}$ \\
\hline Dickcissel & Junco hyemalis oreganus & $\mathrm{O}$ \\
\hline Double-crested Cormorant & Junco hyemalis hyemalis & $\mathrm{W}$ \\
\hline Downy Woodpecker & Junco hyemalis aikeni & $\mathrm{F}$ \\
\hline
\end{tabular}




\begin{tabular}{|c|c|c|}
\hline Common Name & Scientific Name & $\begin{array}{c}\text { Breeding } \\
\text { Habitat }\end{array}$ \\
\hline Dusky Flycatcher & Spiza americana & $\mathrm{F}$ \\
\hline Dusky Grouse & Phalacrocorax auritus & $\mathrm{F}$ \\
\hline Eared Grebe & Dryobates pubescens & $\mathrm{W}$ \\
\hline Eastern Bluebird & Empidonax oberholseri & FE \\
\hline Eastern Kingbird & Dendragapus obscurus & $\mathrm{FE}$ \\
\hline Eastern Meadowlark & Podiceps nigricollis & $\mathrm{O}$ \\
\hline Eastern Phoebe & Sialia sialis & FE \\
\hline Eastern Screech-Owl & Tyrannus tyrannus & $\mathrm{N}$ \\
\hline Eastern Towhee & Sturnella magna & $\mathrm{FE}$ \\
\hline Eastern Whip-poor-will & Sayornis phoebe & $\mathrm{F}$ \\
\hline Eastern Wood-Pewee & Megascops asio & $\mathrm{F}$ \\
\hline Eurasian Collared-Dove & Pipilo erythrophthalmus & $\mathrm{O}$ \\
\hline European Starling & Antrostomus vociferus & $\mathrm{O}$ \\
\hline Evening Grosbeak & Contopus virens & $\mathrm{F}$ \\
\hline Field Sparrow & Streptopelia decaocto & $\mathrm{O}$ \\
\hline Fish Crow & Sturnus vulgaris & FE \\
\hline Forster's Tern & Coccothraustes vespertinus & $\mathrm{W}$ \\
\hline Fox Sparrow & Spizella pusilla & $\mathrm{F}$ \\
\hline Franklin's Gull & Corvus ossifragus & $\mathrm{W}$ \\
\hline Gadwall & Sterna forsteri & $\mathrm{W}$ \\
\hline Glaucous-winged Gull & Passerella iliaca & $\mathrm{W}$ \\
\hline Golden Eagle & Leucophaeus pipixcan & $\mathrm{O}$ \\
\hline Golden-crowned Kinglet & Mareca strepera & $\mathrm{F}$ \\
\hline Golden-crowned Sparrow & Larus glaucescens & $\mathrm{O}$ \\
\hline Golden-winged Warbler & Aquila chrysaetos & FE \\
\hline Grace's Warbler & Regulus satrapa & $\mathrm{F}$ \\
\hline Grasshopper Sparrow & Zonotrichia atricapilla & $\mathrm{O}$ \\
\hline Gray Catbird & Vermivora chrysoptera & FE \\
\hline Gray Flycatcher & Setophaga graciae & $\mathrm{O}$ \\
\hline Gray Kingbird & Ammodramus savannarum & $\mathrm{F}$ \\
\hline Gray-cheeked Thrush & Dumetella carolinensis & $\mathrm{F}$ \\
\hline Gray-crowned Rosy-Finch & Empidonax wrightii & $\mathrm{O}$ \\
\hline Great Black-backed Gull & Tyrannus dominicensis & $\mathrm{W}$ \\
\hline Great Blue Heron & Catharus minimus & $\mathrm{W}$ \\
\hline Great Crested Flycatcher & Leucosticte tephrocotis & $\mathrm{F}$ \\
\hline
\end{tabular}




\begin{tabular}{|c|c|c|}
\hline Common Name & Scientific Name & $\begin{array}{c}\text { Breeding } \\
\text { Habitat }\end{array}$ \\
\hline Great Egret & Larus marinus & $\mathrm{W}$ \\
\hline Great Gray Owl & Ardea herodias & $\mathrm{N}$ \\
\hline Great Horned Owl & Myiarchus crinitus & $\mathrm{N}$ \\
\hline Greater Roadrunner & Ardea alba & $\mathrm{O}$ \\
\hline Greater Yellowlegs & Strix nebulosa & $\mathrm{W}$ \\
\hline Great-tailed Grackle & Bubo virginianus & $\mathrm{FE}$ \\
\hline Green Heron & Geococcyx californianus & $\mathrm{W}$ \\
\hline Green-tailed Towhee & Tringa melanoleuca & $\mathrm{O}$ \\
\hline Green-winged Teal & Quiscalus mexicanus & $\mathrm{W}$ \\
\hline Hairy Woodpecker & Butorides virescens & $\mathrm{F}$ \\
\hline Hammond's Flycatcher & Pipilo chlorurus & $\mathrm{F}$ \\
\hline Harlequin Duck & Anas crecca & $\mathrm{W}$ \\
\hline Heermann's Gull & Dryobates villosus & $\mathrm{W}$ \\
\hline Henslow's Sparrow & Empidonax hammondii & $\mathrm{O}$ \\
\hline Hepatic Tanager & Histrionicus histrionicus & $\mathrm{F}$ \\
\hline Hermit Thrush & Larus heermanni & $\mathrm{F}$ \\
\hline Hermit Warbler & Centronyx henslowii & $\mathrm{F}$ \\
\hline Herring Gull & Piranga flava & $\mathrm{W}$ \\
\hline Hooded Merganser & Catharus guttatus & $\mathrm{W}$ \\
\hline Hooded Oriole & Setophaga occidentalis & $\mathrm{F}$ \\
\hline Hooded Warbler & Larus argentatus & $\mathrm{F}$ \\
\hline Horned Lark & Lophodytes cucullatus & $\mathrm{O}$ \\
\hline House Finch & Icterus cucullatus & $\mathrm{FE}$ \\
\hline House Sparrow & Setophaga citrina & $\mathrm{O}$ \\
\hline House Wren & Eremophila alpestris & FE \\
\hline Hutton's Vireo & Haemorhous mexicanus & $\mathrm{F}$ \\
\hline Inca Dove & Passer domesticus & $\mathrm{O}$ \\
\hline Indigo Bunting & Troglodytes aedon & FE \\
\hline Juniper Titmouse & Vireo huttoni & $\mathrm{F}$ \\
\hline Kentucky Warbler & Columbina inca & $\mathrm{F}$ \\
\hline Killdeer & Passerina cyanea & $\mathrm{O}$ \\
\hline King Rail & Baeolophus ridgwayi & $\mathrm{W}$ \\
\hline Ladder-backed Woodpecker & Geothlypis formosa & $\mathrm{O}$ \\
\hline Lark Sparrow & Charadrius vociferus & $\mathrm{O}$ \\
\hline Laughing Gull & Rallus elegans & $\mathrm{W}$ \\
\hline
\end{tabular}




\begin{tabular}{|c|c|c|}
\hline Common Name & Scientific Name & $\begin{array}{c}\text { Breeding } \\
\text { Habitat }\end{array}$ \\
\hline Lawrence's Goldfinch & Dryobates scalaris & $\mathrm{O}$ \\
\hline Lazuli Bunting & Chondestes grammacus & $\mathrm{F}$ \\
\hline Least Bittern & Leucophaeus atricilla & $\mathrm{W}$ \\
\hline Least Flycatcher & Spinus lawrencei & $\mathrm{F}$ \\
\hline Least Tern & Passerina amoena & $\mathrm{W}$ \\
\hline LeConte's Sparrow & Ixobrychus exilis & $\mathrm{O}$ \\
\hline Lesser Goldfinch & Empidonax minimus & $\mathrm{O}$ \\
\hline Lesser Scaup & Sternula antillarum & $\mathrm{W}$ \\
\hline Lesser Yellowlegs & Ammospiza leconteii & $\mathrm{W}$ \\
\hline Lewis's Woodpecker & Spinus psaltria & $\mathrm{F}$ \\
\hline Limpkin & Aythya affinis & $\mathrm{W}$ \\
\hline Lincoln's Sparrow & Tringa flavipes & FE \\
\hline Little Blue Heron & Melanerpes lewis & $\mathrm{W}$ \\
\hline Loggerhead Shrike & Aramus guarauna & $\mathrm{O}$ \\
\hline Long-eared Owl & Melospiza lincolnii & $\mathrm{N}$ \\
\hline Louisiana Waterthrush & Egretta caerulea & $\mathrm{F}$ \\
\hline Lucy's Warbler & Lanius ludovicianus & $\mathrm{O}$ \\
\hline MacGillivray's Warbler & Asio otus & $\mathrm{FE}$ \\
\hline Magnolia Warbler & Parkesia motacilla & $\mathrm{F}$ \\
\hline Mallard & Leiothlypis luciae & $\mathrm{W}$ \\
\hline Marsh Wren & Geothlypis tolmiei & $\mathrm{O}$ \\
\hline Merlin & Setophaga magnolia & $\mathrm{FE}$ \\
\hline Mexican Whip-poor-will & Anas platyrhynchos & $\mathrm{F}$ \\
\hline Mississippi Kite & Cistothorus palustris & $\mathrm{FE}$ \\
\hline Montezuma Quail & Falco columbarius & $\mathrm{F}$ \\
\hline Mountain Bluebird & Antrostomus arizonae & FE \\
\hline Mountain Chickadee & Ictinia mississippiensis & $\mathrm{F}$ \\
\hline Mountain Quail & Cyrtonyx montezumae & $\mathrm{O}$ \\
\hline Mourning Dove & Sialia currucoides & FE \\
\hline Mourning Warbler & Poecile gambeli & FE \\
\hline Nashville Warbler & Oreortyx pictus & $\mathrm{F}$ \\
\hline Neotropic Cormorant & Zenaida macroura & $\mathrm{W}$ \\
\hline Northern Bobwhite & Geothlypis philadelphia & $\mathrm{F}$ \\
\hline Northern Cardinal & Leiothlypis ruficapilla & FE \\
\hline Northern Flicker & Phalacrocorax brasilianus & $\mathrm{F}$ \\
\hline
\end{tabular}




\begin{tabular}{|c|c|c|}
\hline Common Name & Scientific Name & $\begin{array}{c}\text { Breeding } \\
\text { Habitat }\end{array}$ \\
\hline Northern Gannet & Colinus virginianus & $\mathrm{W}$ \\
\hline Northern Goshawk & Cardinalis cardinalis & $\mathrm{F}$ \\
\hline Northern Harrier & Colaptes auratus cafer & $\mathrm{O}$ \\
\hline Northern Hawk Owl & Colaptes auratus auratus & $\mathrm{F}$ \\
\hline Northern Mockingbird & Morus bassanus & $\mathrm{FE}$ \\
\hline Northern Parula & Accipiter gentilis & $\mathrm{F}$ \\
\hline Northern Pintail & Circus hudsonius & $\mathrm{W}$ \\
\hline Northern Pygmy-Owl & Surnia ulula & $\mathrm{F}$ \\
\hline Northern Rough-winged Swallow & Mimus polyglottos & $\mathrm{O}$ \\
\hline Northern Saw-whet Owl & Setophaga americana & $\mathrm{N}$ \\
\hline Northern Shoveler & Anas acuta & $\mathrm{W}$ \\
\hline Northern Waterthrush & Glaucidium gnoma & $\mathrm{F}$ \\
\hline Nuttall's Woodpecker & Stelgidopteryx serripennis & $\mathrm{F}$ \\
\hline Oak Titmouse & Aegolius acadicus & $\mathrm{F}$ \\
\hline Olive Warbler & Spatula clypeata & $\mathrm{F}$ \\
\hline Olive-sided Flycatcher & Parkesia noveboracensis & $\mathrm{F}$ \\
\hline Orange-crowned Warbler & Dryobates nuttallii & $\mathrm{F}$ \\
\hline Orchard Oriole & Baeolophus inornatus & $\mathrm{F}$ \\
\hline Osprey & Peucedramus taeniatus & FE \\
\hline Ovenbird & Contopus cooperi & $\mathrm{F}$ \\
\hline Pacific Wren & Leiothlypis celata & $\mathrm{F}$ \\
\hline Pacific-slope Flycatcher & Icterus spurius & $\mathrm{F}$ \\
\hline Painted Bunting & Pandion haliaetus & $\mathrm{O}$ \\
\hline Palm Warbler & Seiurus aurocapilla & $\mathrm{F}$ \\
\hline Pelagic Cormorant & Troglodytes pacificus & $\mathrm{W}$ \\
\hline Peregrine Falcon & Empidonax difficilis & $\mathrm{O}$ \\
\hline Phainopepla & Passerina ciris & $\mathrm{O}$ \\
\hline Philadelphia Vireo & Setophaga palmarum & $\mathrm{F}$ \\
\hline Pied-billed Grebe & Phalacrocorax pelagicus & $\mathrm{W}$ \\
\hline Pileated Woodpecker & Falco peregrinus & $\mathrm{F}$ \\
\hline Pine Grosbeak & Phainopepla nitens & $\mathrm{F}$ \\
\hline Pine Siskin & Vireo philadelphicus & $\mathrm{F}$ \\
\hline Pine Warbler & Podilymbus podiceps & $\mathrm{F}$ \\
\hline Pinyon Jay & Dryocopus pileatus & FE \\
\hline Plumbeous Vireo & Pinicola enucleator & $\mathrm{F}$ \\
\hline
\end{tabular}




\begin{tabular}{|c|c|c|}
\hline Common Name & Scientific Name & $\begin{array}{c}\text { Breeding } \\
\text { Habitat }\end{array}$ \\
\hline Prairie Falcon & Spinus pinus & $\mathrm{O}$ \\
\hline Prairie Warbler & Setophaga pinus & $\mathrm{O}$ \\
\hline Prothonotary Warbler & Gymnorhinus cyanocephalus & $\mathrm{F}$ \\
\hline Purple Finch & Vireo plumbeus & $\mathrm{F}$ \\
\hline Purple Gallinule & Falco mexicanus & $\mathrm{W}$ \\
\hline Purple Martin & Setophaga discolor & FE \\
\hline Pygmy Nuthatch & Protonotaria citrea & $\mathrm{F}$ \\
\hline Red Crossbill & Haemorhous purpureus & $\mathrm{F}$ \\
\hline Red-bellied Woodpecker & Porphyrio martinicus & $\mathrm{F}$ \\
\hline Red-breasted Merganser & Progne subis & $\mathrm{W}$ \\
\hline Red-breasted Nuthatch & Sitta pygmaea & $\mathrm{F}$ \\
\hline Red-breasted Sapsucker & Loxia curvirostra & $\mathrm{F}$ \\
\hline Red-cockaded Woodpecker & Melanerpes carolinus & $\mathrm{F}$ \\
\hline Red-eyed Vireo & Mergus serrator & $\mathrm{F}$ \\
\hline Red-faced Warbler & Sitta canadensis & $\mathrm{F}$ \\
\hline Redhead & Sphyrapicus ruber & $\mathrm{W}$ \\
\hline Red-headed Woodpecker & Dryobates borealis & $\mathrm{F}$ \\
\hline Red-naped Sapsucker & Vireo olivaceus & $\mathrm{F}$ \\
\hline Red-necked Grebe & Cardellina rubrifrons & $\mathrm{W}$ \\
\hline Red-shouldered Hawk & Aythya americana & $\mathrm{F}$ \\
\hline Red-tailed Hawk & Melanerpes erythrocephalus & FE \\
\hline Red-winged Blackbird & Sphyrapicus nuchalis & $\mathrm{O}$ \\
\hline Ring-billed Gull & Podiceps grisegena & $\mathrm{W}$ \\
\hline Ring-necked Duck & Buteo lineatus & $\mathrm{W}$ \\
\hline Ring-necked Pheasant & Buteo jamaicensis & $\mathrm{O}$ \\
\hline Rock Pigeon & Agelaius phoeniceus & $\mathrm{O}$ \\
\hline Rock Wren & Larus delawarensis & $\mathrm{O}$ \\
\hline Rose-breasted Grosbeak & Aythya collaris & $\mathrm{F}$ \\
\hline Rough-legged Hawk & Phasianus colchicus & $\mathrm{O}$ \\
\hline Ruby-crowned Kinglet & Columba livia & $\mathrm{F}$ \\
\hline Ruby-throated Hummingbird & Salpinctes obsoletus & $\mathrm{F}$ \\
\hline Ruddy Duck & Pheucticus ludovicianus & $\mathrm{W}$ \\
\hline Ruffed Grouse & Buteo lagopus & $\mathrm{F}$ \\
\hline Rufous Hummingbird & Regulus calendula & $\mathrm{F}$ \\
\hline Rufous-crowned Sparrow & Archilochus colubris & $\mathrm{O}$ \\
\hline
\end{tabular}




\begin{tabular}{|c|c|c|}
\hline Common Name & Scientific Name & $\begin{array}{c}\text { Breeding } \\
\text { Habitat }\end{array}$ \\
\hline Rusty Blackbird & Oxyura jamaicensis & $\mathrm{F}$ \\
\hline Sage Thrasher & Bonasa umbellus & $\mathrm{O}$ \\
\hline Sandhill Crane & Selasphorus rufus & $\mathrm{W}$ \\
\hline Savannah Sparrow & Aimophila ruficeps & $\mathrm{O}$ \\
\hline Say's Phoebe & Euphagus carolinus & $\mathrm{O}$ \\
\hline Scarlet Tanager & Oreoscoptes montanus & $\mathrm{F}$ \\
\hline Scissor-tailed Flycatcher & Antigone canadensis & $\mathrm{O}$ \\
\hline Scott's Oriole & Passerculus sandwichensis & $\mathrm{F}$ \\
\hline Sedge Wren & Sayornis saya & $\mathrm{O}$ \\
\hline Sharp-shinned Hawk & Piranga olivacea & $\mathrm{F}$ \\
\hline Sharp-tailed Grouse & Tyrannus forficatus & $\mathrm{O}$ \\
\hline Short-eared Owl & Icterus parisorum & $\mathrm{O}$ \\
\hline Snowy Egret & Cistothorus platensis & $\mathrm{W}$ \\
\hline Solitary Sandpiper & Accipiter striatus & $\mathrm{W}$ \\
\hline Song Sparrow & Tympanuchus phasianellus & $\mathrm{O}$ \\
\hline Sooty Grouse & Asio flammeus & $\mathrm{F}$ \\
\hline Sora & Egretta thula & $\mathrm{W}$ \\
\hline Spotted Owl & Tringa solitaria & $\mathrm{N}$ \\
\hline Spotted Sandpiper & Melospiza melodia & $\mathrm{W}$ \\
\hline Spotted Towhee & Dendragapus fuliginosus & $\mathrm{F}$ \\
\hline Spruce Grouse & Porzana carolina & $\mathrm{F}$ \\
\hline Steller's Jay & Strix occidentalis & $\mathrm{F}$ \\
\hline Summer Tanager & Actitis macularius & $\mathrm{F}$ \\
\hline Swainson's Hawk & Pipilo maculatus & $\mathrm{O}$ \\
\hline Swainson's Thrush & Falcipennis canadensis & $\mathrm{F}$ \\
\hline Swainson's Warbler & Cyanocitta stelleri & $\mathrm{F}$ \\
\hline Swallow-tailed Kite & Piranga rubra & $\mathrm{FE}$ \\
\hline Swamp Sparrow & Buteo swainsoni & $\mathrm{O}$ \\
\hline Tennessee Warbler & Catharus ustulatus & $\mathrm{F}$ \\
\hline Townsend's Solitaire & Limnothlypis swainsonii & $\mathrm{F}$ \\
\hline Townsend's Warbler & Elanoides forficatus & $\mathrm{F}$ \\
\hline Tree Swallow & Melospiza georgiana & FE \\
\hline Tricolored Blackbird & Leiothlypis peregrina & $\mathrm{O}$ \\
\hline Tricolored Heron & Myadestes townsendi & $\mathrm{W}$ \\
\hline Trumpeter Swan & Setophaga townsendi & $\mathrm{W}$ \\
\hline
\end{tabular}




\begin{tabular}{|c|c|c|}
\hline Common Name & Scientific Name & $\begin{array}{c}\text { Breeding } \\
\text { Habitat }\end{array}$ \\
\hline Tufted Titmouse & Tachycineta bicolor & $\mathrm{F}$ \\
\hline Turkey Vulture & Agelaius tricolor & $\mathrm{O}$ \\
\hline Varied Thrush & Egretta tricolor & $\mathrm{F}$ \\
\hline Vaux's Swift & Cygnus buccinator & FE \\
\hline Veery & Baeolophus bicolor & $\mathrm{F}$ \\
\hline Vesper Sparrow & Cathartes aura & $\mathrm{O}$ \\
\hline Violet-green Swallow & Ixoreus naevius & $\mathrm{FE}$ \\
\hline Virginia Rail & Chaetura vauxi & $\mathrm{W}$ \\
\hline Virginia's Warbler & Catharus fuscescens & $\mathrm{F}$ \\
\hline Warbling Vireo & Pooecetes gramineus & $\mathrm{F}$ \\
\hline Western Bluebird & Tachycineta thalassina & $\mathrm{FE}$ \\
\hline Western Grebe & Rallus limicola & $\mathrm{W}$ \\
\hline Western Gull & Leiothlypis virginiae & $\mathrm{W}$ \\
\hline Western Kingbird & Vireo gilvus & $\mathrm{O}$ \\
\hline Western Meadowlark & Sialia mexicana & $\mathrm{O}$ \\
\hline Western Screech-Owl & Aechmophorus occidentalis & $\mathrm{N}$ \\
\hline Western Tanager & Larus occidentalis & $\mathrm{F}$ \\
\hline Western Wood-Pewee & Tyrannus verticalis & $\mathrm{F}$ \\
\hline White Ibis & Sturnella neglecta & $\mathrm{W}$ \\
\hline White-breasted Nuthatch & Megascops kennicottii & $\mathrm{F}$ \\
\hline White-crowned Sparrow & Piranga ludoviciana & $\mathrm{F}$ \\
\hline White-eyed Vireo & Contopus sordidulus & $\mathrm{F}$ \\
\hline White-headed Woodpecker & Eudocimus albus & $\mathrm{F}$ \\
\hline White-tailed Kite & Sitta carolinensis & $\mathrm{O}$ \\
\hline White-tailed Ptarmigan & Zonotrichia leucophrys & $\mathrm{O}$ \\
\hline White-throated Sparrow & Vireo griseus & $\mathrm{F}$ \\
\hline White-throated Swift & Dryobates albolarvatus & $\mathrm{O}$ \\
\hline White-winged Crossbill & Elanus leucurus & $\mathrm{F}$ \\
\hline White-winged Dove & Lagopus leucura & $\mathrm{F}$ \\
\hline Wild Turkey & Zonotrichia albicollis & $\mathrm{O}$ \\
\hline Willet & Aeronautes saxatalis & $\mathrm{W}$ \\
\hline Williamson's Sapsucker & Loxia leucoptera & $\mathrm{F}$ \\
\hline Willow Flycatcher & Zenaida asiatica & $\mathrm{FE}$ \\
\hline Wilson's Phalarope & Meleagris gallopavo & $\mathrm{W}$ \\
\hline Wilson's Snipe & Tringa semipalmata & $\mathrm{W}$ \\
\hline
\end{tabular}




\begin{tabular}{lll}
\hline \multicolumn{1}{c}{ Common Name } & \multicolumn{1}{c}{ Scientific Name } & $\begin{array}{c}\text { Breeding } \\
\text { Habitat }\end{array}$ \\
\hline Wilson's Warbler & Sphyrapicus thyroideus & $\mathrm{F}$ \\
\hline Winter Wren & Empidonax traillii & $\mathrm{F}$ \\
\hline Wood Duck & Phalaropus tricolor & $\mathrm{W}$ \\
\hline Wood Stork & Gallinago delicata & $\mathrm{W}$ \\
\hline Wood Thrush & Cardellina pusilla & $\mathrm{F}$ \\
\hline Worm-eating Warbler & Troglodytes hiemalis & $\mathrm{F}$ \\
\hline Wrentit & Aix sponsa & $\mathrm{O}$ \\
\hline Yellow Warbler & Mycteria americana & $\mathrm{O}$ \\
\hline Yellow-bellied Flycatcher & Hylocichla mustelina & $\mathrm{F}$ \\
\hline Yellow-bellied Sapsucker & Helmitheros vermivorum & $\mathrm{F}$ \\
\hline Yellow-billed Cuckoo & Chamaea fasciata & $\mathrm{F}$ \\
\hline Yellow-breasted Chat & Setophaga petechia & $\mathrm{O}$ \\
\hline Yellow-crowned Night-Heron & Empidonax flaviventris & $\mathrm{W}$ \\
\hline Yellow-headed Blackbird & Sphyrapicus varius & $\mathrm{O}$ \\
\hline Yellow-rumped Warbler & Coccyzus americanus & $\mathrm{F}$ \\
\hline Yellow-throated Vireo & Icteria virens & $\mathrm{F}$ \\
\hline Yellow-throated Warbler & Nyctanassa violacea & $\mathrm{F}$ \\
\hline Zone-tailed Hawk & Xanthocephalus & $\mathrm{FE}$ \\
\hline & xanthocephalus & \\
\hline & & \\
\hline
\end{tabular}




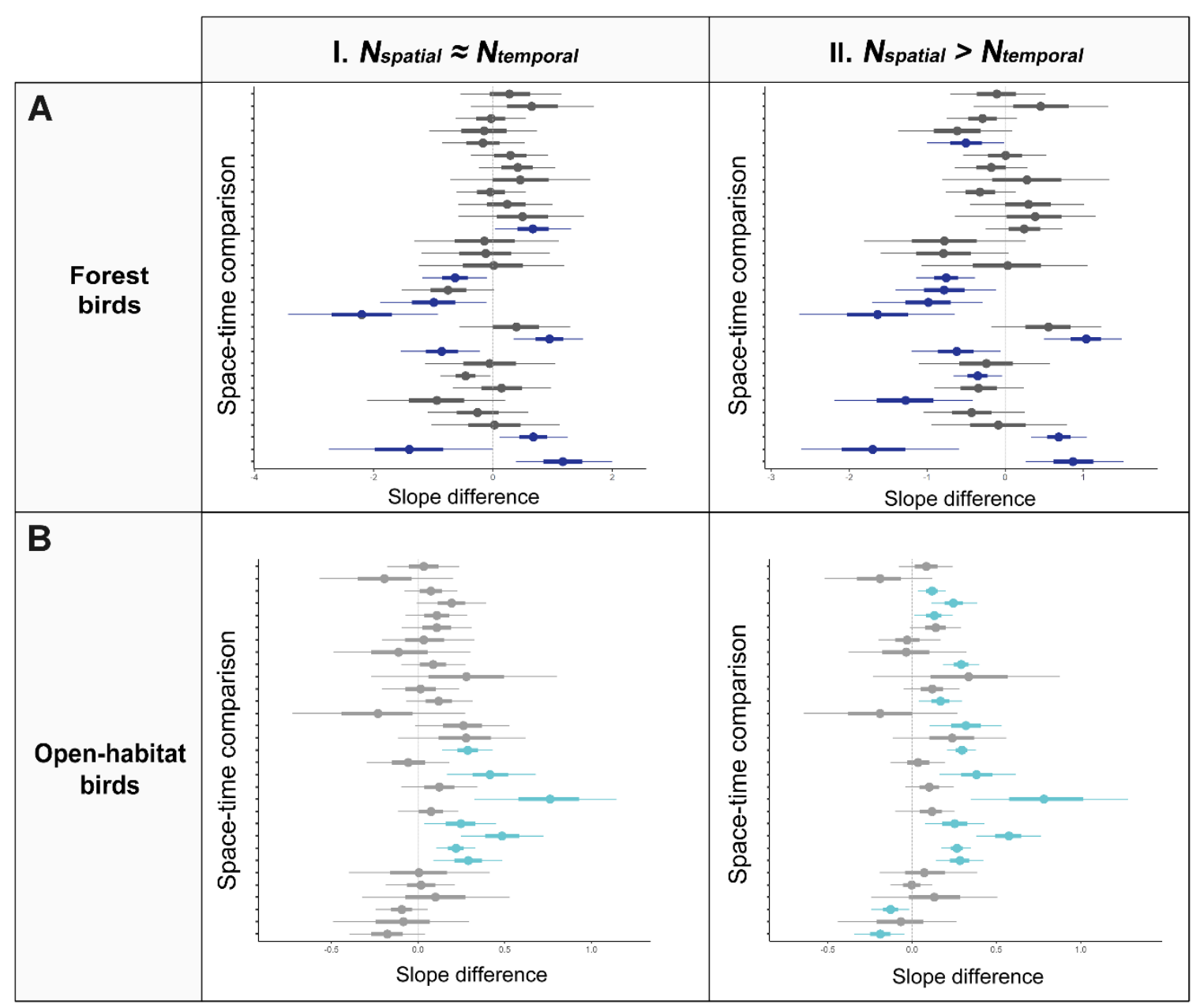

Figure A. Posterior difference between temporal slopes and spatial slopes (= temporal slope - spatial slope) measuring the effect of forest cover on mean forest (A) and open-habitat (B) bird species richness over time at a temporal site from 2000 to 2019 and in space across neighbouring spatial sites in 2019, respectively. The 31 space-time comparisons are listed in order from top-to-bottom. Spatial slopes were estimated twice: once where the number of spatial sites informing the spatial slope matched with the number of years informing the corresponding temporal slope (scenario I) and again where the maximum number of eligible spatial sites was used to inform the spatial slope (scenario II). Space-time comparisons where the difference between temporal and spatial slopes do not overlap with zero are highlighted in colour, representing comparisons where the estimated forest cover effects in time and space are significantly unequal and thus, where space-for-time substitution fails most notably. 


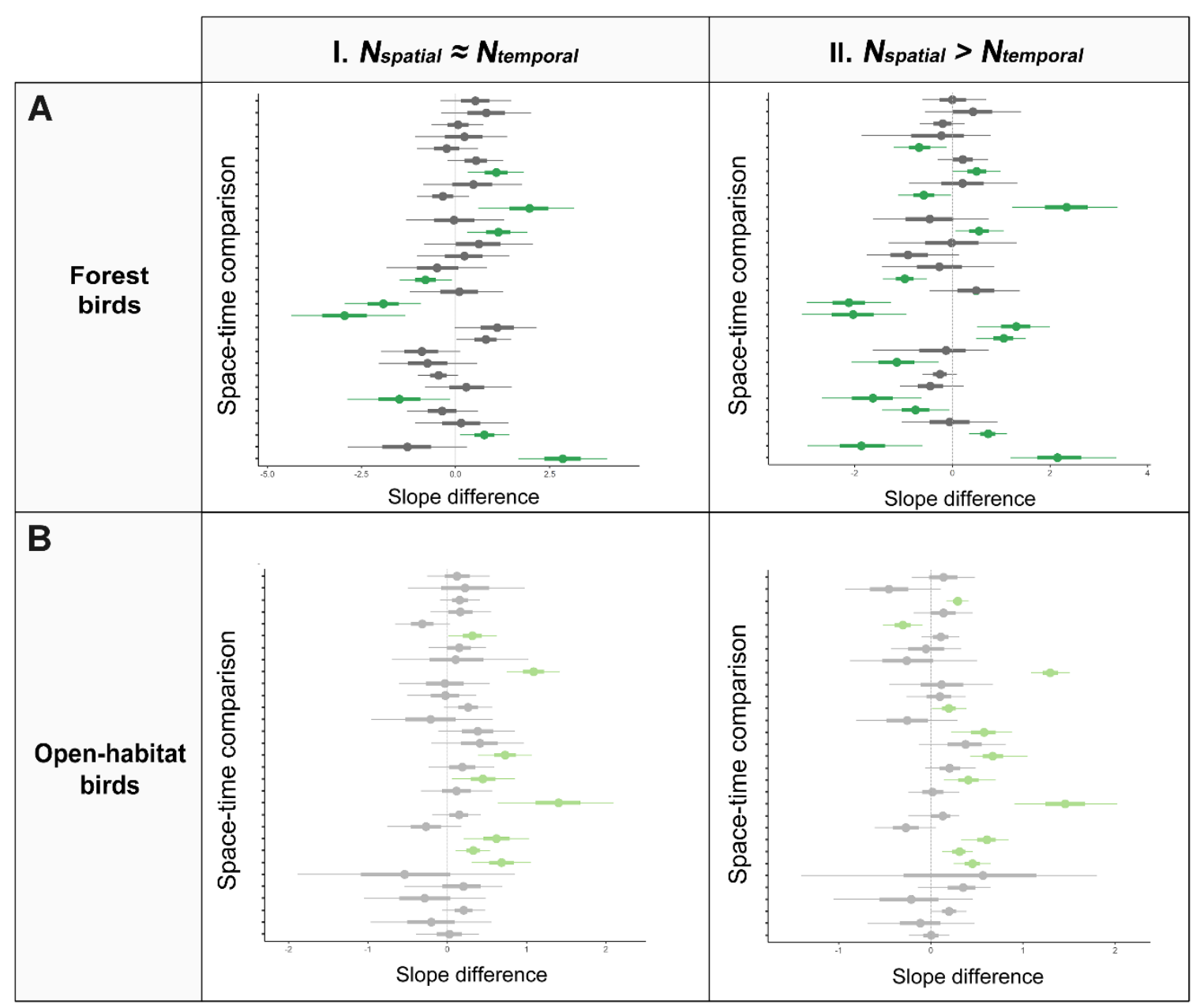

Figure B. Posterior difference between temporal slopes and spatial slopes (= temporal slope - spatial slope), each measuring the effect of forest cover on mean forest (A) and open-habitat (B) bird abundance over time at a temporal site from 2000 to 2019 and in space across neighbouring spatial sites in 2019, respectively. The 31 space-time comparisons are listed from 1 to 31 . Spatial slopes were estimated twice: once where the number of spatial sites informing the spatial slope matched with the number of years informing the corresponding temporal slope (scenario I) and again where the maximum number of eligible spatial sites was used to inform the spatial slope (scenario II). Space-time comparisons where the difference between temporal and spatial slopes do not overlap with zero are highlighted in colour, representing comparisons where the estimated forest cover effects in time and space are significantly unequal and thus, where space-for-time substitution fails most notably. 
Table C. Slope parameter coefficient estimates measuring the effect of forest cover on forest bird mean species richness over time at a temporal site from 2000 to 2019 ("temporal slope") and in space across a set of neighbouring spatial sites in 2019 ("spatial slope") for all 31 space-time comparisons in the U.S. and Canada. Here, each of the spatial slopes were informed by the full number of available spatial sites within each space-time comparison, which may exceed the number of years informing the corresponding temporal slope.

\begin{tabular}{|c|c|c|c|c|c|c|}
\hline & \multicolumn{3}{|c|}{ TIME } & \multicolumn{3}{|c|}{ SPACE } \\
\hline $\begin{array}{l}\text { Space-Time } \\
\text { Comparison }\end{array}$ & mean & $2.5 \%$ & $97.5 \%$ & mean & $2.5 \%$ & $97.5 \%$ \\
\hline 1 & 0.278933 & -0.3466 & 0.943553 & 0.386921 & 0.032148 & 0.733342 \\
\hline 2 & 0.774225 & -0.15427 & 1.69073 & 0.317686 & -0.12397 & 0.756448 \\
\hline 3 & 0.370741 & -0.06279 & 0.804842 & 0.664346 & 0.330418 & 0.997867 \\
\hline 4 & -0.04389 & -0.89237 & 0.73565 & 0.577889 & 0.247724 & 0.910991 \\
\hline 5 & 0.226009 & -0.22886 & 0.690577 & 0.725966 & 0.361677 & 1.078408 \\
\hline 6 & 0.295237 & -0.10375 & 0.687678 & 0.294791 & -0.20201 & 0.801913 \\
\hline 7 & 0.373589 & -0.06908 & 0.799901 & 0.555213 & 0.195055 & 0.915207 \\
\hline 8 & 0.706865 & -0.37108 & 1.785733 & 0.432957 & -0.2497 & 1.123258 \\
\hline 9 & 0.140236 & -0.30033 & 0.615607 & 0.460933 & 0.158504 & 0.751327 \\
\hline 10 & 0.339089 & -0.1328 & 0.792579 & 0.047844 & -0.67613 & 0.786975 \\
\hline 11 & 1.211634 & 0.049915 & 2.056016 & 0.871901 & 0.430948 & 1.291691 \\
\hline 12 & 0.554398 & 0.113926 & 1.006626 & 0.308422 & -0.10909 & 0.717939 \\
\hline 13 & 0.380815 & -0.7271 & 1.498764 & 1.158292 & 0.642847 & 1.6445 \\
\hline 14 & -0.07142 & -1.0022 & 0.876141 & 0.716647 & 0.376949 & 1.045739 \\
\hline 15 & 0.542172 & -0.70613 & 1.714608 & 0.520334 & 0.174423 & 0.866899 \\
\hline 16 & -0.073 & -0.38703 & 0.230797 & 0.686548 & 0.344049 & 1.025584 \\
\hline 17 & -0.43343 & -0.94401 & 0.091186 & 0.342848 & -0.25347 & 0.906375 \\
\hline 18 & -0.7612 & -1.5185 & -0.01744 & 0.231372 & -0.19736 & 0.670591 \\
\hline 19 & -1.21934 & -2.32723 & -0.08626 & 0.419021 & -0.01989 & 0.854529 \\
\hline 20 & 0.704497 & -0.14818 & 1.483568 & 0.159414 & -0.12732 & 0.446761 \\
\hline 21 & 1.252641 & 0.663909 & 1.723993 & 0.230196 & -0.05943 & 0.523226 \\
\hline 22 & -0.33882 & -0.97291 & 0.279871 & 0.290297 & 0.047222 & 0.528971 \\
\hline
\end{tabular}




\begin{tabular}{|c|c|c|c|c|c|c|}
\hline & \multicolumn{3}{|c|}{ TIME } & \multicolumn{3}{|c|}{ SPACE } \\
\hline $\begin{array}{l}\text { Space-Time } \\
\text { Comparison }\end{array}$ & mean & $2.5 \%$ & $97.5 \%$ & mean & $2.5 \%$ & $97.5 \%$ \\
\hline 23 & -0.10051 & -1.07048 & 0.849327 & 0.147227 & -0.09578 & 0.388981 \\
\hline 24 & -0.09222 & -0.37691 & 0.184895 & 0.261326 & 0.00391 & 0.518058 \\
\hline 25 & -0.13512 & -0.70491 & 0.459476 & 0.200449 & -0.16715 & 0.575372 \\
\hline 26 & -0.84625 & -1.88889 & 0.136816 & 0.441905 & 0.104235 & 0.78099 \\
\hline 27 & -0.33407 & -1.00534 & 0.428512 & 0.088626 & -0.2172 & 0.39618 \\
\hline 28 & 0.121028 & -0.86277 & 1.132793 & 0.206127 & -0.01392 & 0.426654 \\
\hline 29 & 0.92346 & 0.544321 & 1.302991 & 0.23533 & 0.024709 & 0.454321 \\
\hline 30 & -1.39432 & -2.48226 & -0.09927 & 0.2712 & 0.009957 & 0.523926 \\
\hline 31 & 0.988601 & 0.352197 & 1.647955 & 0.112716 & -0.265 & 0.479673 \\
\hline
\end{tabular}



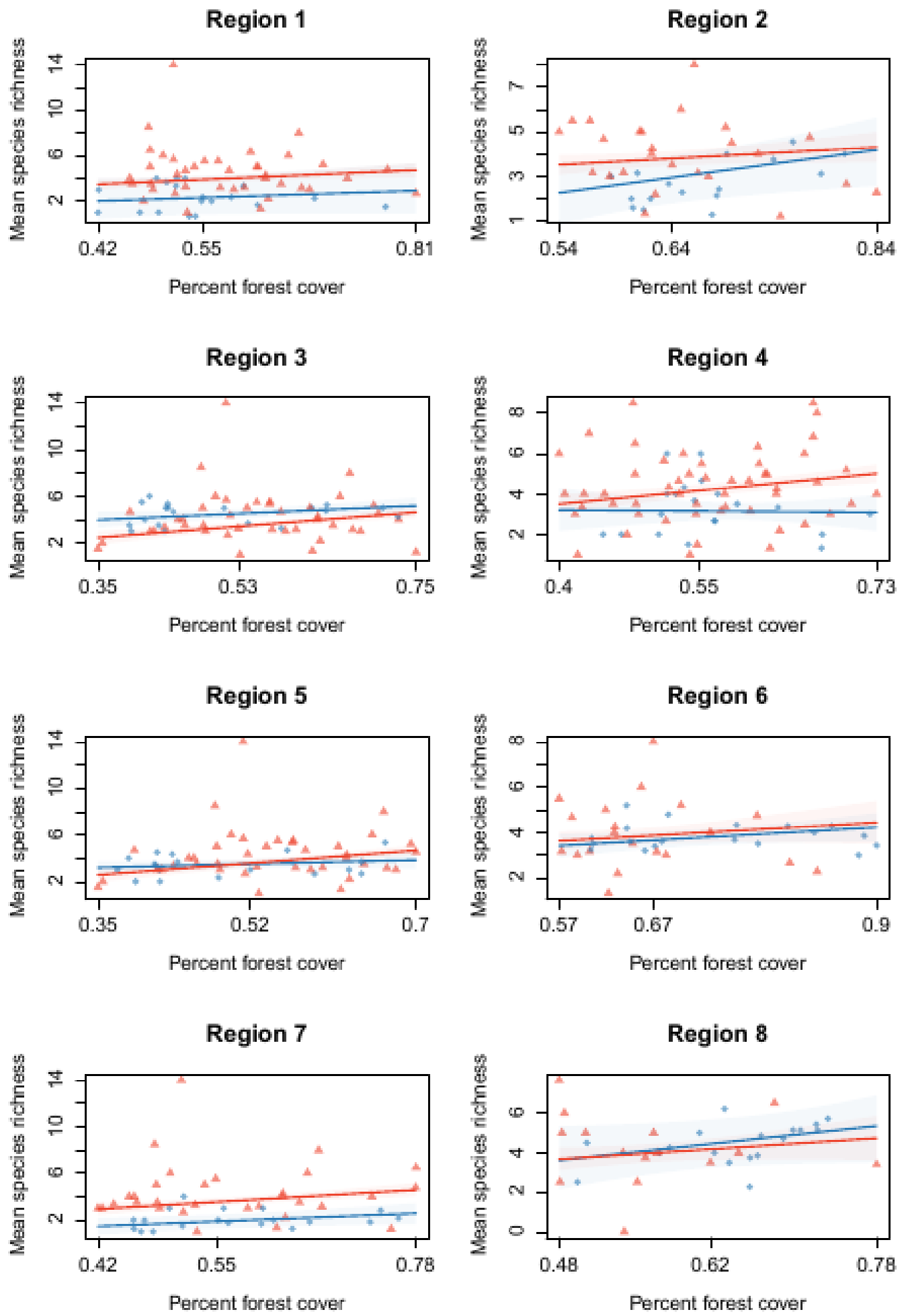
Region 9

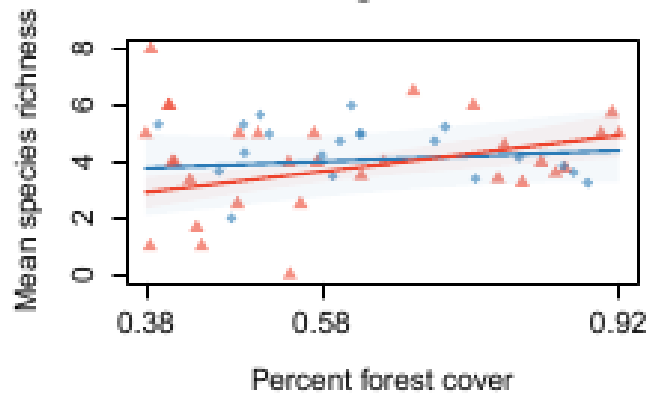

Region 11

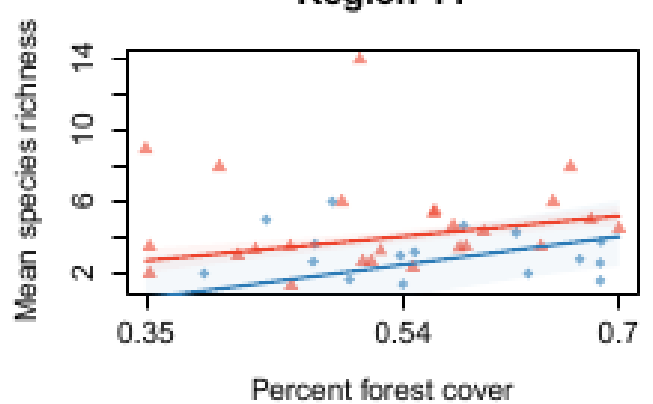

Region 13

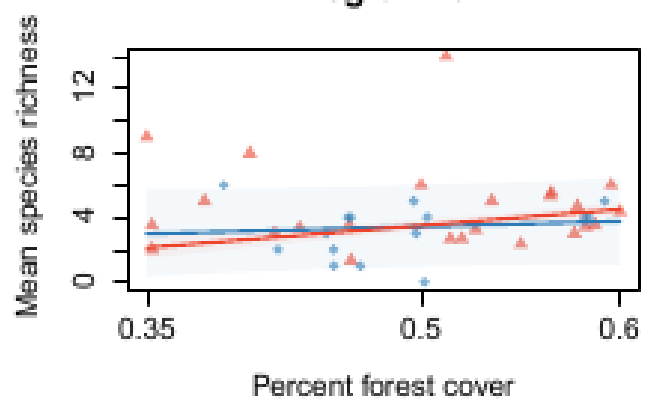

Region 15

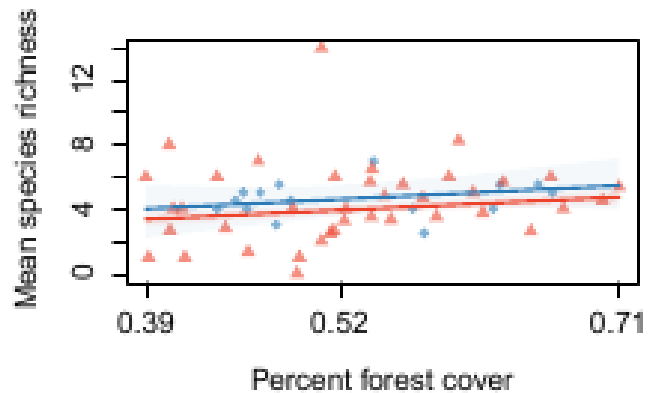

Region 10

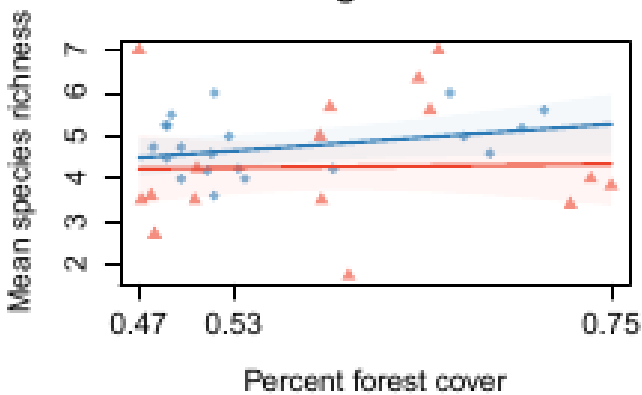

Region 12

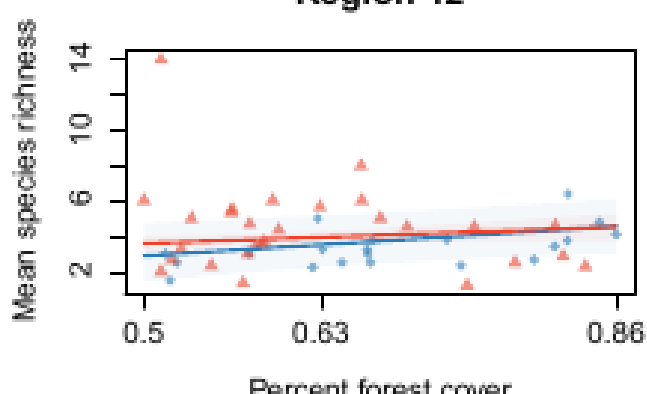

Percent forest cover

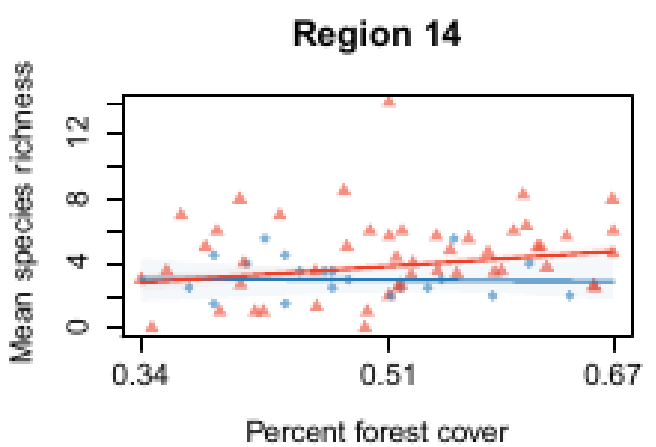

Region 16

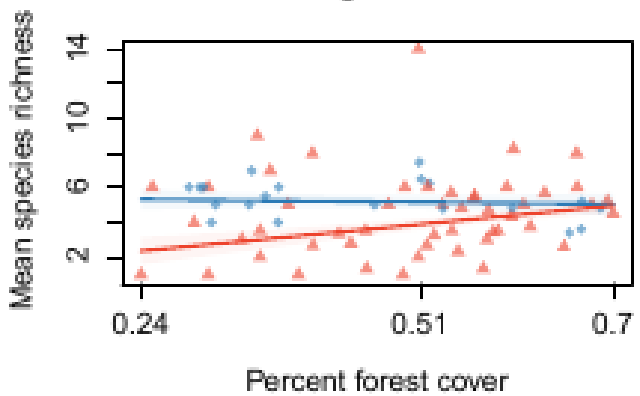



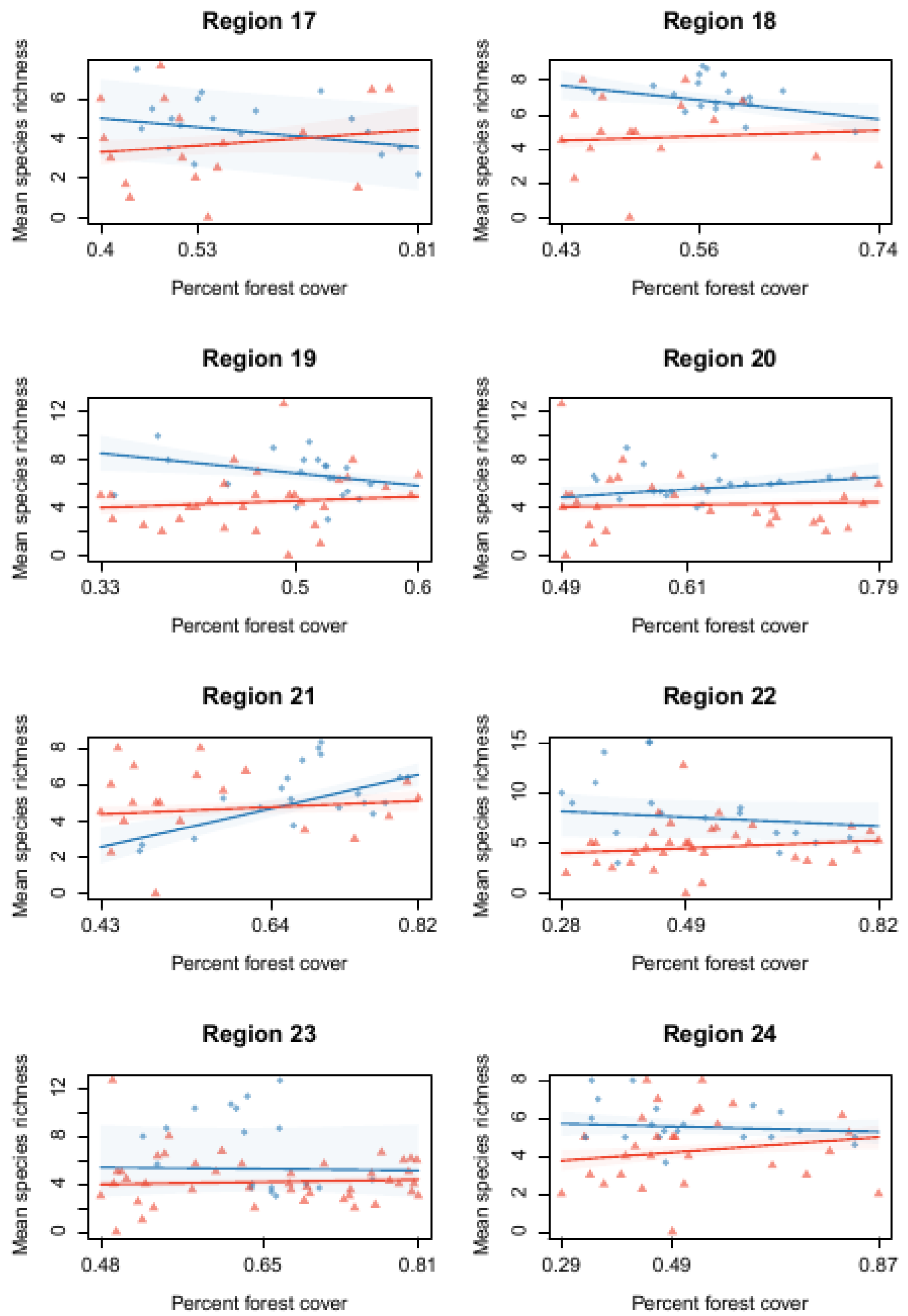

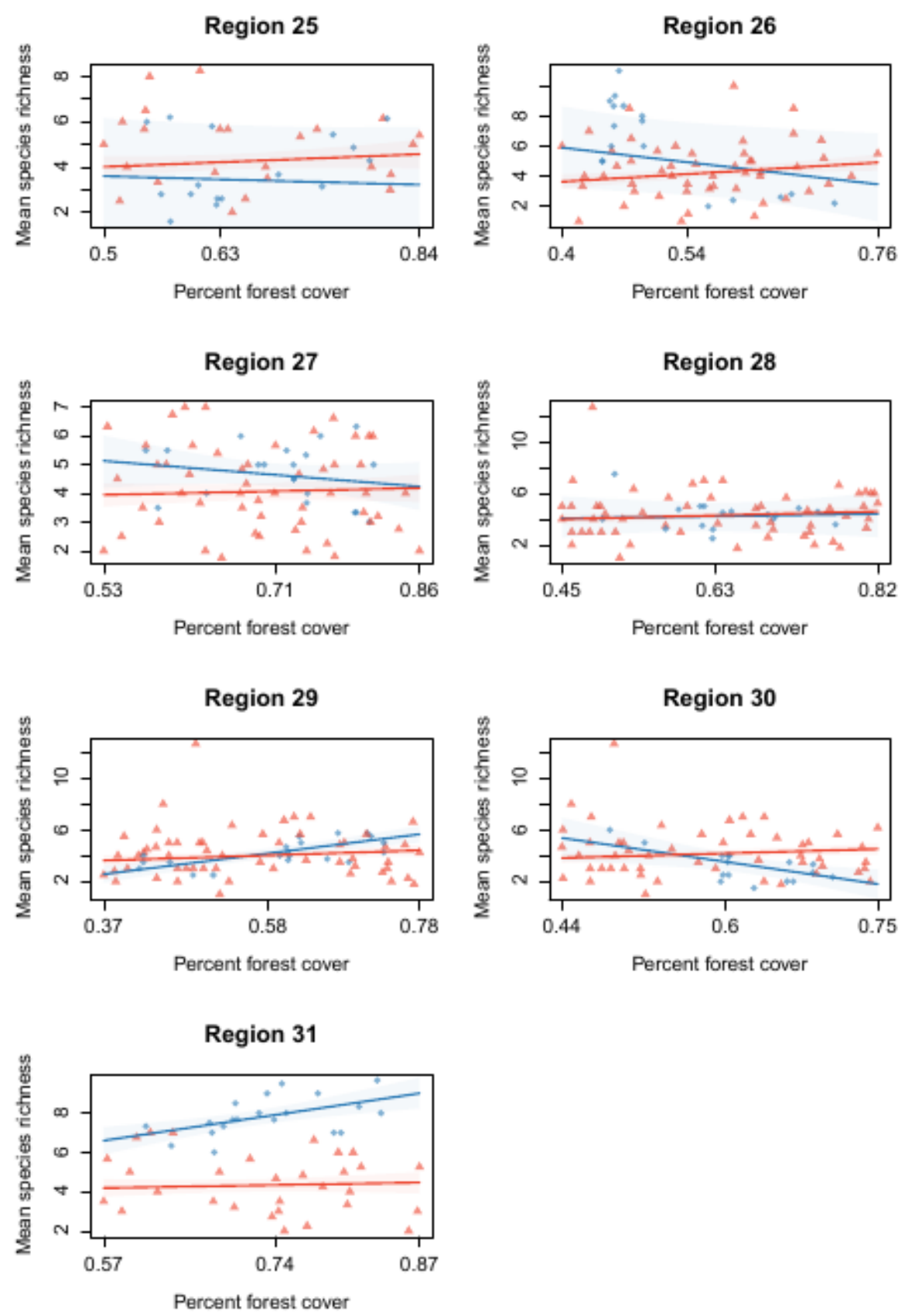

Figure C. Slope estimates (with $95 \%$ percentile interval shaded) measuring the effect of forest cover on forest bird mean species richness over time at a temporal site from 2000 to 2019 (in blue) and in space across a set of neighbouring spatial sites in 2019 (in red) for all 31 space-time comparisons in the U.S. and Canada. Here, each of the spatial slopes were informed by the full number of available spatial sites within each space-time comparison, which may exceed the number of years informing the corresponding temporal slope. 
Table D. Slope parameter coefficient estimates measuring the effect of forest cover on forest bird mean species richness over time at a temporal site from 2000 to 2019 ("temporal slope") and in space across a set of neighbouring spatial sites in 2019 ("spatial slope") for all 31 space-time comparisons in the U.S. and Canada. Here, each of the spatial slopes were informed by a subset number of eligible spatial sites equal to the number of years informing the corresponding temporal slope.

\begin{tabular}{|c|c|c|c|c|c|c|}
\hline & \multicolumn{3}{|c|}{ TIME } & \multicolumn{3}{|c|}{ SPACE } \\
\hline $\begin{array}{l}\text { Space-Time } \\
\text { Comparison }\end{array}$ & mean & $2.5 \%$ & $97.5 \%$ & mean & $2.5 \%$ & $97.5 \%$ \\
\hline 1 & 0.21658 & -0.5305 & 1.003452 & -0.06648 & -0.73922 & 0.597158 \\
\hline 2 & 0.589416 & -0.41435 & 1.577536 & -0.07028 & -0.83355 & 0.715811 \\
\hline 3 & 0.34019 & -0.12066 & 0.813527 & 0.377508 & -0.18311 & 0.935251 \\
\hline 4 & -0.06314 & -0.94849 & 0.764872 & 0.097074 & -0.58532 & 0.786763 \\
\hline 5 & 0.271383 & -0.23531 & 0.792587 & 0.438829 & -0.20053 & 1.071278 \\
\hline 6 & 0.174669 & -0.28149 & 0.625919 & -0.10943 & -0.75155 & 0.549524 \\
\hline 7 & 0.389338 & -0.14674 & 0.917493 & -0.01536 & -0.57367 & 0.551602 \\
\hline 8 & 0.612538 & -0.52149 & 1.758062 & 0.15801 & -0.65951 & 0.99369 \\
\hline 9 & 0.159915 & -0.3589 & 0.702113 & 0.1981 & -0.25746 & 0.658512 \\
\hline 10 & 0.279053 & -0.27252 & 0.82271 & 0.05429 & -0.72722 & 0.862136 \\
\hline 11 & 0.760744 & -0.31521 & 1.681288 & 0.271647 & -0.52853 & 1.016087 \\
\hline 12 & 0.555849 & 0.047807 & 1.056569 & -0.11308 & -0.72074 & 0.503592 \\
\hline 13 & 0.374161 & -0.80297 & 1.622343 & 0.510513 & -0.3112 & 1.29062 \\
\hline 14 & 0.187604 & -0.86569 & 1.228732 & 0.316077 & -0.4027 & 1.047632 \\
\hline 15 & 0.389331 & -0.90178 & 1.595733 & 0.399041 & -0.32622 & 1.135353 \\
\hline 16 & -0.09492 & -0.44655 & 0.263856 & 0.544821 & 0.006468 & 1.08731 \\
\hline 17 & -0.42667 & -1.01221 & 0.166577 & 0.325461 & -0.39118 & 1.024592 \\
\hline 18 & -0.74591 & -1.62614 & 0.156423 & 0.250493 & -0.29849 & 0.826748 \\
\hline 19 & -1.07803 & -2.20344 & 0.089469 & 1.116421 & 0.145242 & 2.053296 \\
\hline 20 & 0.457223 & -0.5401 & 1.388983 & 0.07562 & -0.52105 & 0.678287 \\
\hline 21 & 1.159671 & 0.547579 & 1.705899 & 0.219762 & -0.18179 & 0.619472 \\
\hline 22 & -0.37999 & -1.05199 & 0.261462 & 0.487711 & 0.085121 & 0.907158 \\
\hline 23 & -0.18589 & -1.24946 & 0.855354 & -0.1319 & -0.86769 & 0.604803 \\
\hline
\end{tabular}




\begin{tabular}{cccc|ccc} 
& \multicolumn{3}{c}{ TIME } & \multicolumn{3}{c}{ SPACE } \\
\cline { 2 - 7 } $\begin{array}{c}\text { Space-Time } \\
\text { Comparison }\end{array}$ & mean & $2.5 \%$ & $97.5 \%$ & mean & $2.5 \%$ & $97.5 \%$ \\
\hline 24 & -0.11529 & -0.4489 & 0.219149 & 0.348015 & -0.02477 & 0.728951 \\
\hline 25 & -0.02151 & -0.68533 & 0.697175 & -0.16748 & -0.89735 & 0.541018 \\
\hline 26 & -0.95154 & -2.05625 & 0.118814 & -0.0036 & -0.86397 & 0.850687 \\
\hline 27 & -0.23963 & -0.96646 & 0.52698 & 0.016644 & -0.66511 & 0.689737 \\
\hline 28 & -0.03464 & -1.10809 & 1.058012 & -0.06165 & -0.76486 & 0.635535 \\
\hline 29 & 0.886321 & 0.440188 & 1.358131 & 0.21123 & -0.30289 & 0.718407 \\
\hline 30 & -1.17779 & -2.3633 & 0.146941 & 0.221378 & -0.82499 & 1.276098 \\
\hline 31 & 0.963182 & 0.26797 & 1.683838 & -0.21175 & -0.89246 & 0.452732 \\
\hline
\end{tabular}



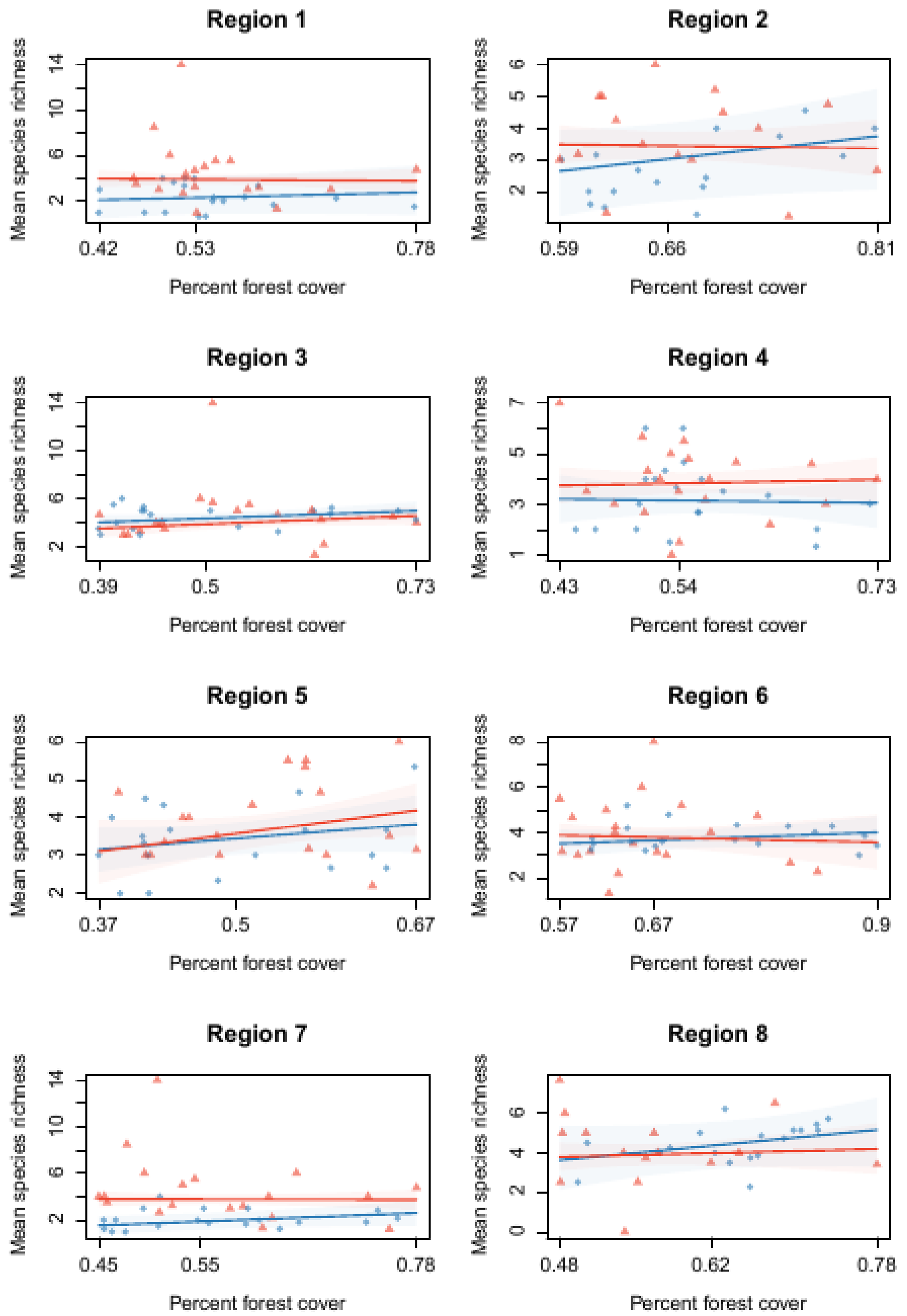

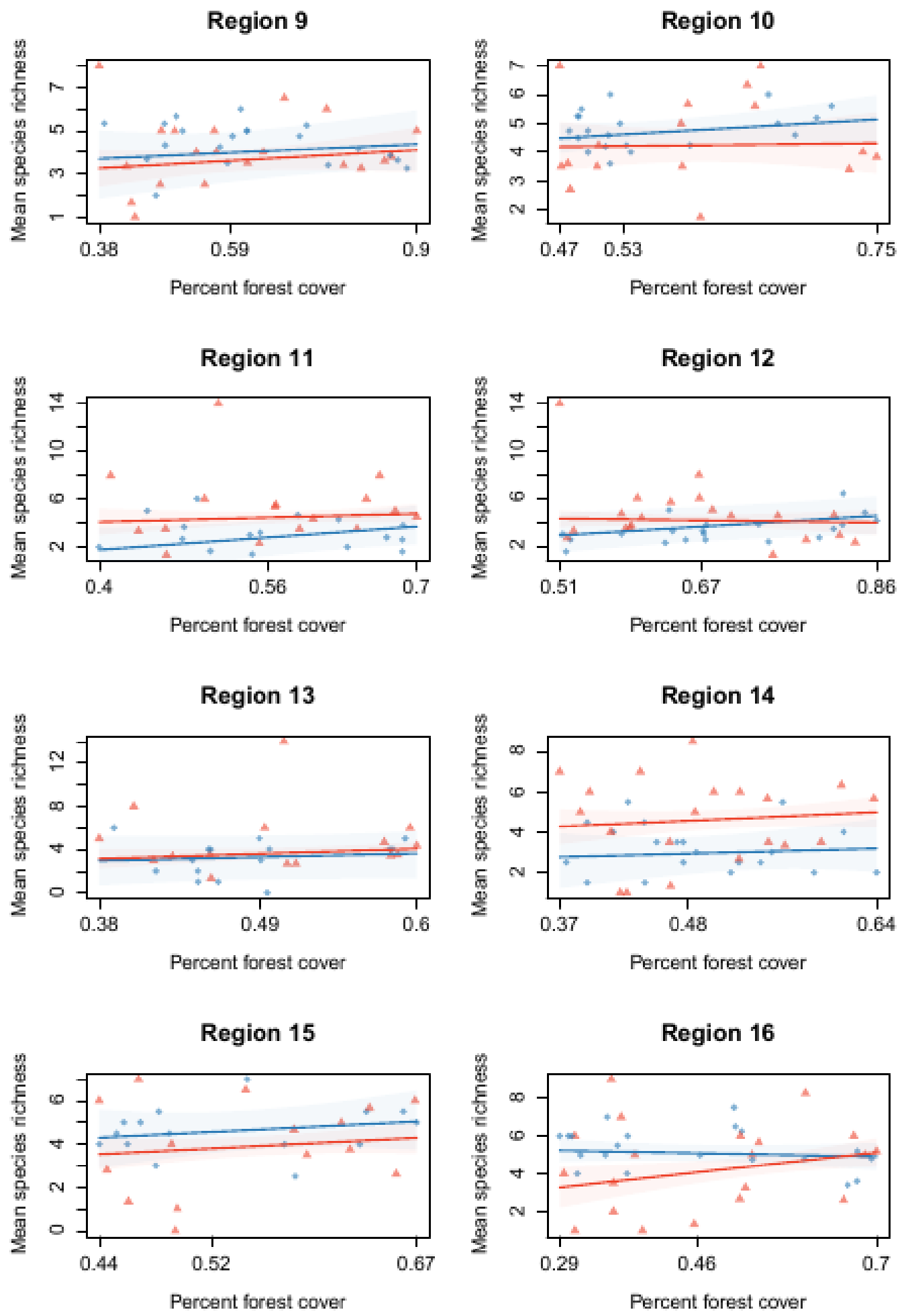

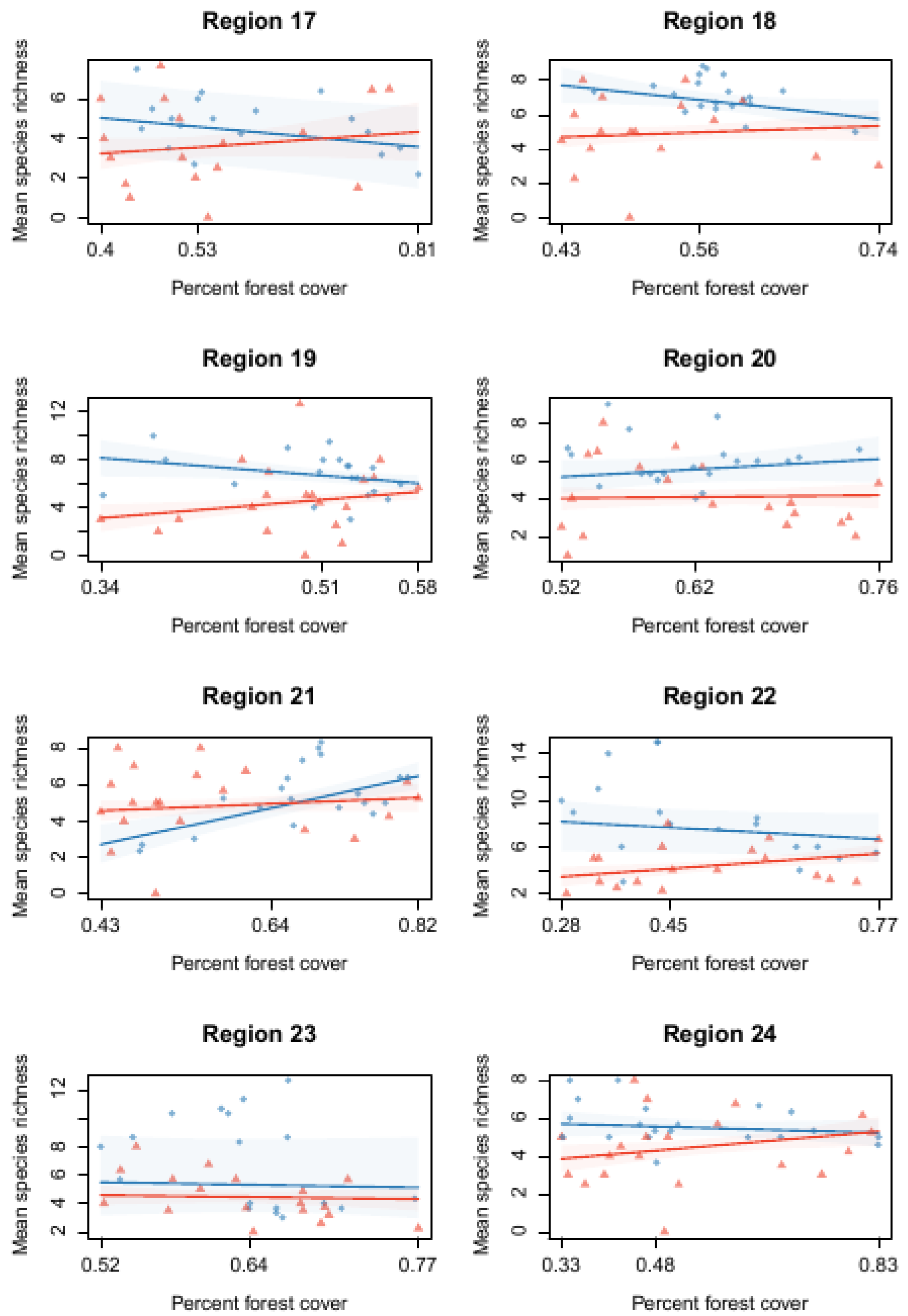

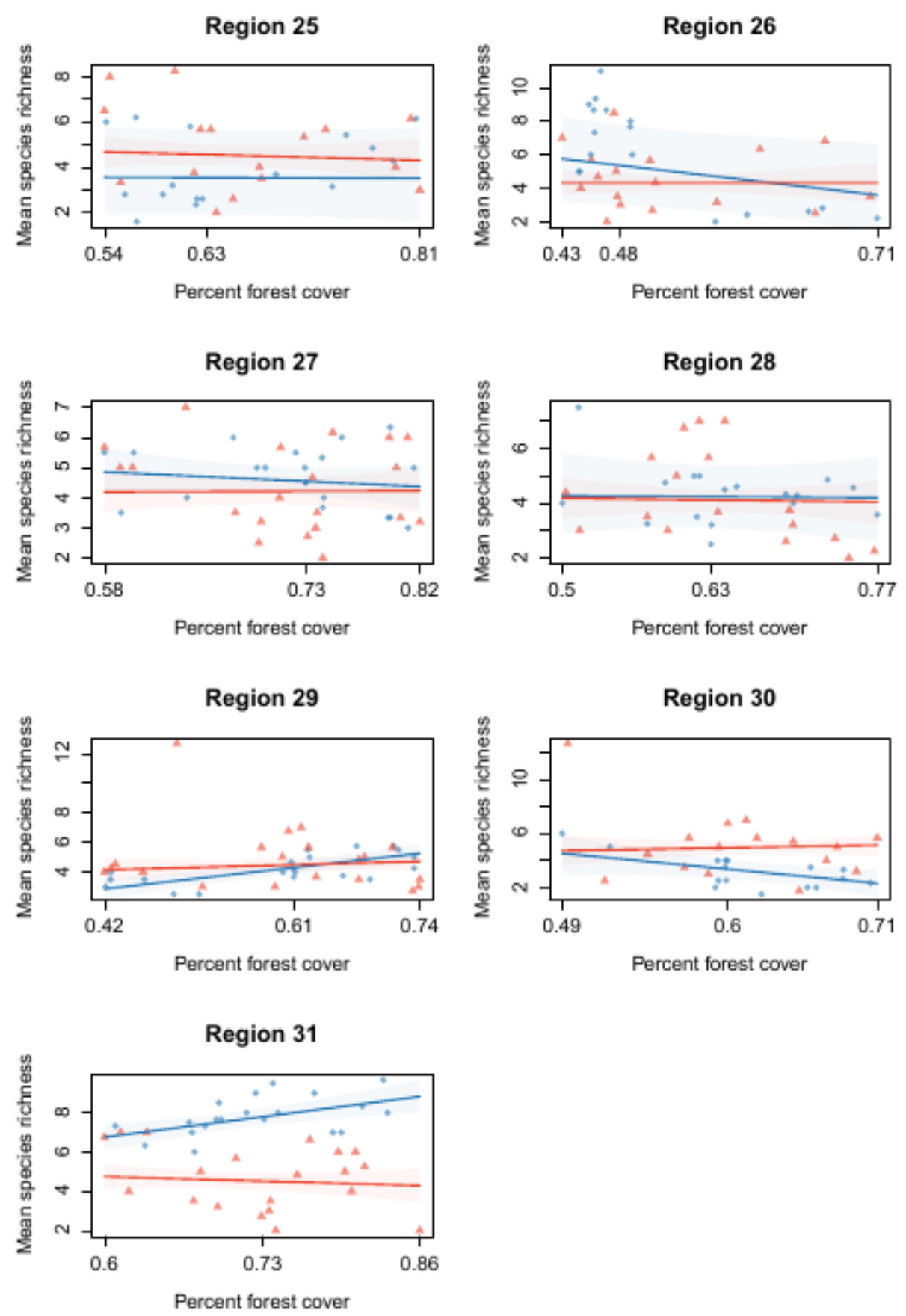

Figure D. Slope estimates (with $95 \%$ percentile interval shaded) measuring the effect of forest cover on forest bird mean species richness over time at a temporal site from 2000 to 2019 (in blue) and in space across a set of neighbouring spatial sites in 2019 (in red) for all 31 space-time comparisons in the U.S. and Canada. Here, each of the spatial slopes were informed by a subset number of eligible spatial sites equal to the number of years informing the corresponding temporal slope. 
Table E. Slope parameter coefficient estimates measuring the effect of forest cover on open-habitat bird mean species richness over time at a temporal site from 2000 to 2019 ("temporal slope") and in space across a set of neighbouring spatial sites in 2019 ("spatial slope") for all 31 space-time comparisons in the U.S. and Canada. Here, each of the spatial slopes were informed by the full number of available spatial sites within each space-time comparison, which may exceed the number of years informing the corresponding temporal slope.

\begin{tabular}{|c|c|c|c|c|c|c|}
\hline & \multicolumn{3}{|c|}{ TIME } & \multicolumn{3}{|c|}{ SPACE } \\
\hline $\begin{array}{l}\text { Space-Time } \\
\text { Comparison }\end{array}$ & mean & $2.5 \%$ & $97.5 \%$ & mean & $2.5 \%$ & $97.5 \%$ \\
\hline 1 & -0.07619 & -0.25735 & 0.095207 & -0.15926 & -0.24402 & -0.07319 \\
\hline 2 & -0.35409 & -0.72389 & -0.00014 & -0.15801 & -0.26778 & -0.04642 \\
\hline 3 & -0.02311 & -0.09824 & 0.05145 & -0.14096 & -0.2105 & -0.07091 \\
\hline 4 & 0.100952 & -0.03282 & 0.251073 & -0.14613 & -0.22811 & -0.06293 \\
\hline 5 & -0.0106 & -0.12672 & 0.095465 & -0.14034 & -0.21372 & -0.06667 \\
\hline 6 & -0.02873 & -0.17041 & 0.100728 & -0.16712 & -0.29518 & -0.04184 \\
\hline 7 & -0.18563 & -0.38064 & 0.056726 & -0.16074 & -0.24271 & -0.07856 \\
\hline 8 & -0.16049 & -0.53621 & 0.243369 & -0.12822 & -0.2928 & 0.027306 \\
\hline 9 & 0.132259 & 0.027492 & 0.235614 & -0.1585 & -0.23867 & -0.0828 \\
\hline 10 & -0.01465 & -0.13779 & 0.105913 & -0.34657 & -0.98077 & 0.324686 \\
\hline 11 & 0.010306 & -0.18039 & 0.196131 & -0.10788 & -0.19201 & -0.02346 \\
\hline 12 & 0.03944 & -0.08652 & 0.164136 & -0.12853 & -0.22789 & -0.03054 \\
\hline 13 & -0.29343 & -0.82475 & 0.261263 & -0.10512 & -0.21058 & 0.00663 \\
\hline 14 & 0.237874 & -0.00602 & 0.48438 & -0.08002 & -0.1539 & -0.00456 \\
\hline 15 & 0.182017 & -0.22966 & 0.565442 & -0.04923 & -0.12287 & 0.025798 \\
\hline 16 & 0.230747 & 0.145677 & 0.311078 & -0.06377 & -0.1311 & 0.00152 \\
\hline 17 & -0.10709 & -0.23668 & 0.026455 & -0.14279 & -0.29392 & 0.009513 \\
\hline 18 & 0.304791 & 0.065862 & 0.565667 & -0.07976 & -0.18156 & 0.022989 \\
\hline 19 & 0.036462 & -0.10379 & 0.177652 & -0.06555 & -0.15776 & 0.029813 \\
\hline 20 & 0.721946 & 0.21179 & 1.262787 & -0.07483 & -0.14585 & -0.0034 \\
\hline 21 & 0.029383 & -0.21885 & 0.181019 & -0.07282 & -0.15166 & 0.005581 \\
\hline 22 & 0.172049 & -0.02806 & 0.37539 & -0.08186 & -0.14834 & -0.01437 \\
\hline
\end{tabular}




\begin{tabular}{cccc|ccc} 
& \multicolumn{3}{c}{ TIME } & \multicolumn{3}{c}{ SPACE } \\
\cline { 2 - 7 } $\begin{array}{c}\text { Space-Time } \\
\text { Comparison }\end{array}$ & mean & $2.5 \%$ & $97.5 \%$ & mean & $2.5 \%$ & $97.5 \%$ \\
\hline 23 & 0.494787 & 0.272697 & 0.717609 & -0.07769 & -0.13796 & -0.019 \\
\hline 24 & 0.182187 & 0.099852 & 0.255027 & -0.08222 & -0.14882 & -0.013 \\
\hline 25 & 0.20101 & 0.051199 & 0.339395 & -0.08092 & -0.16637 & 0.002536 \\
\hline 26 & -0.05368 & -0.36492 & 0.317588 & -0.13499 & -0.22022 & -0.05038 \\
\hline 27 & -0.094 & -0.21522 & 0.030663 & -0.09167 & -0.17265 & -0.01335 \\
\hline 28 & 0.058555 & -0.38761 & 0.498022 & -0.07236 & -0.13121 & -0.01369 \\
\hline 29 & -0.19651 & -0.31295 & -0.08052 & -0.06864 & -0.129 & -0.00772 \\
\hline 30 & -0.1301 & -0.56849 & 0.274013 & -0.05583 & -0.12069 & 0.008917 \\
\hline 31 & -0.26855 & -0.42197 & -0.12442 & -0.07892 & -0.1754 & 0.018167 \\
\hline
\end{tabular}



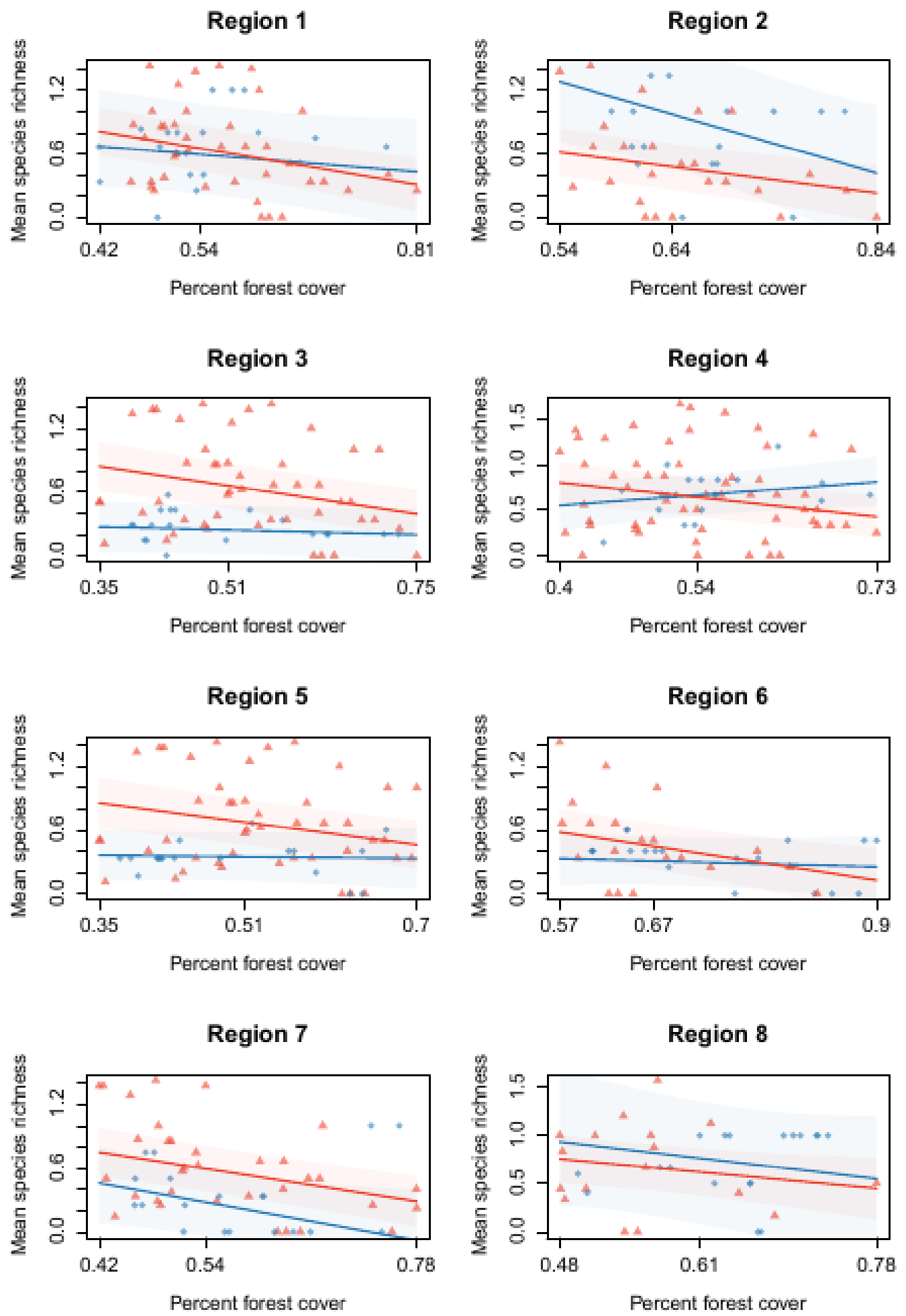

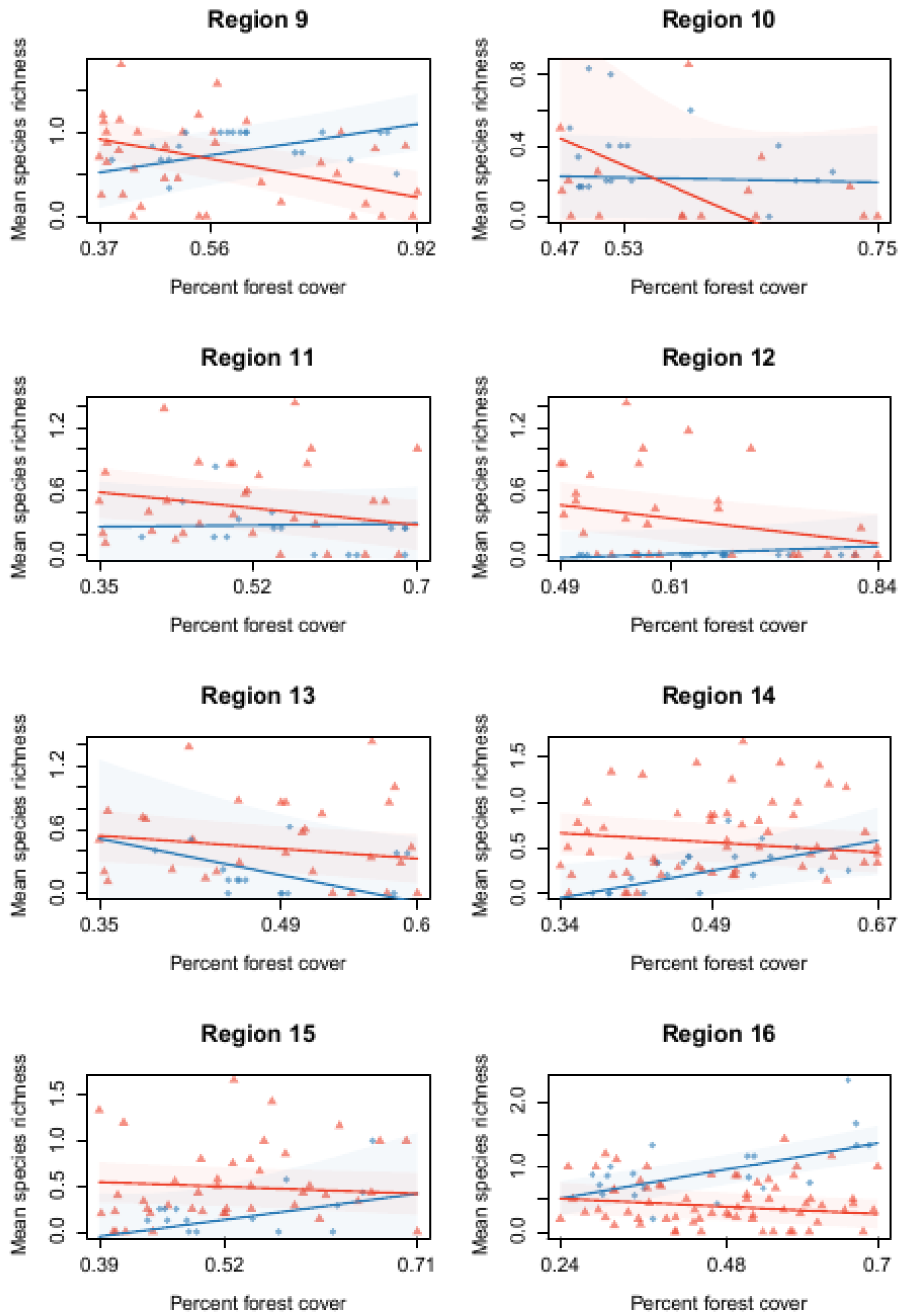

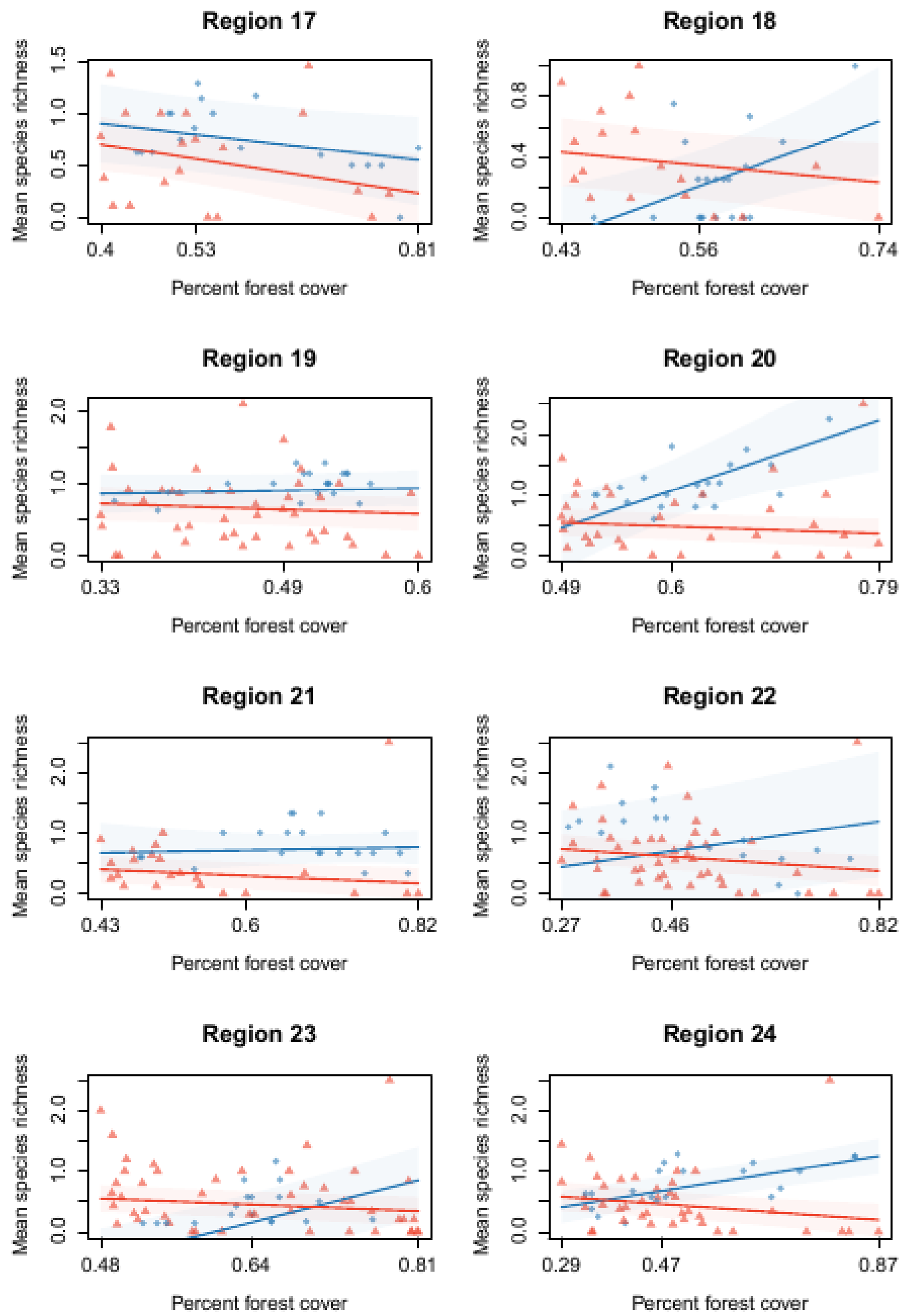

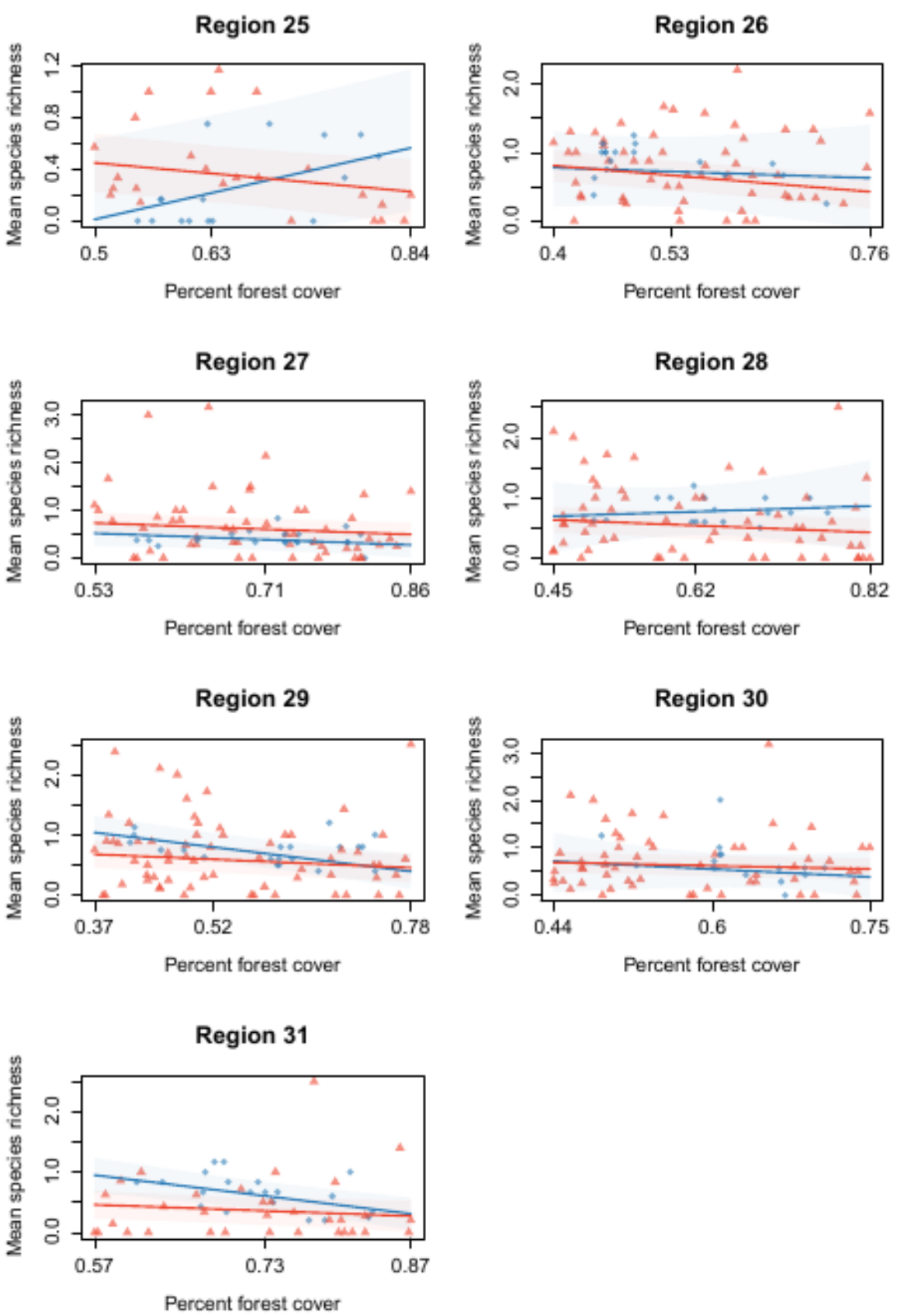

Figure E. Slope estimates (with $95 \%$ percentile interval shaded) measuring the effect of forest cover on open-habitat bird mean species richness over time at a temporal site from 2000 to 2019 (in blue) and in space across a set of neighbouring spatial sites in 2019 (in red) for all 31 space-time comparisons in the U.S. and Canada. Here, each of the spatial slopes were informed by the full number of available spatial sites within each space-time comparison, which may exceed the number of years informing the corresponding temporal slope. 
Table F. Slope parameter coefficient estimates measuring the effect of forest cover on open-habitat bird mean species richness over time at a temporal site from 2000 to 2019 ("temporal slope") and in space across a set of neighbouring spatial sites in 2019 ("spatial slope") for all 31 space-time comparisons in the U.S. and Canada. Here, each of the spatial slopes were informed by a subset number of eligible spatial sites equal to the number of years informing the corresponding temporal slope.

\begin{tabular}{|c|c|c|c|c|c|c|}
\hline & \multicolumn{3}{|c|}{ TIME } & \multicolumn{3}{|c|}{ SPACE } \\
\hline $\begin{array}{l}\text { Space-Time } \\
\text { Comparison }\end{array}$ & mean & $2.5 \%$ & $97.5 \%$ & mean & $2.5 \%$ & $97.5 \%$ \\
\hline 1 & -0.07859 & -0.26381 & 0.104401 & -0.11063 & -0.28779 & 0.065649 \\
\hline 2 & -0.30665 & -0.69948 & 0.087299 & -0.11665 & -0.35245 & 0.119681 \\
\hline 3 & -0.00526 & -0.08867 & 0.07705 & -0.07847 & -0.24449 & 0.084395 \\
\hline 4 & 0.113836 & -0.03165 & 0.277546 & -0.0788 & -0.26184 & 0.108499 \\
\hline 5 & -0.0047 & -0.12508 & 0.110933 & -0.11137 & -0.29485 & 0.07183 \\
\hline 6 & -0.02183 & -0.16642 & 0.118151 & -0.13045 & -0.32763 & 0.064451 \\
\hline 7 & -0.06024 & -0.30992 & 0.238551 & -0.10252 & -0.26107 & 0.052527 \\
\hline 8 & -0.04751 & -0.45391 & 0.398721 & 0.055869 & -0.16107 & 0.269767 \\
\hline 9 & 0.118163 & -0.00481 & 0.243437 & 0.031631 & -0.15218 & 0.211997 \\
\hline 10 & -0.02668 & -0.14776 & 0.092195 & -0.30141 & -0.89982 & 0.319849 \\
\hline 11 & 0.009106 & -0.20048 & 0.204498 & -0.00393 & -0.18449 & 0.182203 \\
\hline 12 & 0.029665 & -0.11829 & 0.174419 & -0.09059 & -0.27692 & 0.095 \\
\hline 13 & -0.26275 & -0.83075 & 0.304411 & -0.02983 & -0.26091 & 0.208737 \\
\hline 14 & 0.187733 & -0.08646 & 0.459355 & -0.07036 & -0.24944 & 0.111142 \\
\hline 15 & 0.180134 & -0.25121 & 0.574358 & -0.08725 & -0.26757 & 0.090081 \\
\hline 16 & 0.228095 & 0.132375 & 0.317733 & -0.05829 & -0.20967 & 0.092909 \\
\hline 17 & -0.10944 & -0.24906 & 0.025472 & -0.05193 & -0.30035 & 0.196406 \\
\hline 18 & 0.367191 & 0.09924 & 0.651015 & -0.05104 & -0.19094 & 0.087821 \\
\hline 19 & 0.06215 & -0.0973 & 0.220513 & -0.06004 & -0.27264 & 0.146058 \\
\hline 20 & 0.707267 & 0.23853 & 1.143003 & -0.04463 & -0.18822 & 0.097594 \\
\hline 21 & 0.024278 & -0.18038 & 0.172102 & -0.04539 & -0.16162 & 0.068431 \\
\hline 22 & 0.189445 & -0.04191 & 0.41735 & -0.0554 & -0.1756 & 0.065609 \\
\hline 23 & 0.479724 & 0.244495 & 0.710159 & -0.0053 & -0.17505 & 0.165694 \\
\hline
\end{tabular}




\begin{tabular}{cccc|ccc} 
& \multicolumn{3}{c}{ TIME } & \multicolumn{3}{c}{ SPACE } \\
\cline { 2 - 7 } $\begin{array}{c}\text { Space-Time } \\
\text { Comparison }\end{array}$ & mean & $2.5 \%$ & $97.5 \%$ & mean & $2.5 \%$ & $97.5 \%$ \\
\hline 24 & 0.169383 & 0.089319 & 0.242648 & -0.04858 & -0.16014 & 0.061969 \\
\hline 25 & 0.210916 & 0.046572 & 0.368582 & -0.07816 & -0.24751 & 0.090418 \\
\hline 26 & -0.04997 & -0.4094 & 0.355935 & -0.05628 & -0.34974 & 0.244815 \\
\hline 27 & -0.04608 & -0.18688 & 0.0951 & -0.06185 & -0.2595 & 0.136221 \\
\hline 28 & 0.068732 & -0.39755 & 0.533761 & -0.03089 & -0.20906 & 0.157651 \\
\hline 29 & -0.13607 & -0.25641 & -0.01299 & -0.04057 & -0.17166 & 0.093068 \\
\hline 30 & -0.12518 & -0.56303 & 0.303218 & -0.03633 & -0.2187 & 0.153209 \\
\hline 31 & -0.27233 & -0.45173 & -0.10743 & -0.09442 & -0.29193 & 0.10501 \\
\hline
\end{tabular}



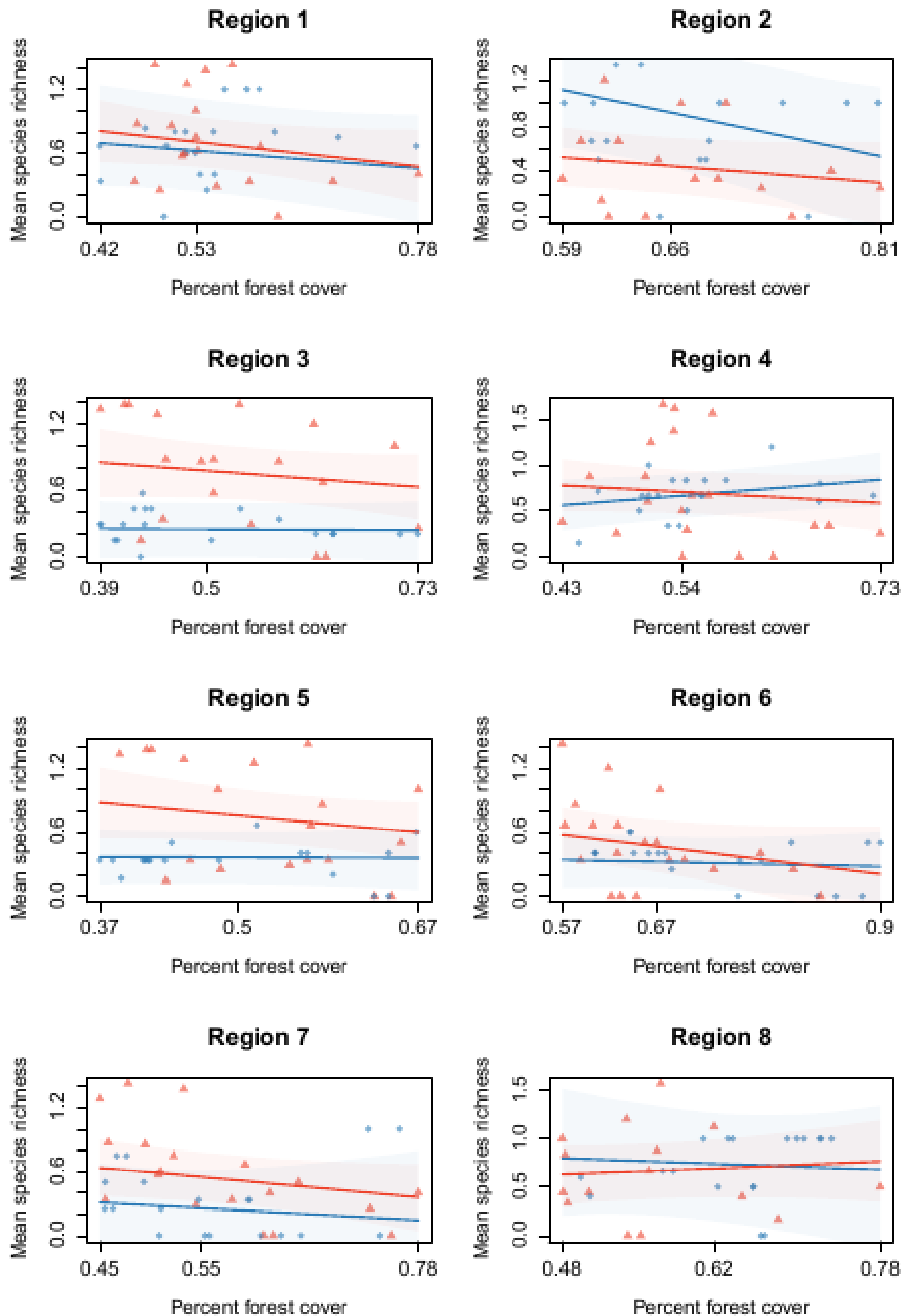

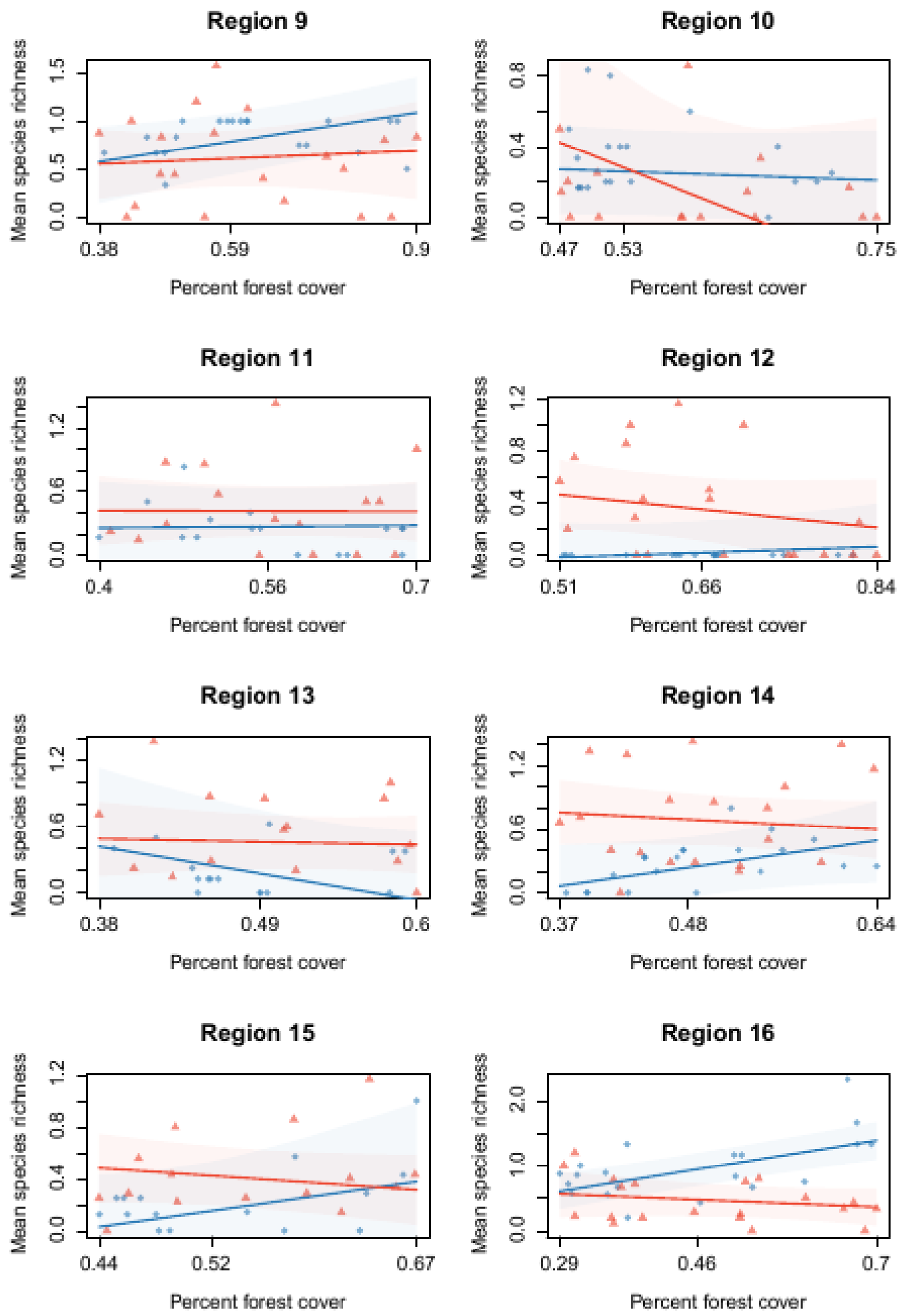

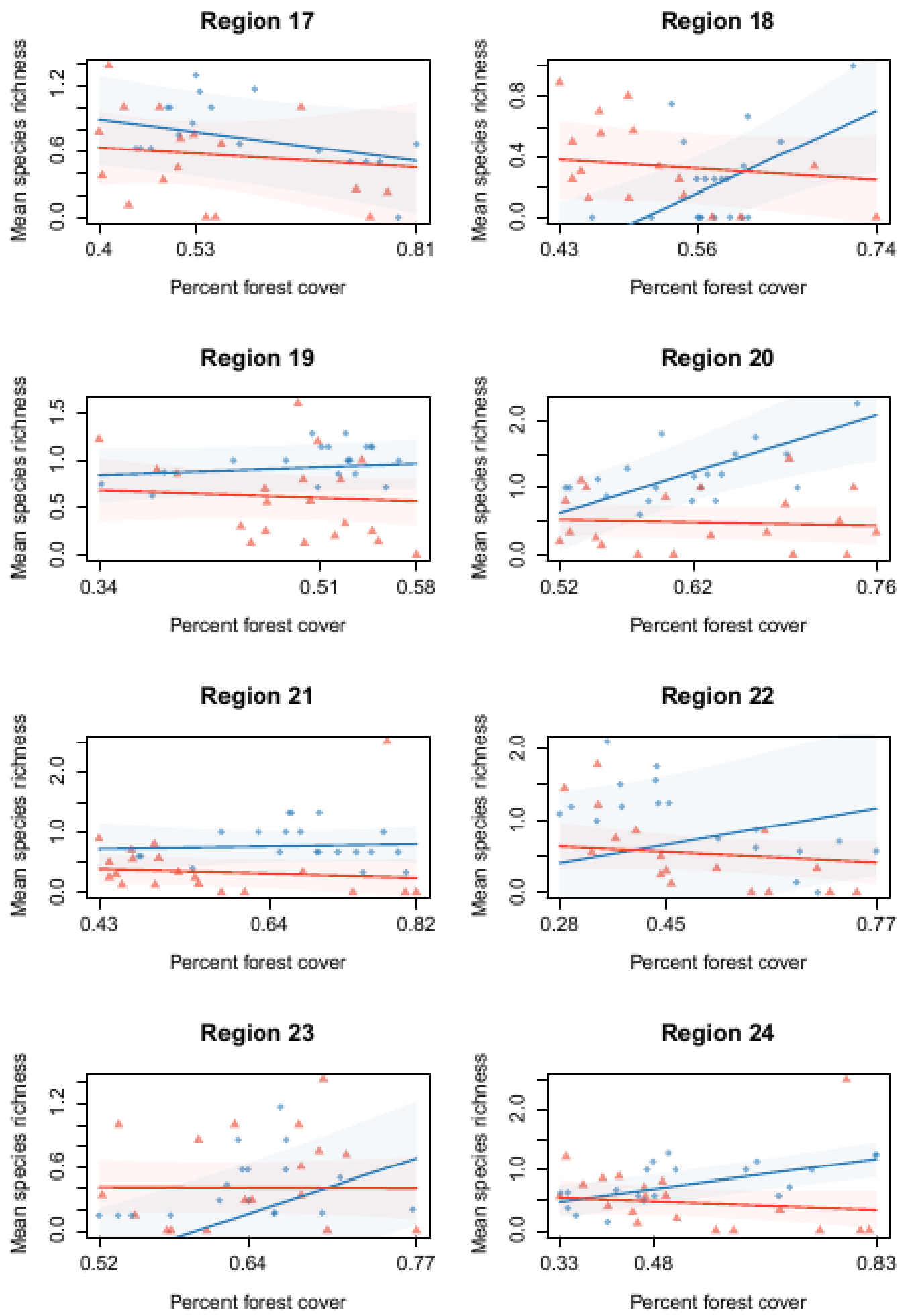

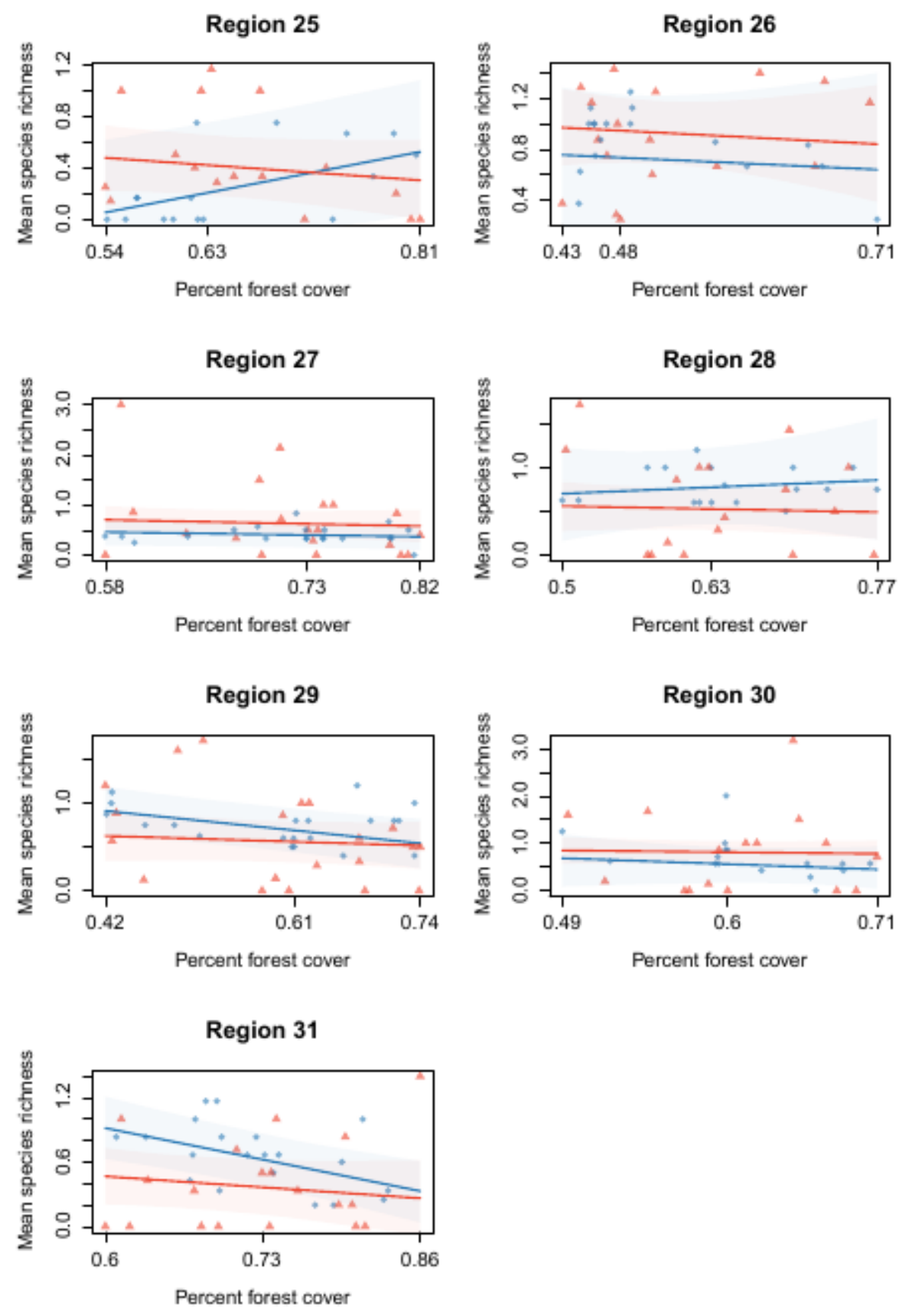

Figure F. Slope estimates (with $95 \%$ percentile interval shaded) measuring the effect of forest cover on open-habitat bird mean species richness over time at a temporal site from 2000 to 2019 (in blue) and in space across a set of neighbouring spatial sites in 2019 (in red) for all 31 space-time comparisons in the U.S. and Canada. Here, each of the spatial slopes were informed by a subset number of eligible spatial sites equal to the number of years informing the corresponding temporal slope. 
Table G. Slope parameter coefficient estimates measuring the effect of forest cover on forest bird mean abundance over time at a temporal site from 2000 to 2019 ("temporal slope") and in space across a set of neighbouring spatial sites in 2019 ("spatial slope") for all 31 space-time comparisons in the U.S. and Canada. Here, each of the spatial slopes were informed by the full number of available spatial sites within each space-time comparison, which may exceed the number of years informing the corresponding temporal slope.

\begin{tabular}{|c|c|c|c|c|c|c|}
\hline & & TIME & & & SPACE & \\
\hline $\begin{array}{l}\text { Space-Time } \\
\text { Comparison }\end{array}$ & mean & $2.5 \%$ & $97.5 \%$ & mean & $2.5 \%$ & $97.5 \%$ \\
\hline 1 & 0.34466 & -0.35222 & 1.102633 & 0.330187 & 0.004786 & 0.647001 \\
\hline 2 & 0.6467 & -0.42671 & 1.782249 & 0.23066 & -0.18814 & 0.650064 \\
\hline 3 & 0.295982 & -0.17062 & 0.755055 & 0.499448 & 0.186159 & 0.814115 \\
\hline 4 & 0.154276 & -1.68602 & 1.419535 & 0.496417 & 0.181741 & 0.802169 \\
\hline 5 & -0.12731 & -0.65678 & 0.443705 & 0.545315 & 0.207604 & 0.875937 \\
\hline 6 & 0.440945 & 0.042039 & 0.822366 & 0.225007 & -0.26442 & 0.712496 \\
\hline 7 & 0.95912 & 0.468545 & 1.446037 & 0.461805 & 0.124643 & 0.796727 \\
\hline 8 & 0.567974 & -0.50935 & 1.673616 & 0.35657 & -0.37922 & 1.081811 \\
\hline 9 & -0.04409 & -0.5843 & 0.539919 & 0.536943 & 0.199667 & 0.850311 \\
\hline 10 & 1.375108 & 0.442674 & 2.031231 & -0.9419 & -1.98301 & 0.099542 \\
\hline 11 & 0.141247 & -1.18897 & 1.532197 & 0.598528 & 0.200413 & 0.975163 \\
\hline 12 & 0.755844 & 0.325334 & 1.228959 & 0.207137 & -0.2116 & 0.623795 \\
\hline 13 & 0.760263 & -0.71437 & 2.268953 & 0.769753 & 0.297035 & 1.256801 \\
\hline 14 & -0.37092 & -1.37608 & 0.816394 & 0.501408 & 0.185097 & 0.810426 \\
\hline 15 & 0.162028 & -1.23396 & 1.478096 & 0.436085 & 0.10117 & 0.77364 \\
\hline 16 & -0.49596 & -0.97201 & -0.04329 & 0.481406 & 0.172184 & 0.784086 \\
\hline 17 & 0.228436 & -0.5118 & 0.862208 & -0.2474 & -1.06807 & 0.666897 \\
\hline 18 & -1.87111 & -2.84693 & -0.87447 & 0.249767 & -0.14146 & 0.647886 \\
\hline 19 & -1.6015 & -2.78694 & -0.24525 & 0.419555 & 0.025041 & 0.81853 \\
\hline 20 & 1.476741 & 0.560228 & 2.269328 & 0.190253 & -0.08855 & 0.46753 \\
\hline 21 & 1.285957 & 0.643015 & 1.759922 & 0.252107 & -0.01239 & 0.523898 \\
\hline 22 & 0.054558 & -1.57088 & 1.150828 & 0.30034 & 0.069098 & 0.533363 \\
\hline
\end{tabular}




\begin{tabular}{cccc|ccc} 
& \multicolumn{3}{c}{ TIME } & \multicolumn{3}{c}{ SPACE } \\
\cline { 2 - 7 } $\begin{array}{c}\text { Space-Time } \\
\text { Comparison }\end{array}$ & mean & $2.5 \%$ & $97.5 \%$ & mean & $2.5 \%$ & $97.5 \%$ \\
\hline 23 & -0.9794 & -2.06921 & 0.047091 & 0.172859 & -0.07057 & 0.407975 \\
\hline 24 & 0.022781 & -0.34795 & 0.377304 & 0.277129 & 0.038608 & 0.529014 \\
\hline 25 & -0.27869 & -0.94025 & 0.451176 & 0.162071 & -0.22286 & 0.518308 \\
\hline 26 & -1.19913 & -2.41915 & -0.05021 & 0.442384 & 0.11355 & 0.776013 \\
\hline 27 & -0.65183 & -1.39956 & 0.129362 & 0.102392 & -0.20167 & 0.3925 \\
\hline 28 & 0.15688 & -0.96276 & 1.305674 & 0.213403 & 0.006358 & 0.421556 \\
\hline 29 & 0.97747 & 0.541215 & 1.439544 & 0.248135 & 0.047179 & 0.452509 \\
\hline 30 & -1.59092 & -2.90076 & -0.15983 & 0.241056 & -0.00365 & 0.487593 \\
\hline 31 & 2.272576 & 1.170349 & 3.569141 & 0.072935 & -0.28512 & 0.429642 \\
\hline
\end{tabular}



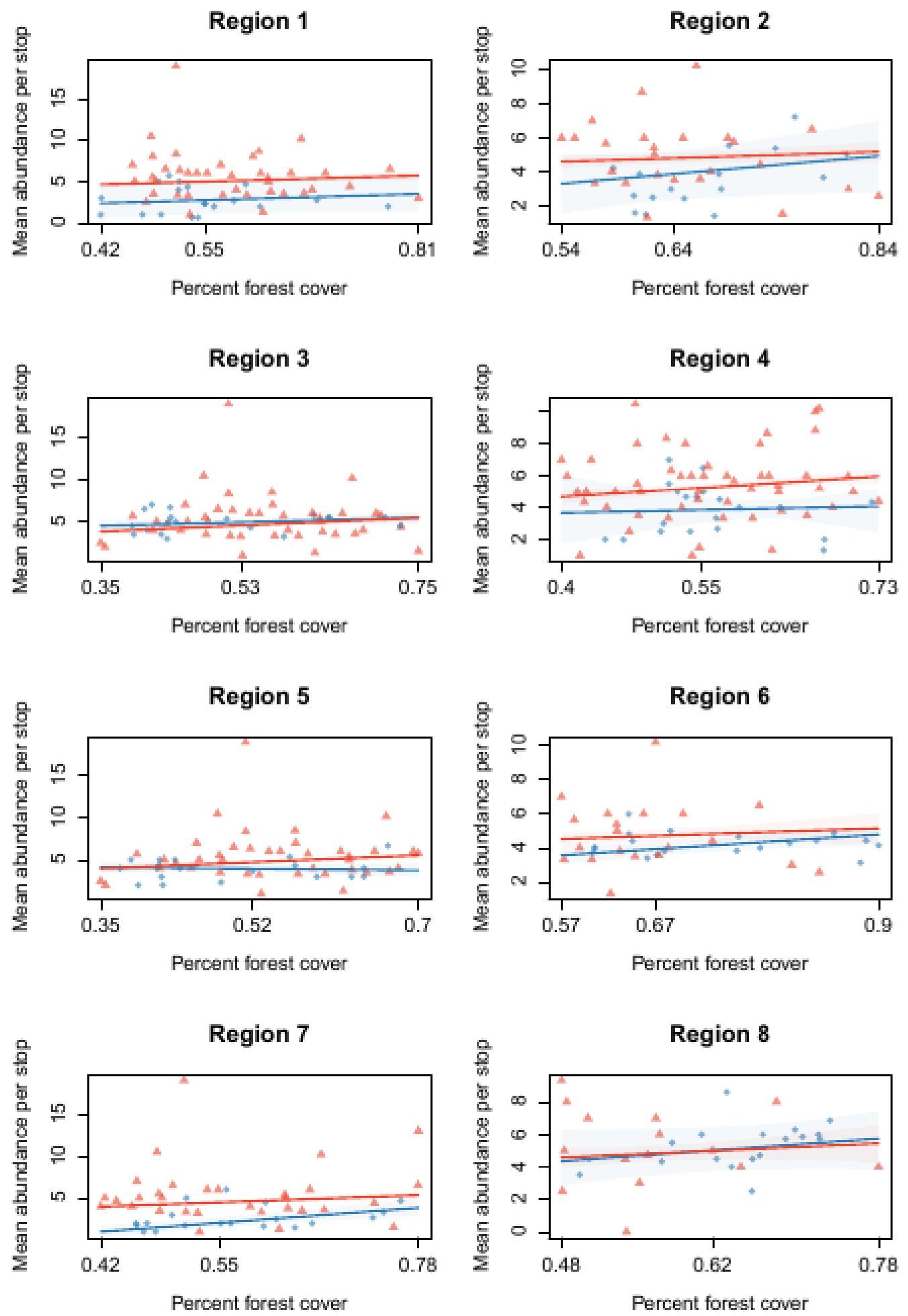

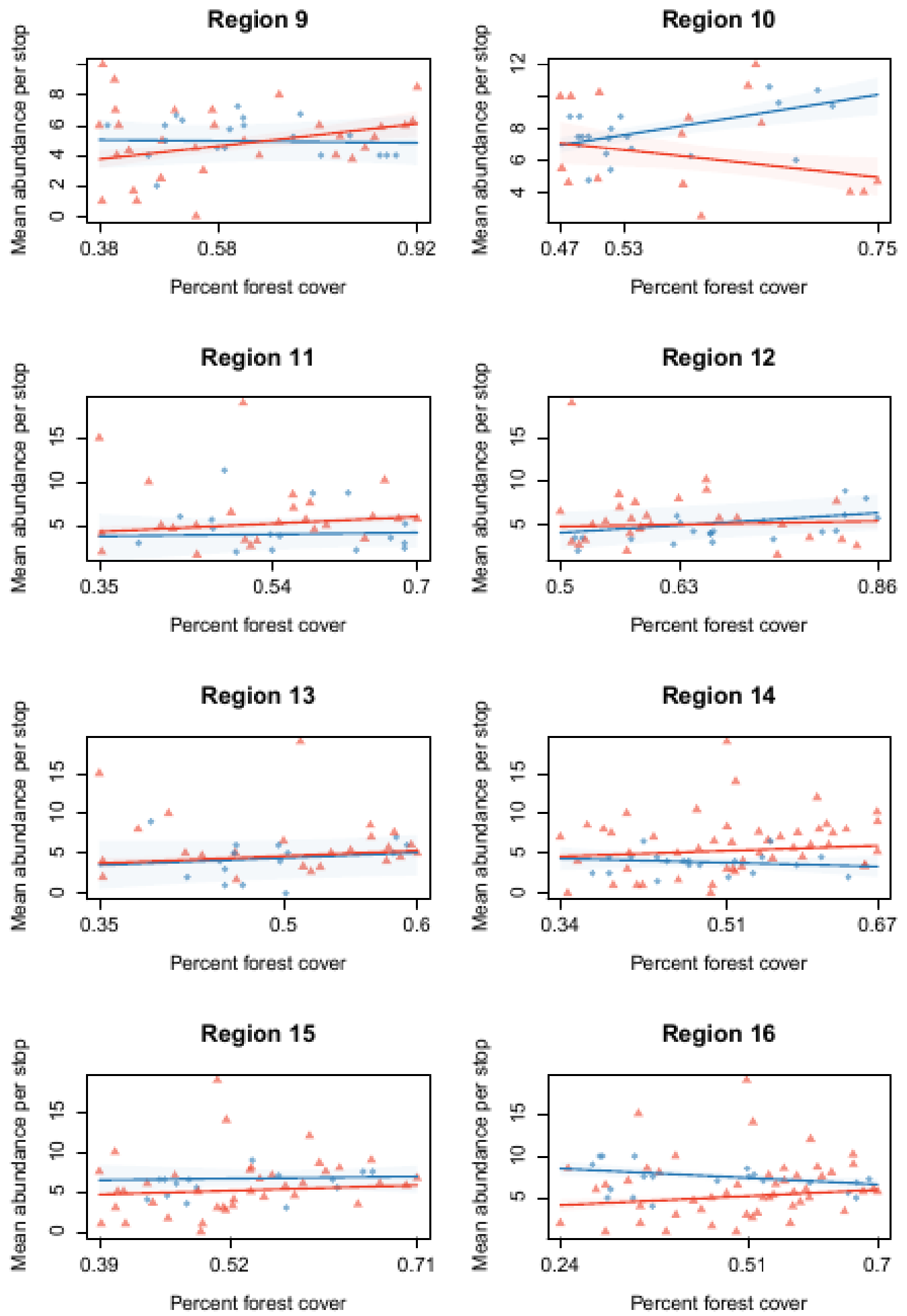

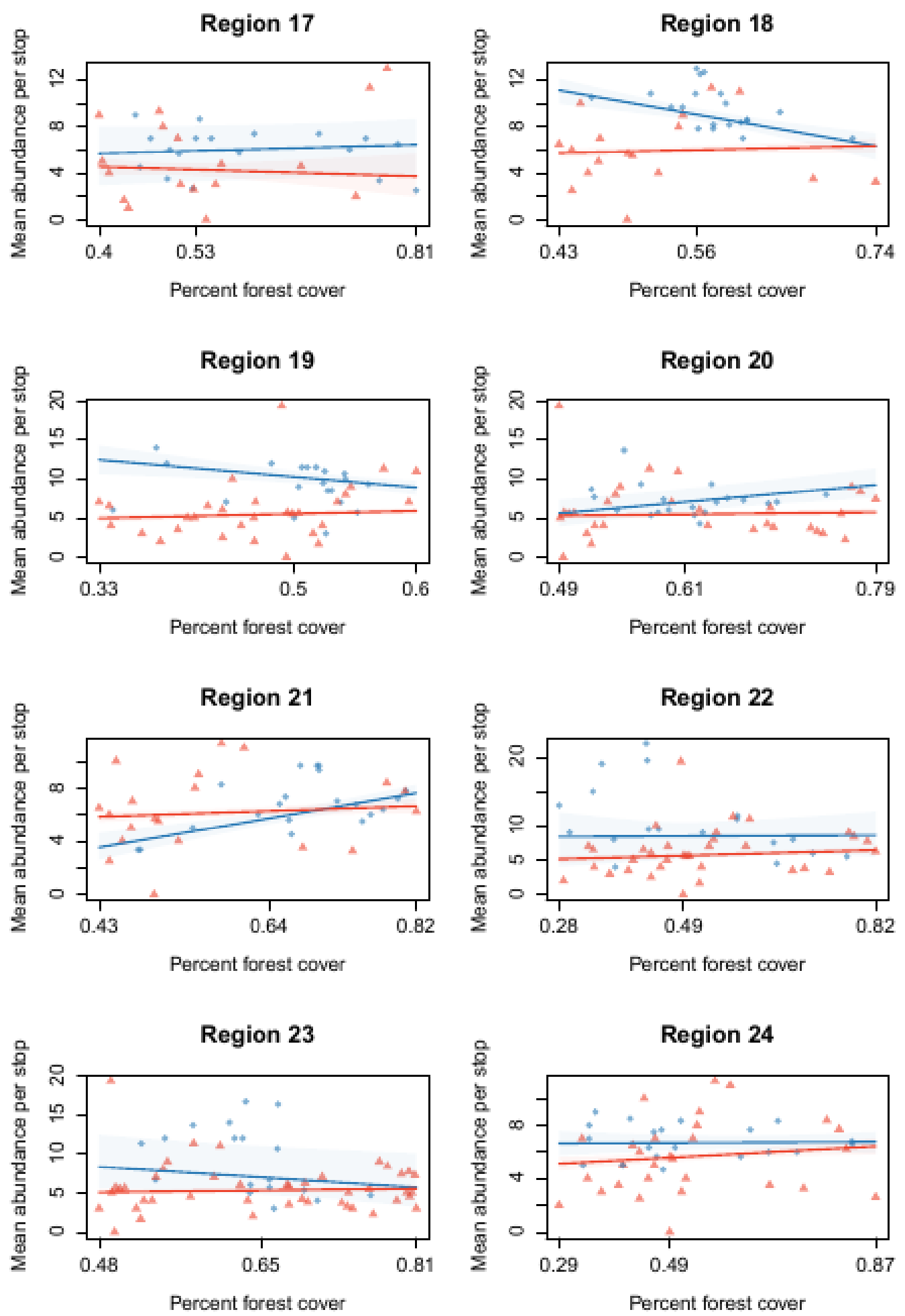

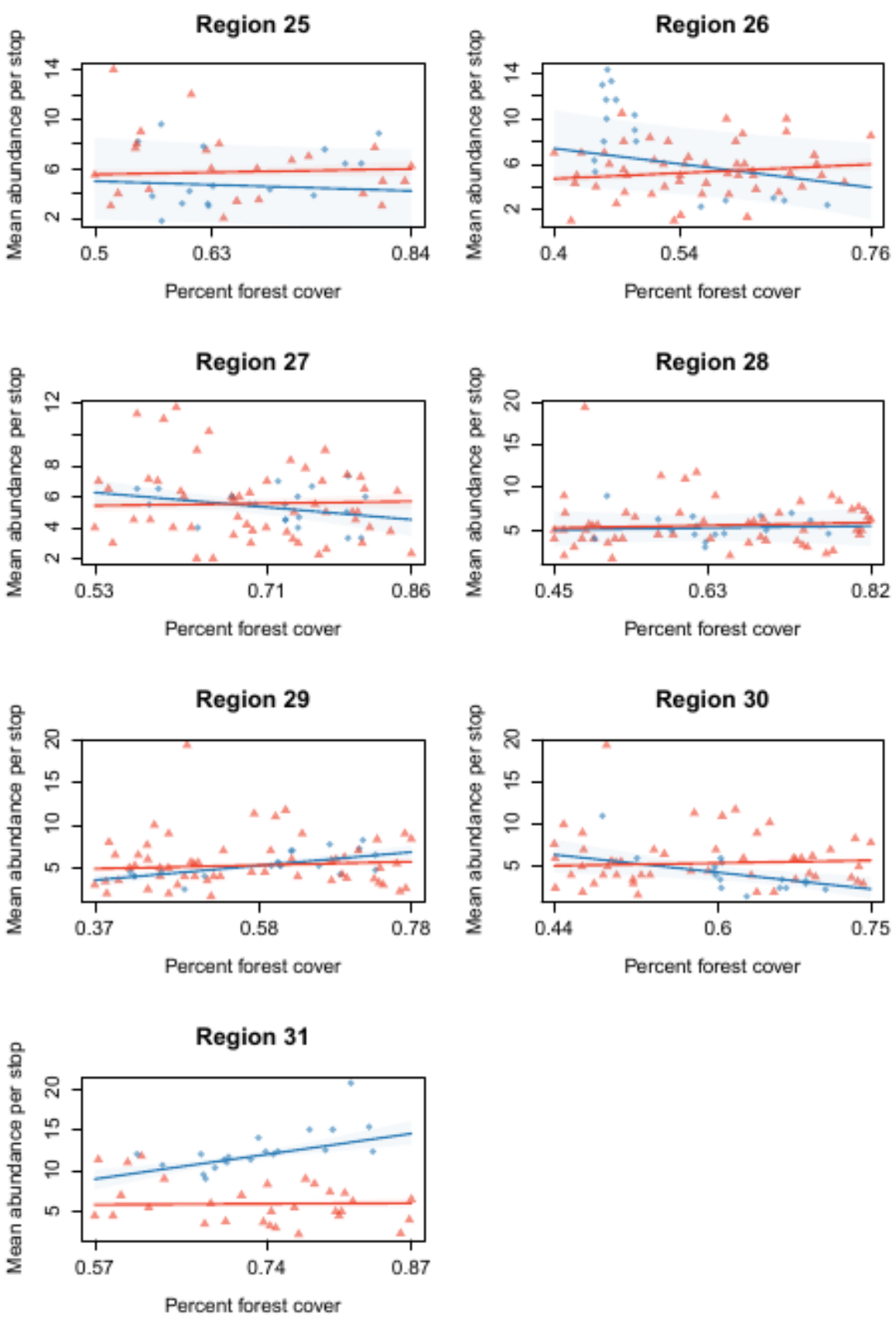

Figure G. Slope estimates (with $95 \%$ percentile interval shaded) measuring the effect of forest cover on forest bird mean abundance over time at a temporal site from 2000 to 2019 (in blue) and in space across a set of neighbouring spatial sites in 2019 (in red) for all 31 space-time comparisons in the U.S. and Canada. Here, each of the spatial slopes were informed by the full number of available spatial sites within each space-time comparison, which may exceed the number of years informing the corresponding temporal slope. 
Table H. Slope parameter coefficient estimates measuring the effect of forest cover on forest bird mean abundance over time at a temporal site from 2000 to 2019 ("temporal slope") and in space across a set of neighbouring spatial sites in 2019 ("spatial slope") for all 31 space-time comparisons in the U.S. and Canada. Here, each of the spatial slopes were informed by a subset number of eligible spatial sites equal to the number of years informing the corresponding temporal slope.

\begin{tabular}{|c|c|c|c|c|c|c|}
\hline & \multicolumn{3}{|c|}{ TIME } & \multicolumn{3}{|c|}{ SPACE } \\
\hline $\begin{array}{l}\text { Space-Time } \\
\text { Comparison }\end{array}$ & mean & $2.5 \%$ & $97.5 \%$ & mean & $2.5 \%$ & $97.5 \%$ \\
\hline 1 & 0.24852 & -0.59662 & 1.155697 & -0.2769 & -1.02944 & 0.4349 \\
\hline 2 & 0.467303 & -0.6527 & 1.598623 & -0.34452 & -1.19204 & 0.519556 \\
\hline 3 & 0.232067 & -0.35202 & 0.780539 & 0.170485 & -0.42915 & 0.77931 \\
\hline 4 & 0.062601 & -1.2929 & 1.241977 & -0.13908 & -0.8799 & 0.611192 \\
\hline 5 & 0.001065 & -0.6325 & 0.705534 & 0.23536 & -0.46816 & 0.932941 \\
\hline 6 & 0.213744 & -0.31884 & 0.730466 & -0.32448 & -1.04311 & 0.44043 \\
\hline 7 & 0.879667 & 0.224575 & 1.519722 & -0.19477 & -0.82659 & 0.434426 \\
\hline 8 & 0.518118 & -0.7172 & 1.733113 & 0.067998 & -0.90147 & 1.047098 \\
\hline 9 & -0.00545 & -0.63758 & 0.64703 & 0.336261 & -0.19342 & 0.853441 \\
\hline 10 & 1.049696 & -0.19557 & 1.927892 & -0.88009 & -1.98058 & 0.260126 \\
\hline 11 & 0.118035 & -1.17056 & 1.382854 & 0.148548 & -0.70577 & 0.997113 \\
\hline 12 & 0.79677 & 0.224077 & 1.387115 & -0.33011 & -1.06062 & 0.43225 \\
\hline 13 & 0.854967 & -0.63164 & 2.337422 & 0.246535 & -0.62964 & 1.094499 \\
\hline 14 & 0.351435 & -0.85986 & 1.534428 & 0.13482 & -0.71294 & 0.9568 \\
\hline 15 & 0.237831 & -1.13682 & 1.576543 & 0.731845 & -0.12109 & 1.59628 \\
\hline 16 & -0.50514 & -1.04288 & 0.085556 & 0.294328 & -0.30951 & 0.951886 \\
\hline 17 & 0.057878 & -0.89097 & 0.882906 & -0.01371 & -1.09262 & 1.245913 \\
\hline 18 & -1.58246 & -2.59222 & -0.5194 & 0.344288 & -0.2984 & 1.025027 \\
\hline 19 & -1.56409 & -2.87333 & 0.147425 & 1.352958 & 0.252086 & 2.359249 \\
\hline 20 & 1.032134 & -0.15012 & 2.104546 & -0.05525 & -0.74384 & 0.645969 \\
\hline 21 & 1.138147 & 0.332612 & 1.789446 & 0.356386 & -0.14015 & 0.860434 \\
\hline 22 & -0.29121 & -1.46171 & 0.801264 & 0.621431 & 0.122687 & 1.141799 \\
\hline 23 & -1.01751 & -2.30049 & 0.312621 & -0.28021 & -1.13759 & 0.568973 \\
\hline
\end{tabular}




\begin{tabular}{cccc|ccc} 
& \multicolumn{3}{c}{ TIME } & \multicolumn{3}{c}{ SPACE } \\
\cline { 2 - 7 } $\begin{array}{c}\text { Space-Time } \\
\text { Comparison }\end{array}$ & mean & $2.5 \%$ & $97.5 \%$ & mean & $2.5 \%$ & $97.5 \%$ \\
\hline 24 & -0.00839 & -0.46862 & 0.44812 & 0.450552 & -0.00326 & 0.931454 \\
\hline 25 & -0.02583 & -0.93536 & 1.010978 & -0.32675 & -1.26193 & 0.632011 \\
\hline 26 & -1.53408 & -2.81396 & -0.29968 & -0.03506 & -1.04605 & 0.999681 \\
\hline 27 & -0.51984 & -1.32538 & 0.323701 & -0.16896 & -0.91443 & 0.566979 \\
\hline 28 & -0.00763 & -1.23096 & 1.22286 & -0.15706 & -0.9856 & 0.67947 \\
\hline 29 & 0.996996 & 0.420373 & 1.572369 & 0.231235 & -0.33445 & 0.780958 \\
\hline 30 & -1.30696 & -2.7829 & 0.246565 & -0.02177 & -1.17979 & 1.105217 \\
\hline 31 & 2.330649 & 1.19308 & 3.518722 & -0.51358 & -1.3408 & 0.304392 \\
\hline
\end{tabular}



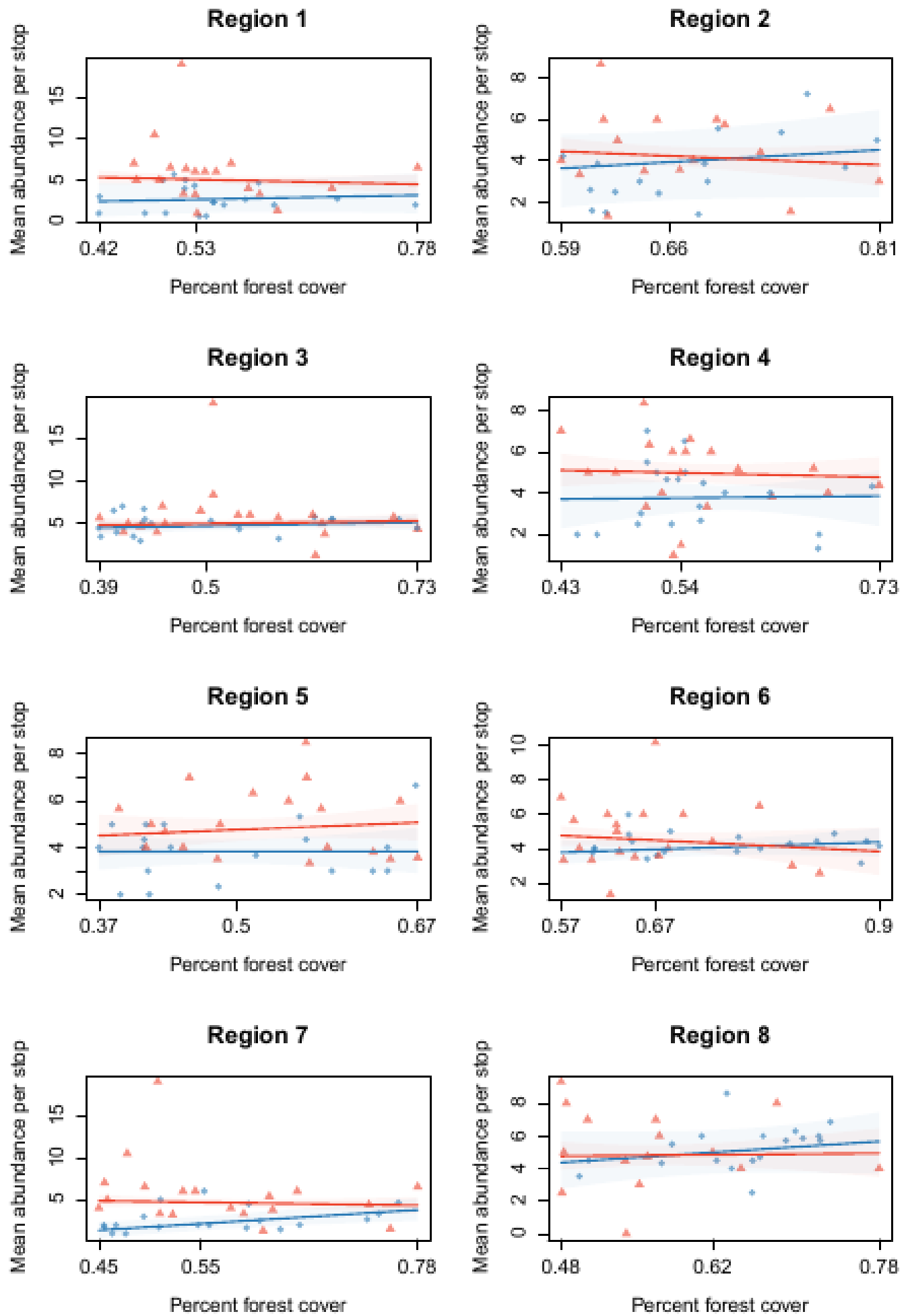

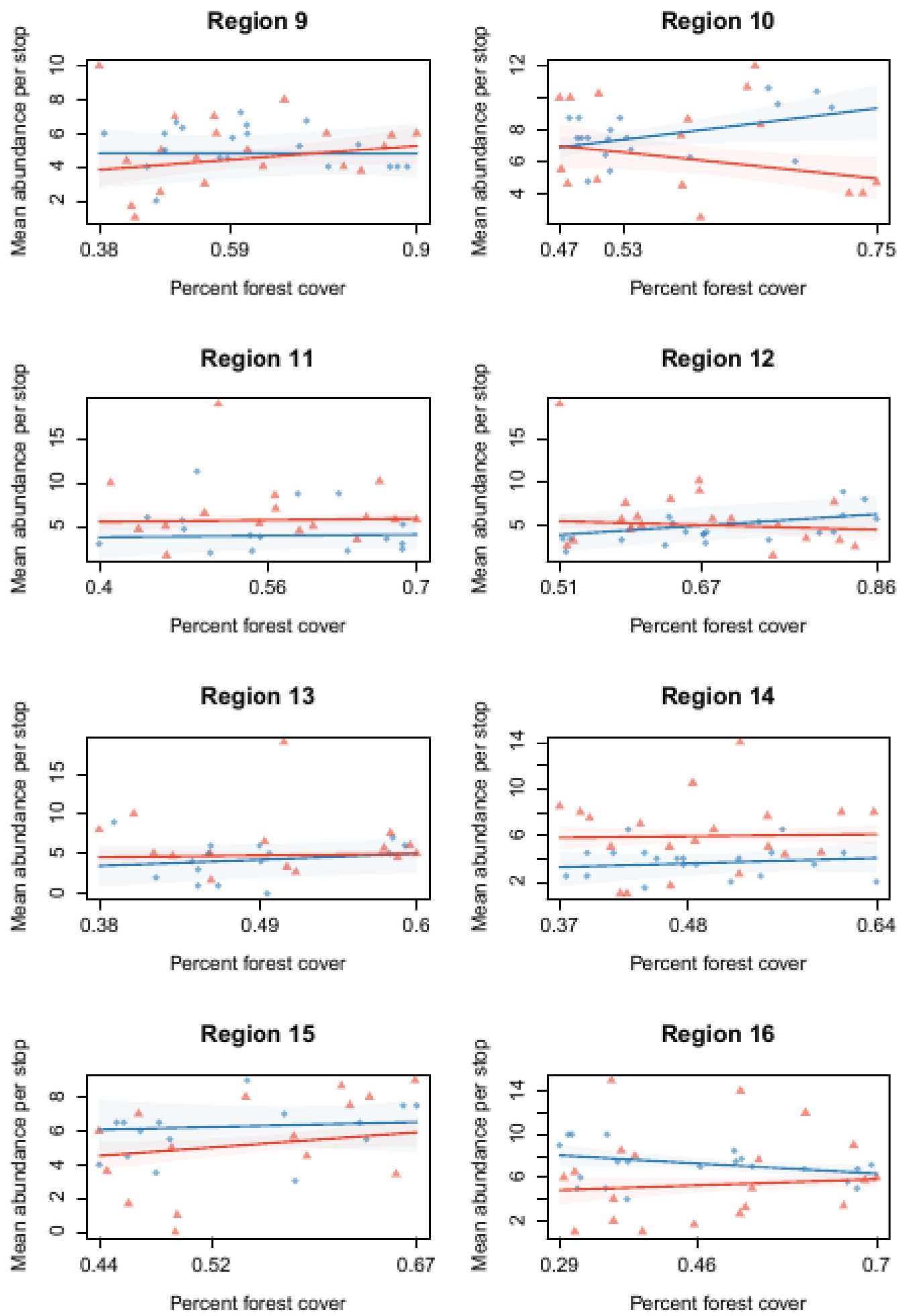

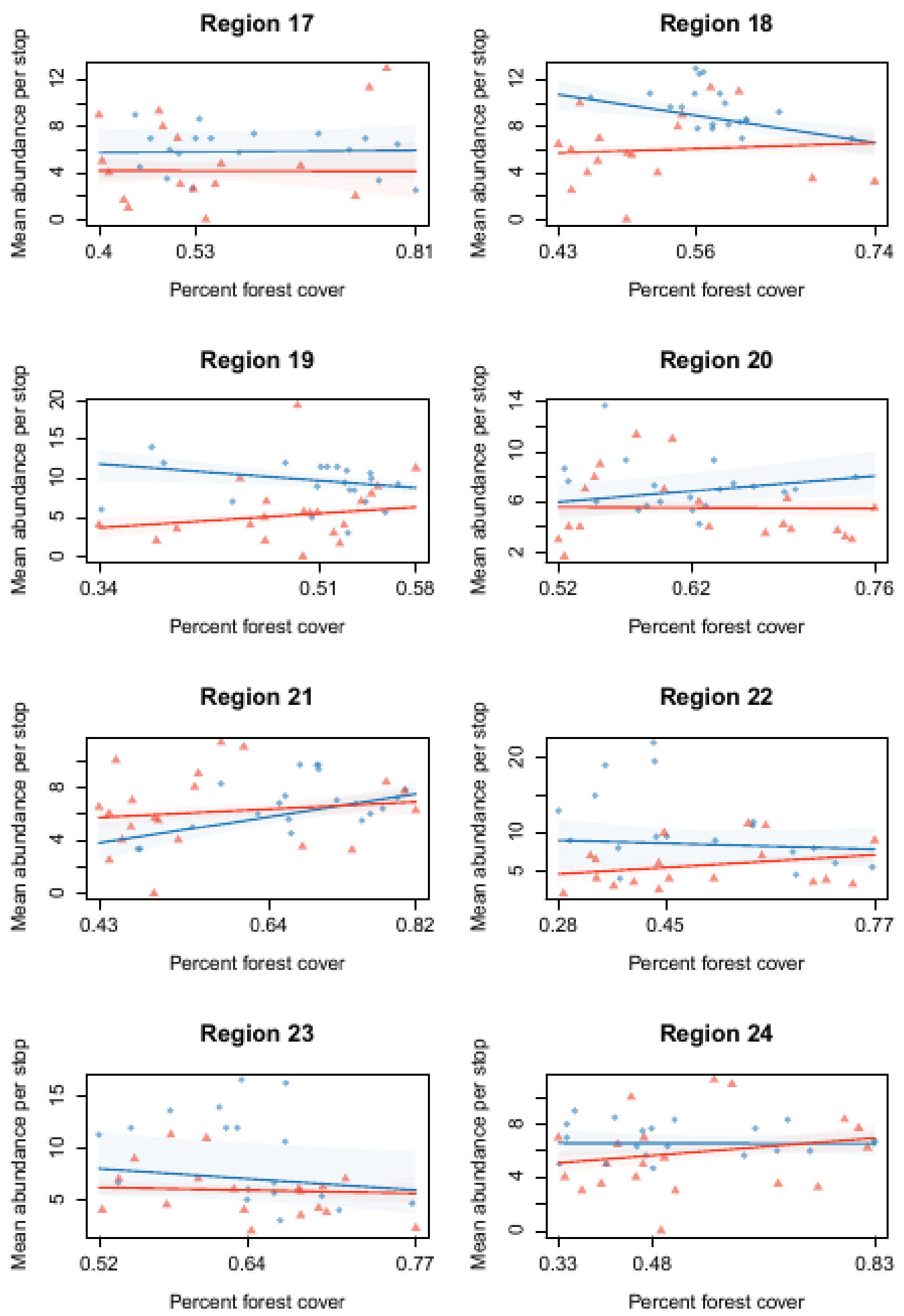

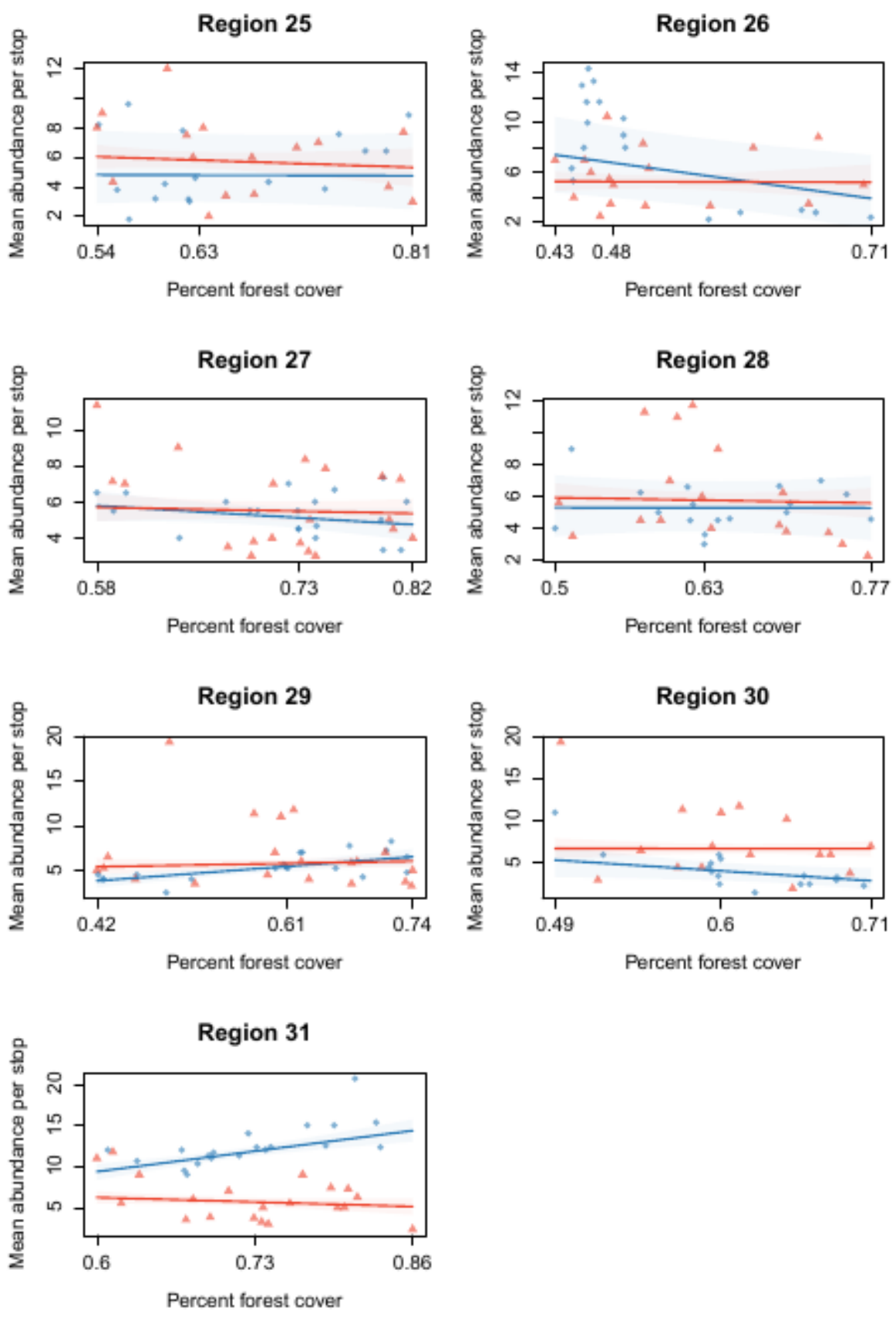

Figure H. Slope estimates (with $95 \%$ percentile interval shaded) measuring the effect of forest cover on forest bird mean abundance over time at a temporal site from 2000 to 2019 (in blue) and in space across a set of neighbouring spatial sites in 2019 (in red) for all 31 space-time comparisons in the U.S. and Canada. Here, each of the spatial slopes were informed by a subset number of eligible spatial sites equal to the number of years informing the corresponding temporal slope. 
Table I. Slope parameter coefficient estimates measuring the effect of forest cover on open-habitat bird mean abundance over time at a temporal site from 2000 to 2019 ("temporal slope") and in space across a set of neighbouring spatial sites in 2019 ("spatial slope") for all 31 space-time comparisons in the U.S. and Canada. Here, each of the spatial slopes were informed by the full number of available spatial sites within each space-time comparison, which may exceed the number of years informing the corresponding temporal slope.

\begin{tabular}{|c|c|c|c|c|c|c|}
\hline & \multicolumn{3}{|c|}{ TIME } & \multicolumn{3}{|c|}{ SPACE } \\
\hline $\begin{array}{l}\text { Space-Time } \\
\text { Comparison }\end{array}$ & mean & $2.5 \%$ & $97.5 \%$ & mean & $2.5 \%$ & $97.5 \%$ \\
\hline 1 & -0.12489 & -0.49668 & 0.262553 & -0.26039 & -0.37045 & -0.15536 \\
\hline 2 & -0.6987 & -1.26447 & -0.01309 & -0.25914 & -0.39886 & -0.12672 \\
\hline 3 & 0.039783 & -0.057 & 0.137102 & -0.24835 & -0.34561 & -0.15348 \\
\hline 4 & -0.09808 & -0.45329 & 0.271766 & -0.23068 & -0.3377 & -0.12685 \\
\hline 5 & -0.5537 & -0.79847 & -0.31257 & -0.24826 & -0.34821 & -0.14903 \\
\hline 6 & -0.16275 & -0.36546 & 0.030395 & -0.26721 & -0.42378 & -0.11824 \\
\hline 7 & -0.30858 & -0.73256 & 0.119914 & -0.25652 & -0.36699 & -0.14901 \\
\hline 8 & -0.3767 & -1.0796 & 0.525262 & -0.14133 & -0.35298 & 0.060504 \\
\hline 9 & 1.137556 & 0.914821 & 1.367891 & -0.15903 & -0.27399 & -0.06505 \\
\hline 10 & 0.019634 & -0.16224 & 0.185716 & -0.09722 & -0.72624 & 0.551655 \\
\hline 11 & -0.15543 & -0.55692 & 0.166888 & -0.23658 & -0.35891 & -0.11174 \\
\hline 12 & -0.04237 & -0.23076 & 0.155463 & -0.23754 & -0.37282 & -0.10474 \\
\hline 13 & -0.49315 & -1.14798 & 0.140064 & -0.23422 & -0.39693 & -0.0658 \\
\hline 14 & 0.411379 & -0.00042 & 0.761265 & -0.1522 & -0.2588 & -0.05207 \\
\hline 15 & 0.236046 & -0.36148 & 0.767288 & -0.12448 & -0.23252 & -0.02312 \\
\hline 16 & 0.548637 & 0.278996 & 0.928576 & -0.14088 & -0.25319 & -0.03088 \\
\hline 17 & -0.06468 & -0.3187 & 0.205385 & -0.27076 & -0.4594 & -0.08976 \\
\hline 18 & 0.338245 & 0.036183 & 0.6838 & -0.07244 & -0.18855 & 0.044567 \\
\hline 19 & -0.03615 & -0.33013 & 0.281643 & -0.05742 & -0.16337 & 0.050215 \\
\hline 20 & 1.382794 & 0.683159 & 2.07279 & -0.07104 & -0.15442 & 0.0115 \\
\hline 21 & 0.020573 & -0.38032 & 0.243066 & -0.07028 & -0.1586 & 0.020812 \\
\hline 22 & -0.34659 & -0.75729 & 0.038997 & -0.07005 & -0.14342 & 0.005073 \\
\hline
\end{tabular}




\begin{tabular}{cccc|ccc} 
& \multicolumn{3}{c}{ TIME } & \multicolumn{3}{c}{ SPACE } \\
\cline { 2 - 7 } $\begin{array}{c}\text { Space-Time } \\
\text { Comparison }\end{array}$ & mean & $2.5 \%$ & $97.5 \%$ & mean & $2.5 \%$ & $97.5 \%$ \\
\hline 23 & 0.521568 & 0.198529 & 0.803508 & -0.077 & -0.14758 & -0.00787 \\
\hline 24 & 0.227449 & 0.027403 & 0.378397 & -0.07302 & -0.14827 & 0.005838 \\
\hline 25 & 0.375315 & 0.138899 & 0.583735 & -0.07315 & -0.17697 & 0.03024 \\
\hline 26 & 0.176618 & -1.8736 & 1.783403 & -0.22072 & -0.32876 & -0.11103 \\
\hline 27 & 0.217447 & -0.41199 & 0.582962 & -0.09232 & -0.18587 & -0.00229 \\
\hline 28 & -0.32421 & -1.27013 & 0.485191 & -0.0741 & -0.14195 & -0.00618 \\
\hline 29 & 0.127394 & -0.09035 & 0.337997 & -0.0678 & -0.13591 & 0.002354 \\
\hline 30 & -0.17842 & -0.89337 & 0.566886 & -0.06323 & -0.13683 & 0.011266 \\
\hline 31 & -0.08752 & -0.34755 & 0.124917 & -0.08344 & -0.18763 & 0.024732 \\
\hline
\end{tabular}



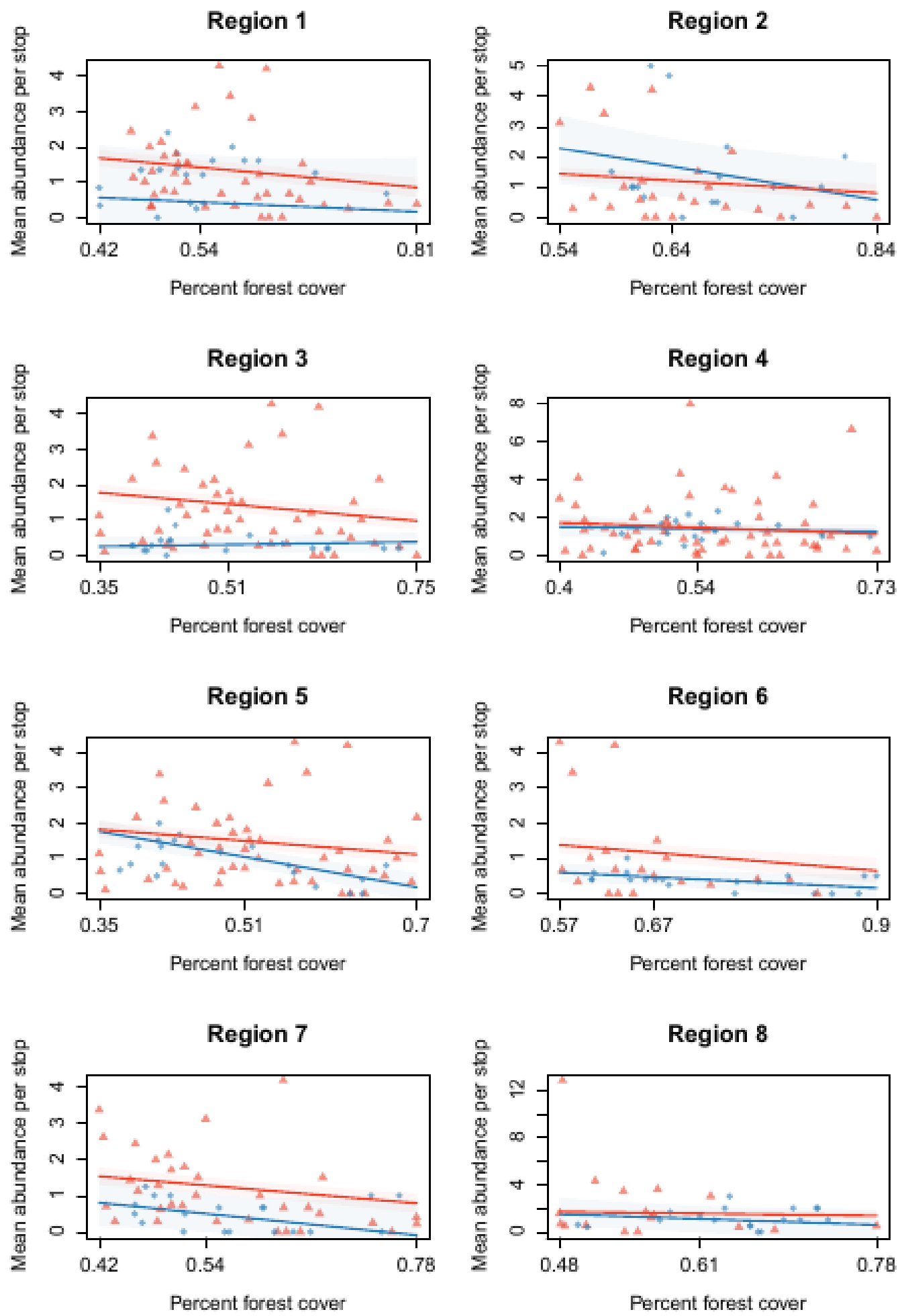

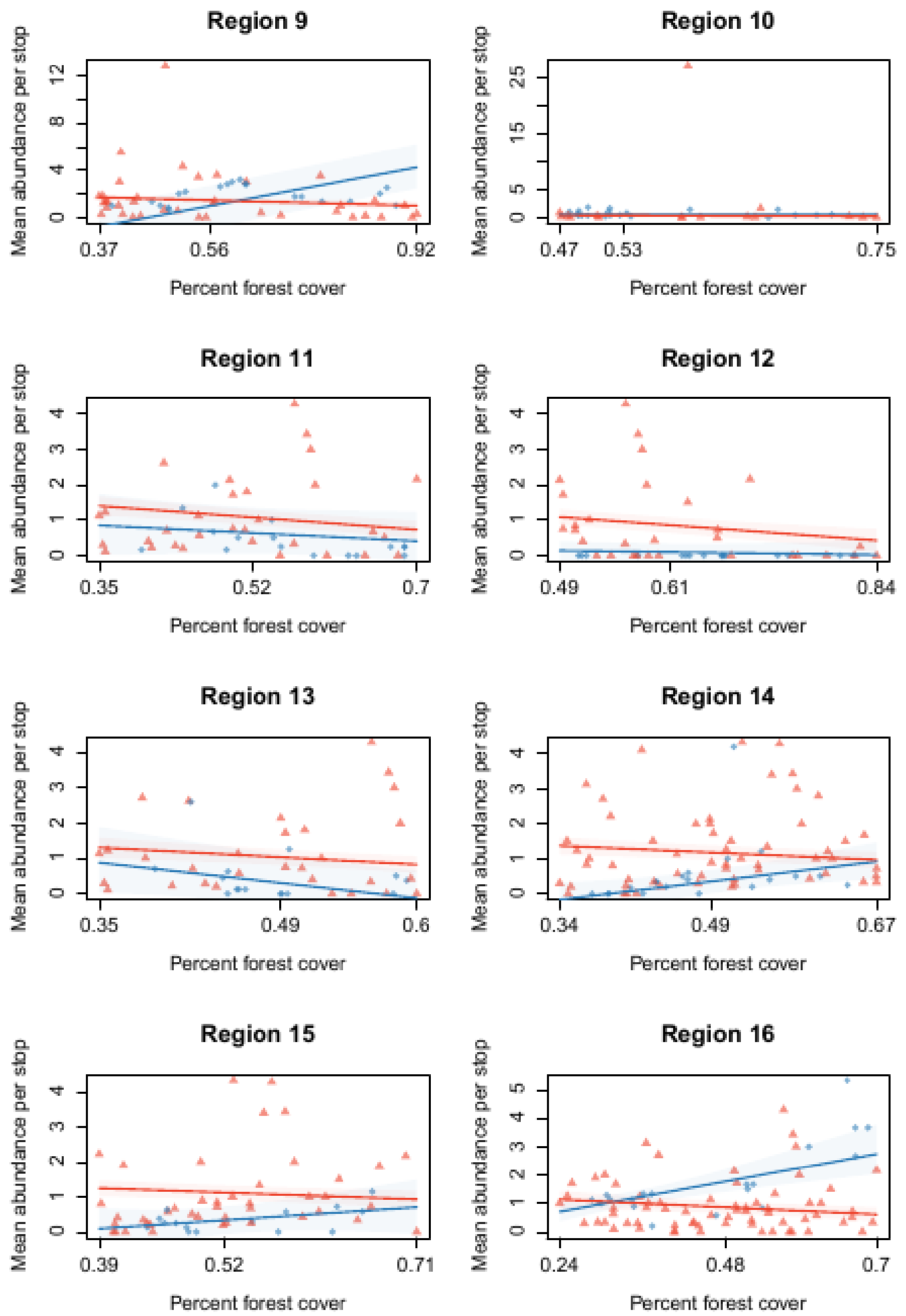

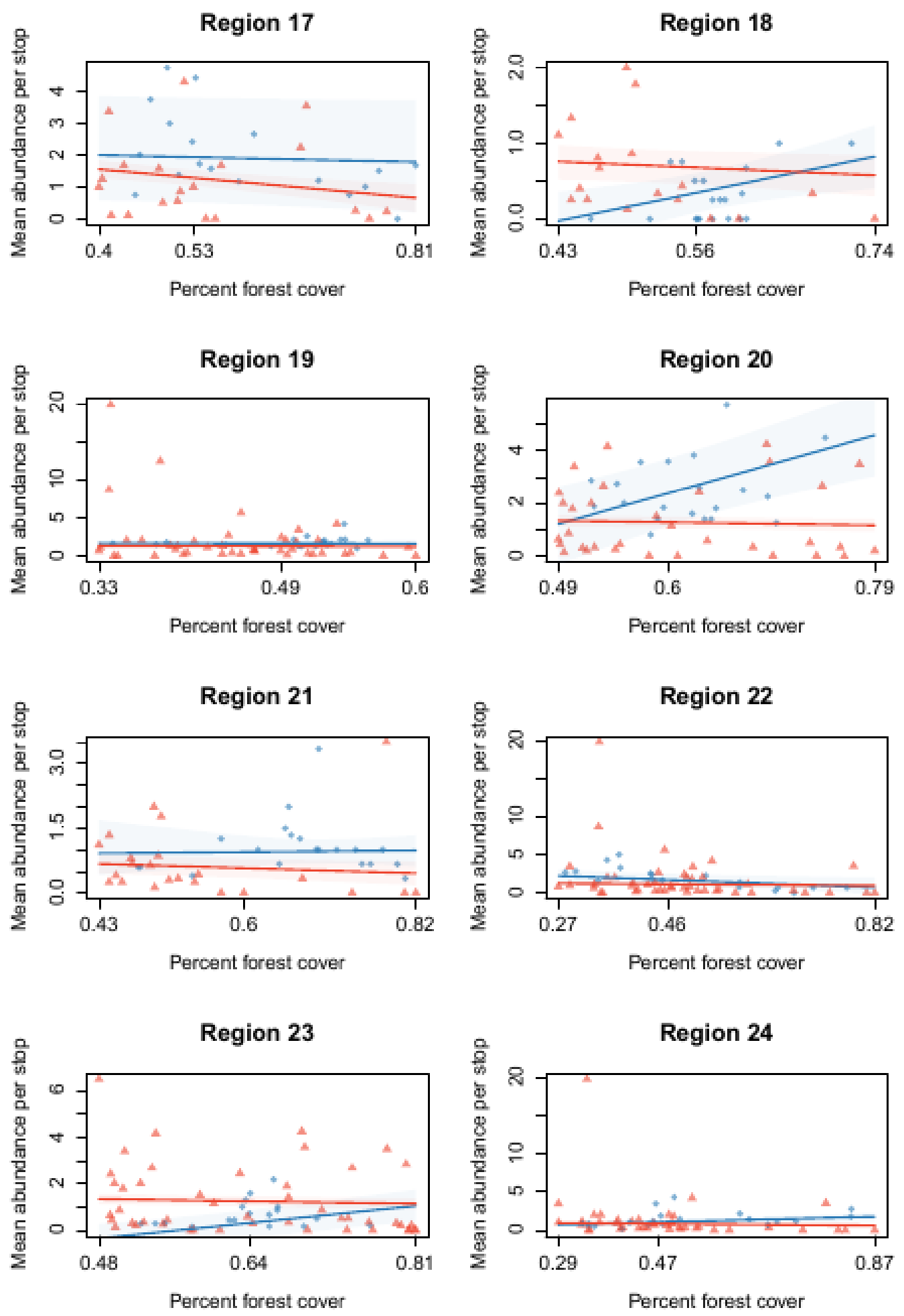

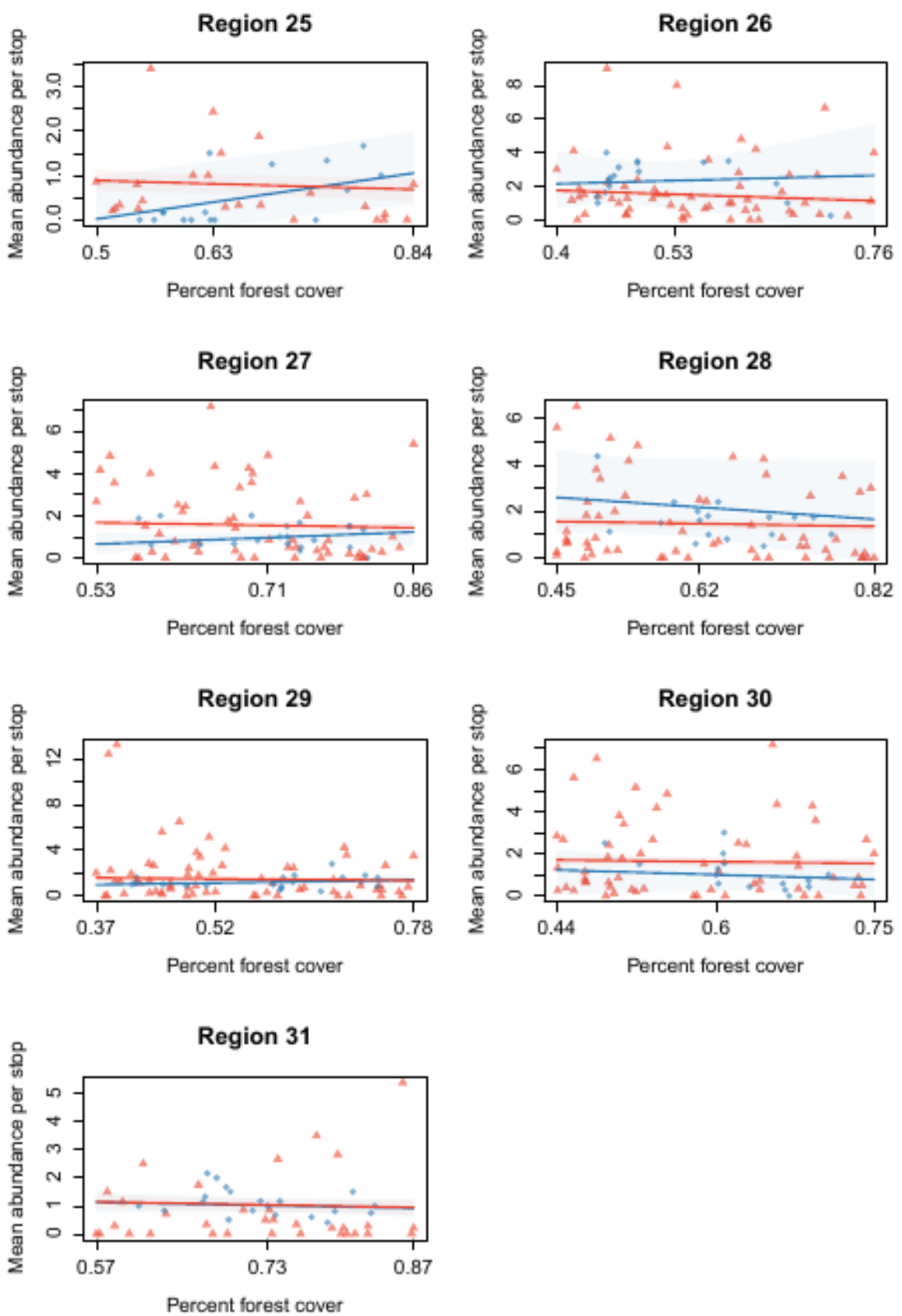

Figure I. Slope estimates (with $95 \%$ percentile interval shaded) measuring the effect of forest cover on open-habitat bird mean abundance over time at a temporal site from 2000 to 2019 (in blue) and in space across a set of neighbouring spatial sites in 2019 (in red) for all 31 space-time comparisons in the U.S. and Canada. Here, each of the spatial slopes were informed by the full number of available spatial sites within each space-time comparison, which may exceed the number of years informing the corresponding temporal slope. 
Table J. Slope parameter coefficient estimates measuring the effect of forest cover on open-habitat bird mean abundance over time at a temporal site from 2000 to 2019 ("temporal slope") and in space across a set of neighbouring spatial sites in 2019 ("spatial slope") for all 31 space-time comparisons in the U.S. and Canada. Here, each of the spatial slopes were informed by a subset number of eligible spatial sites equal to the number of years informing the corresponding temporal slope.

\begin{tabular}{|c|c|c|c|c|c|c|}
\hline & \multicolumn{3}{|c|}{ TIME } & \multicolumn{3}{|c|}{ SPACE } \\
\hline $\begin{array}{l}\text { Space-Time } \\
\text { Comparison }\end{array}$ & mean & $2.5 \%$ & $97.5 \%$ & mean & $2.5 \%$ & $97.5 \%$ \\
\hline 1 & -0.11991 & -0.46812 & 0.282393 & -0.24673 & -0.5348 & 0.043124 \\
\hline 2 & -0.05222 & -0.84132 & 0.749778 & -0.28035 & -0.63952 & 0.082182 \\
\hline 3 & -0.006 & -0.1573 & 0.142695 & -0.16232 & -0.43247 & 0.106625 \\
\hline 4 & -0.02839 & -0.38426 & 0.343304 & -0.19444 & -0.49485 & 0.109722 \\
\hline 5 & -0.49276 & -0.77177 & -0.20523 & -0.17685 & -0.47456 & 0.12072 \\
\hline 6 & 0.019615 & -0.21027 & 0.242376 & -0.29494 & -0.59887 & 0.008464 \\
\hline 7 & -0.08239 & -0.4787 & 0.259286 & -0.2228 & -0.48141 & 0.028553 \\
\hline 8 & 0.102894 & -0.78463 & 1.150421 & -0.02116 & -0.38401 & 0.326528 \\
\hline 9 & 1.037316 & 0.740287 & 1.33345 & -0.04931 & -0.30897 & 0.209262 \\
\hline 10 & -0.05488 & -0.31367 & 0.202917 & -0.02034 & -0.64365 & 0.61096 \\
\hline 11 & -0.11387 & -0.55359 & 0.256921 & -0.07413 & -0.40157 & 0.291183 \\
\hline 12 & 0.045954 & -0.20426 & 0.294478 & -0.21672 & -0.50541 & 0.068 \\
\hline 13 & -0.36099 & -1.16549 & 0.508187 & -0.15521 & -0.58381 & 0.281916 \\
\hline 14 & 0.246437 & -0.26774 & 0.718736 & -0.12786 & -0.43868 & 0.201776 \\
\hline 15 & 0.275173 & -0.39918 & 0.872929 & -0.12784 & -0.43086 & 0.186337 \\
\hline 16 & 0.580841 & 0.28107 & 0.885343 & -0.14607 & -0.40788 & 0.139638 \\
\hline 17 & -0.09065 & -0.43321 & 0.225064 & -0.27383 & -0.62256 & 0.083235 \\
\hline 18 & 0.365509 & -0.0459 & 0.788703 & -0.083 & -0.31575 & 0.157951 \\
\hline 19 & 0.058013 & -0.26892 & 0.398931 & -0.05576 & -0.47291 & 0.359544 \\
\hline 20 & 1.290148 & 0.415077 & 2.10217 & -0.09884 & -0.3334 & 0.146882 \\
\hline 21 & 0.046185 & -0.3043 & 0.303511 & -0.08933 & -0.28295 & 0.107845 \\
\hline 22 & -0.38452 & -0.93595 & 0.120253 & -0.10515 & -0.31295 & 0.09936 \\
\hline 23 & 0.530725 & 0.132594 & 0.924517 & -0.08851 & -0.38557 & 0.201354 \\
\hline
\end{tabular}




\begin{tabular}{cccc|ccc} 
& \multicolumn{3}{c}{ TIME } & \multicolumn{3}{c}{ SPACE } \\
\cline { 2 - 7 } $\begin{array}{c}\text { Space-Time } \\
\text { Comparison }\end{array}$ & mean & $2.5 \%$ & $97.5 \%$ & mean & $2.5 \%$ & $97.5 \%$ \\
\hline 24 & 0.233174 & 0.051339 & 0.412292 & -0.09064 & -0.27643 & 0.101054 \\
\hline 25 & 0.479656 & 0.128522 & 0.800799 & -0.20066 & -0.50167 & 0.085208 \\
\hline 26 & -0.44127 & -1.91798 & 1.068067 & 0.088394 & -0.4335 & 0.655484 \\
\hline 27 & -0.002 & -0.76356 & 0.511734 & -0.15988 & -0.49768 & 0.160232 \\
\hline 28 & -0.41667 & -1.26582 & 0.436477 & -0.13149 & -0.43541 & 0.181747 \\
\hline 29 & 0.105931 & -0.13261 & 0.342082 & -0.09797 & -0.31222 & 0.117376 \\
\hline 30 & -0.27788 & -1.12852 & 0.588616 & -0.07561 & -0.41048 & 0.238967 \\
\hline 31 & -0.12841 & -0.49737 & 0.190251 & -0.14588 & -0.46669 & 0.187104 \\
\hline
\end{tabular}



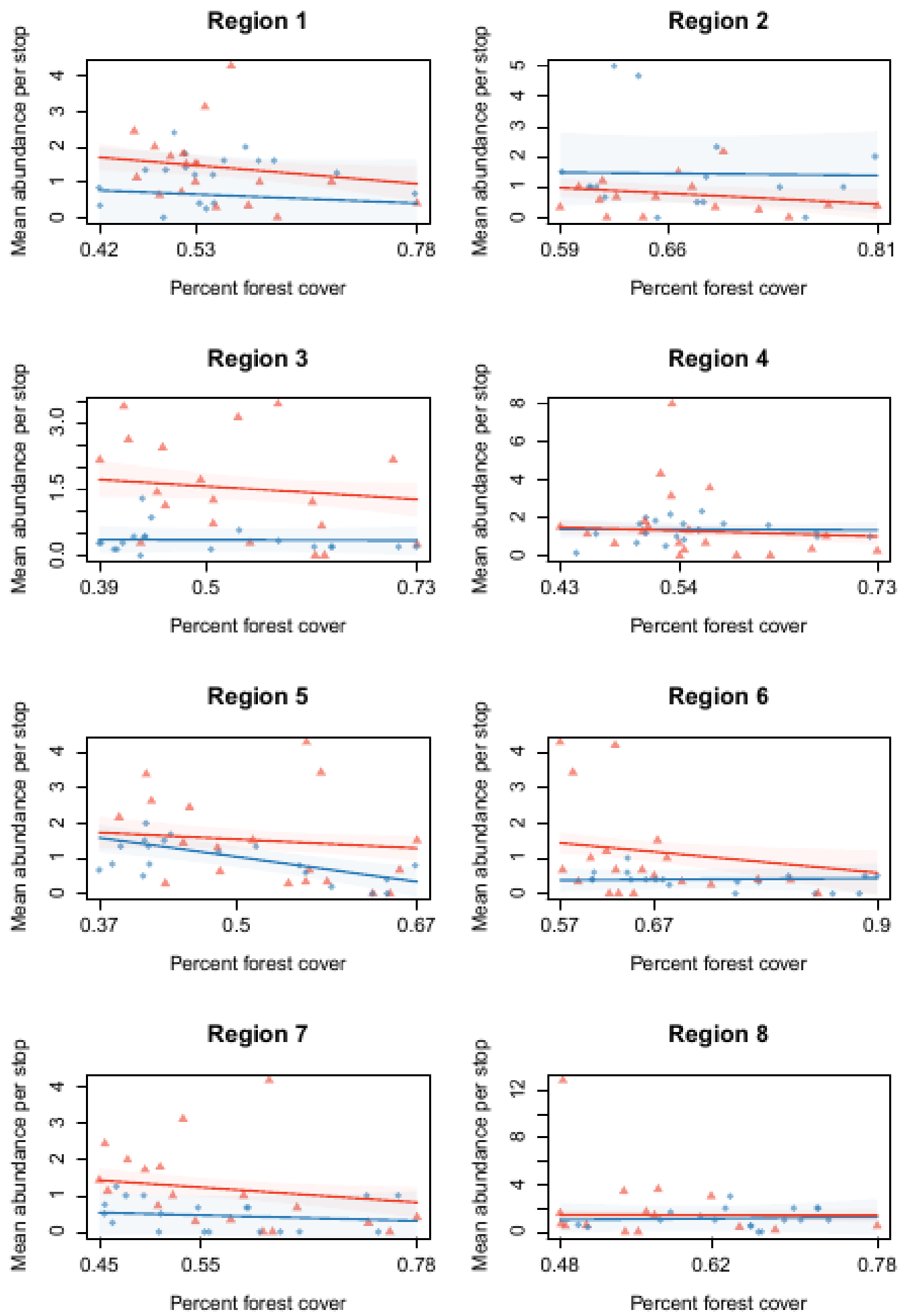

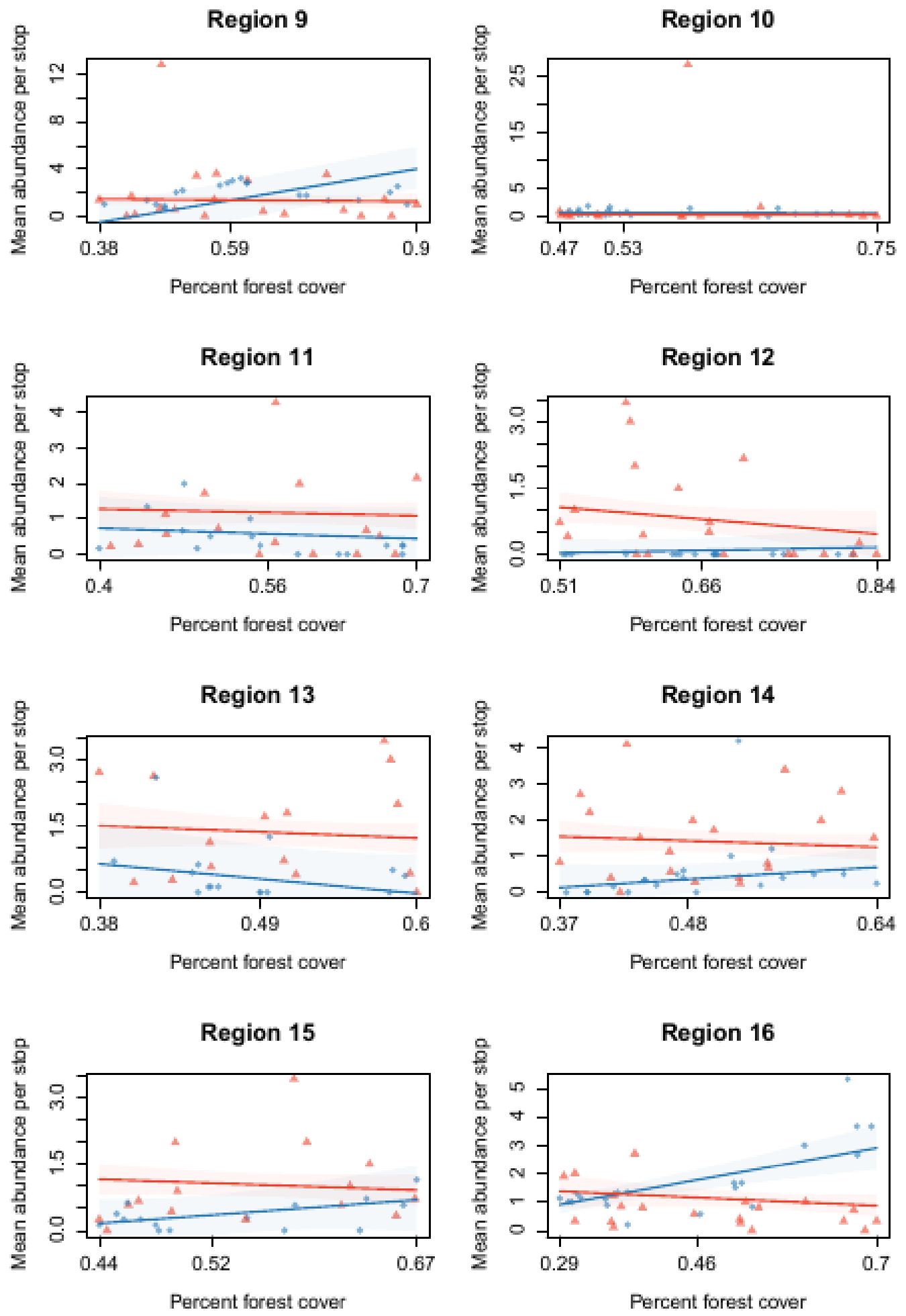

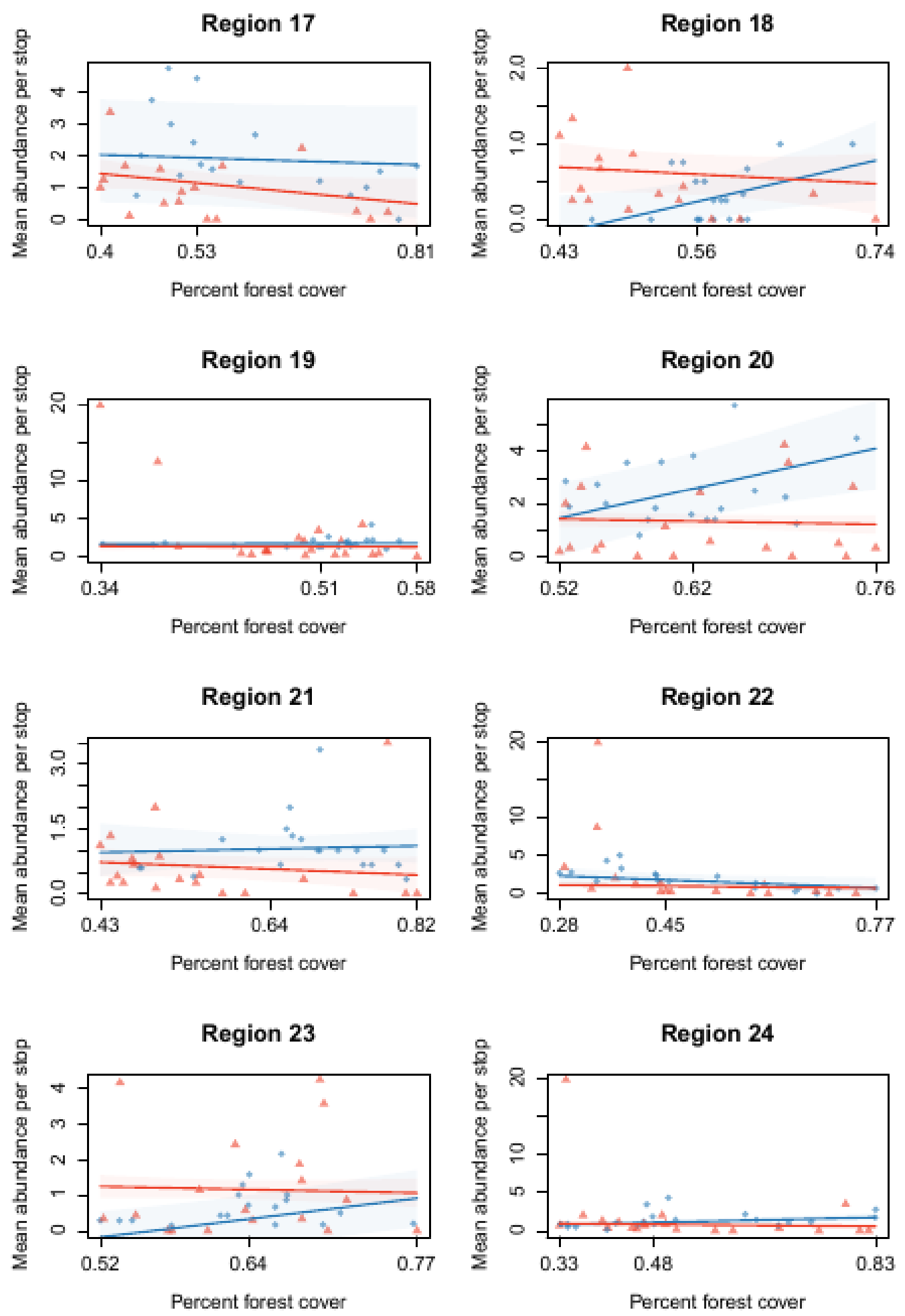

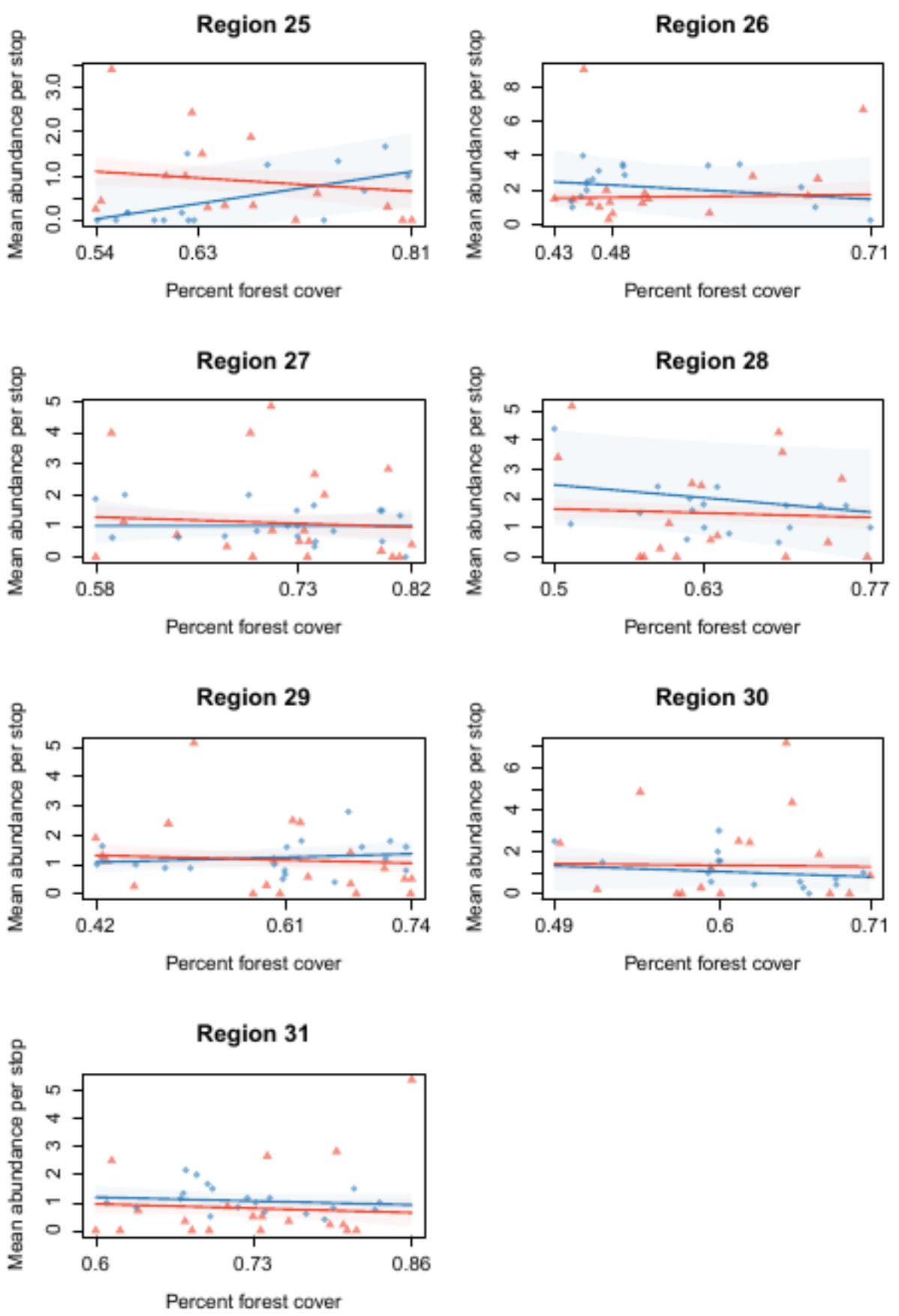

Figure J. Slope estimates (with 95\% percentile interval shaded) measuring the effect of forest cover on open-habitat bird mean abundance at a temporal site from 2000 to 2019 (in blue) and in space across a set of neighbouring spatial sites in 2019 (in red) for all 31 space-time comparisons in the U.S. and Canada. Here, each of the spatial slopes were informed by a subset number of eligible spatial sites equal to the number of years informing the corresponding temporal slope. 